\title{
Rule-Based Filtering of Risk Scenarios by the Disruption of Management Priorities
}

\author{
A Thesis \\ Presented to \\ the faculty of the School of Engineering and Applied Science \\ University of Virginia
}

In Partial Fulfillment of the requirements for the Degree Master of Science in Systems Engineering

by

Heimir Thorisson

May 2016 


\section{APPROVAL SHEET}

The thesis

is submitted in partial fulfillment of the requirements

for the degree of

Master of Science

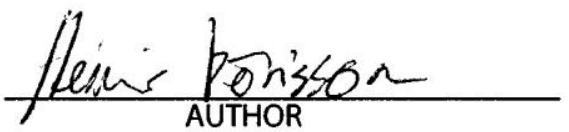

The thesis has been read and approved by the examining committee:

\begin{tabular}{|c|}
\hline Advisor \\
\hline Yacov Y. Haimes \\
\hline Cody $\mathrm{H}$. Fleming \\
\hline
\end{tabular}

Accepted for the School of Engineering and Applied Science:

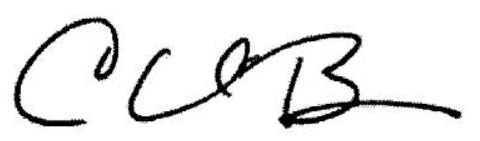

Craig H. Benson, Dean, School of Engineering and Applied Science May 


\section{Abstract}

This thesis develops a rule-based approach to filtering of the risk scenarios that most disrupt current agency or organizational priorities. The approach is demonstrated in priority-setting for the electric power sector of Afghanistan. Various scenarios are shown to relatively influence the prioritization of capacity-building initiatives for electric power. The effort extends existing methodologies for disruption of priorities with scenario-based analysis, adding rule-based inputs and calculations in place of utility or value assessments. A sensitivity analysis is performed by comparing the outputs of the rule-based methodology with alternative sets of criteria. The effort creates a focus of risk analysis on the sources of risk that bring about a changing-of-minds or changing-of-interests among decision makers. It is complementary and compatible with a focus on the sources of risk with the highest likelihoods and consequences. The implications of this work are important for the theory and practice of systems engineering, which is foremost concerned with priorities and circumstances that are unprecedented and evolving. 


\section{Acknowledgements}

I am grateful to the various individuals and organizations that have supported me throughout the pursuit of this degree and my time at the University of Virginia. First, I would like to thank my advisor, Professor James H. Lambert, for his continuous guidance and support that started even before my arrival in Charlottesville. I am grateful to my other committee members, Professor Yacov Y. Haimes and Professor Cody H. Fleming, for their help and guidance during the preparation of this thesis. I would especially like to thank Professor Haimes for his two courses on risk analysis and the art and science of modeling, that have shaped my understanding of systems engineering.

I am grateful to Major David Wilson of CSTC-A, John Cardenas of USAID, Shane Hirshi and Igor Linkov of USACE, among others, for their inputs and enabling the realization of this

research. I am grateful to the US Department of State and the Icelandic Fulbright Commission for their support of my studies, and for enriching my career through connections to Fulbrighters from all across the world.

I am grateful to my family and friends in Iceland for their unquestioned support and understanding, and my friends and colleagues at UVa, who have made Charlottesville my home for the past years. Finally, I would like to dedicate this thesis to my grandparents, Pór and Ragnhildur, whose influence and inspiration will continue to guide me throughout my life and career. 


\section{Contents}

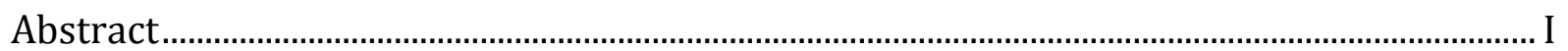

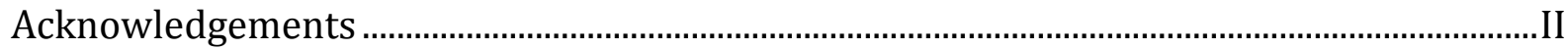

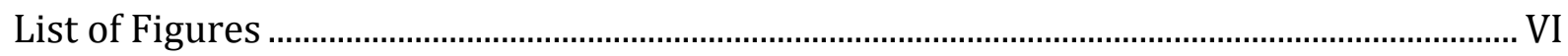

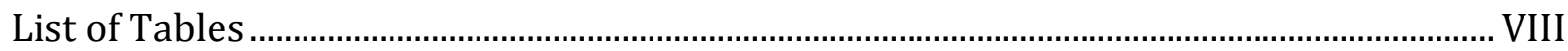

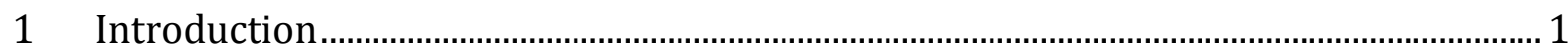

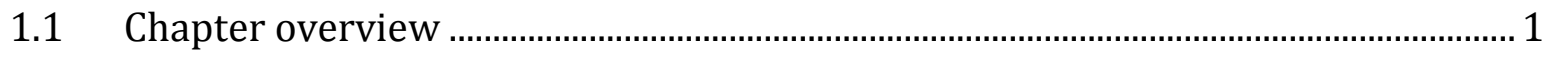

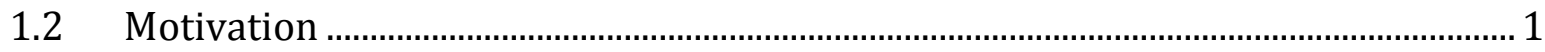

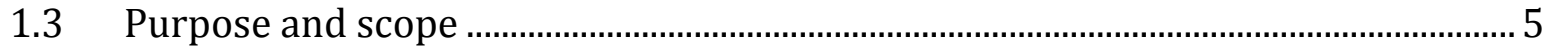

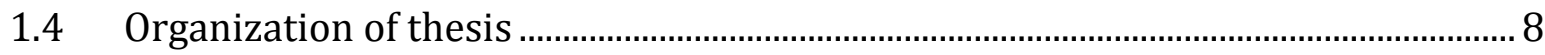

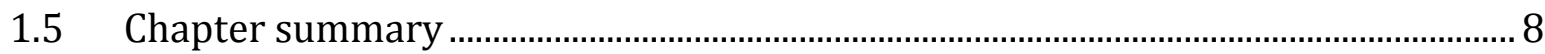




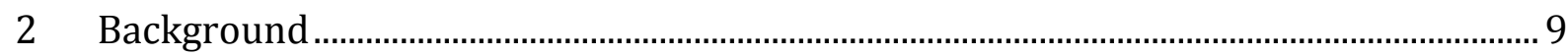

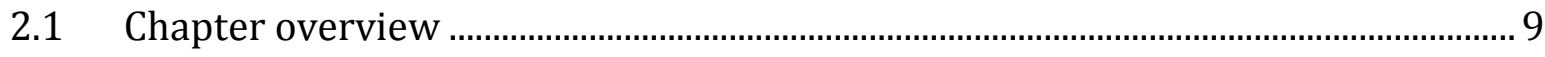

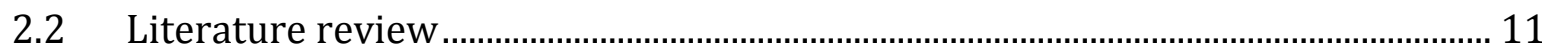

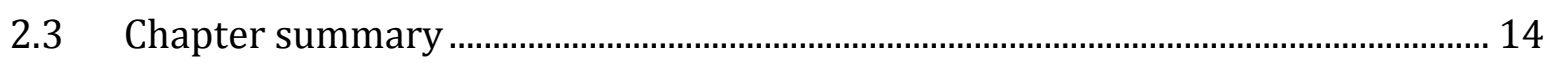

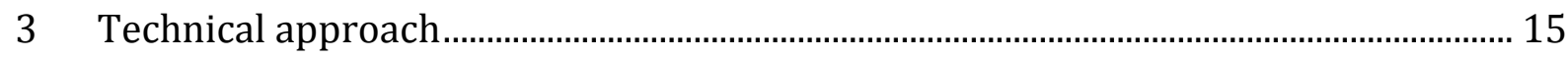

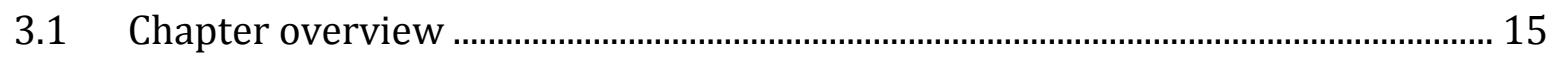

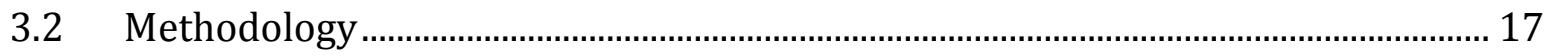

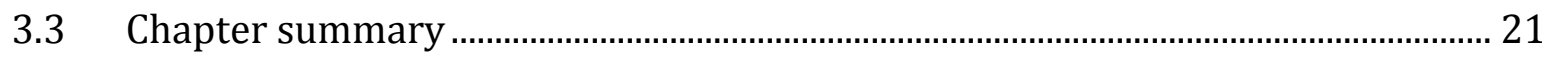

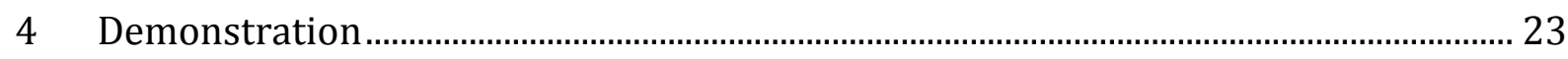

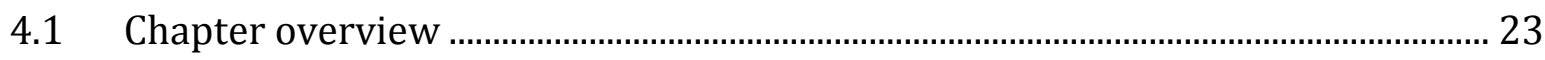

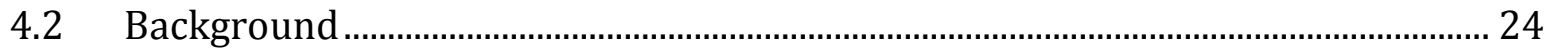

4.3 Demonstration of methods ……………………………………………………... 31

4.4 Software interface .................................................................................................... 82

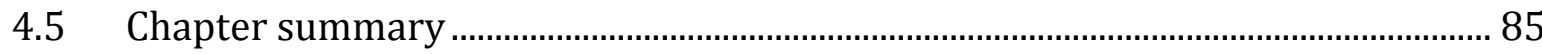

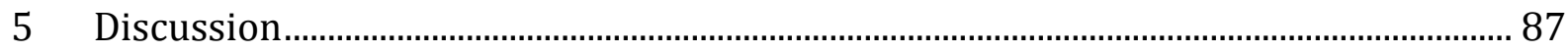

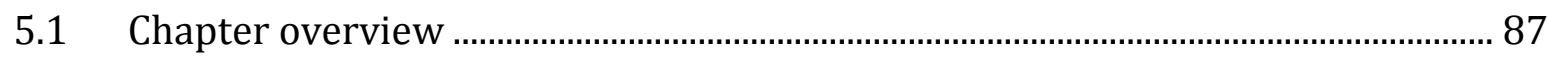

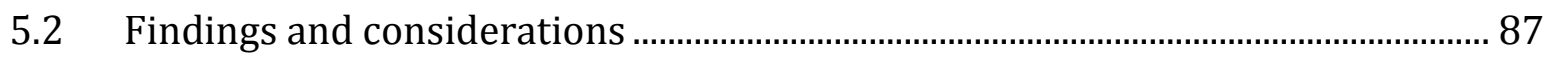

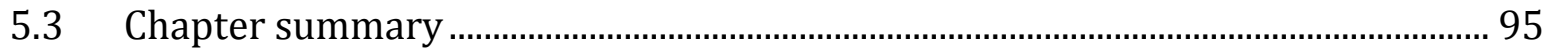




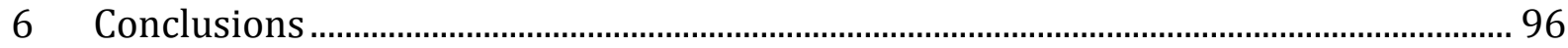

6.1 Chapter overview ………………………………………………………………... 96

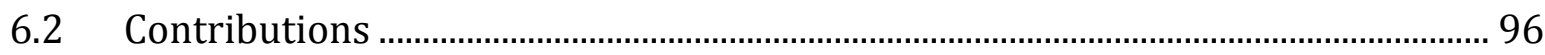

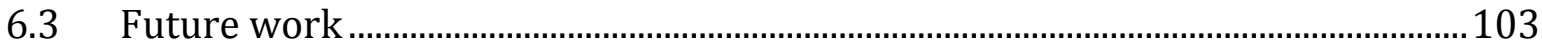

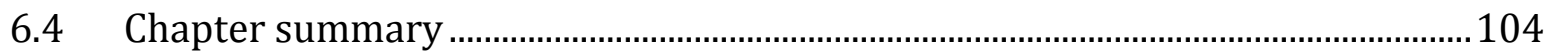

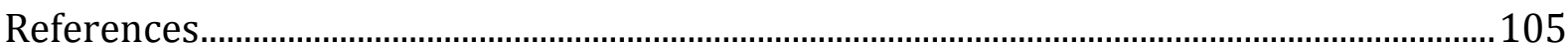

Appendix A: Goal structure of the Afghanistan National Development Strategy..............114

Appendix B: Goal structure of US strategic documents.........................................................115

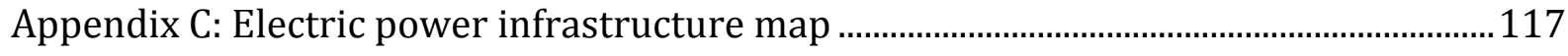

Appendix D: Sample of news coverage of PDPPA 


\section{List of Figures}

Figure 1. Key questions addressed by the thesis regarding the disruption of scenarios to a timeline or prioritization in relation to risk assessment and management. A, B and C in the figure are initiatives, which relative prioritization is subject to external or internal

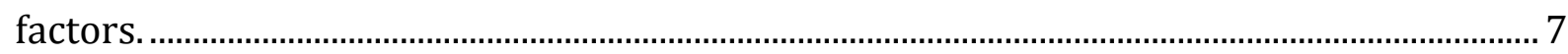

Figure 2. Sample literature reviewed during the preparation of the thesis. The proximity to the three corners indicates the relative emphasis of the publication on theory, methods and

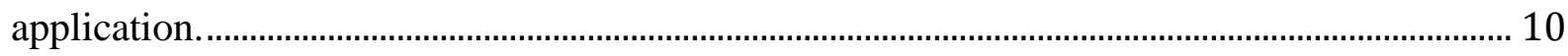

Figure 3. Methodology for rule-based prioritization of initiatives ........................................ 16 
Figure 4. Range of priority classes of initiatives for the national government criteria. The diamond respresents the baseline prioritization of the whiskers extend to the highest and lowest class the initiative in classified to under any scenario 73

Figure 5. Range of priority classes of initiatives for the US government criteria. The diamond represents the baseline prioritization of the whiskers extend to the highest and lowest class the initiative in classified to under any scenario.................................................. 74

Figure 6. Sample of worksheet where impact assessment is performed.............................. 83 Figure 7. Sample of results worksheet. Assignment into priority classes is achieved using IF statements. 84

Figure 8. Illustration of the disruption of a timeline of priorities. The methods developed in this thesis characterize the separation of the timeline from an as-planned timeline when subjected to scenarios 89

Figure 9. Innovations of this thesis to theory and methodology of systems engineering and risk analysis. 


\section{List of Tables}

Table 1. Stressors that, alone and in combination, might disrupt the prioritization of initiatives in the electric power sector of Afghanistan............................................................ 32 Table 2. Summary of definition and properties of scenario sc1: Insufficient power supply.

Table 3. Summary of definition and properties of scenario sc2: Unsatisfactory local

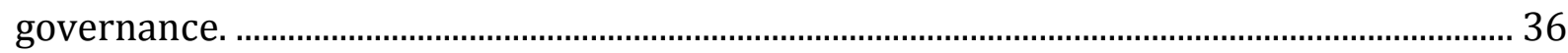

Table 4. Summary of definition and properties of scenario sc3: Deteriorating security conditions

Table 5. Summary of definition and properties of scenario sc4: Public perception problems. 38 
Table 6. Summary of definition and properties of scenario sc5: Electricity imports disrupted.

Table 7. Summary of definition and properties of scenario sc6: International management and oversight lacking. 40

Table 8. National government criteria, success criteria derived from the Afghanistan National Development Strategy

Table 9. US government criteria, derived from the US Civil-Military Strategic Framework for Afghanistan and the Office of the Special Inspector General for Afghanistan

Reconstruction. 45

Table 10. Initiatives in the Afghan electric power sector (Type: PG = Power Generation, $\mathrm{T}_{\text {Kabul }}=$ Transmission in Kabul, $\mathrm{T}_{\text {urban }}=$ Transmission in urban area outside Kabul, $\mathrm{T}_{\text {rural }}=$ Transmission in rural area, $\mathrm{T}_{\text {border }}=$ Transmission connecting to border, $\mathrm{SS}=$ Substation, $\mathrm{EQ}=$ Equipment, $\mathrm{PM}=$ Project management, oversight or monitoring. Program: USAID = US Agency for International Development; ADB = Asian Development Bank).................. 46

Table 11. Assessment of impacts of initiatives on national government criteria............... 50

Table 12. Assessments of impacts of initiatives on US government criteria........................ 53

Table 13. Definitions of priority classes that initiatives are assigned to............................. 57

Table 14. Rules for classifying initiatives into priority classes under the baseline scenario. 58

Table 15. Primary criteria defined for the different scenarios for both criteria sets. Primary criteria are the basis on which initiatives are re-ordered for each scenario...... 60 
Table 16. Rules for classification of initiatives into priority classes for sc1: Insufficient

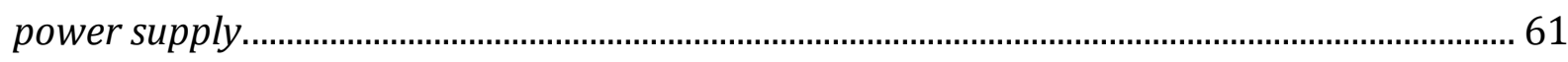

Table 17. Rules used to adjust priority classification of initiatives for scenarios SC2-SC6. 62 Table 18. Prioritization of initiatives for the national government criteria (Immediate = I, Near-term = N, Mid-term = M, Long-term = L, Distant future = D) ...................................... 65

Table 19. Prioritization of initiatives for the US government criteria (Immediate = I,

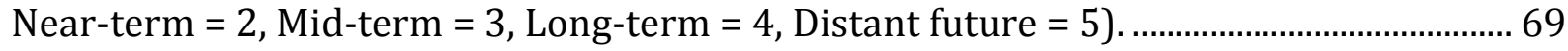

Table 20. Disruption of scenarios to the prioritization of initiatives under the national

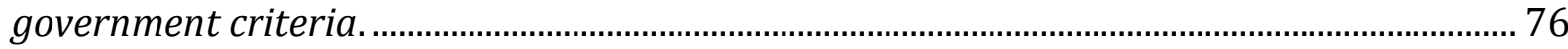

Table 21. Disruption of scenarios to the prioritization of initiatives under the US

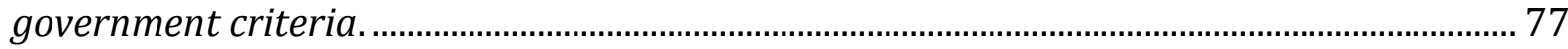

Table 22. Absolute difference in prioritization of initiatives for the national government

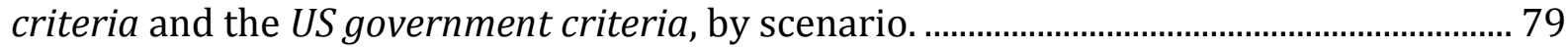

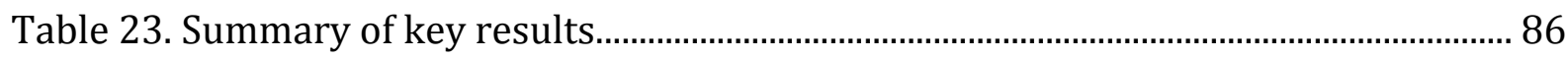

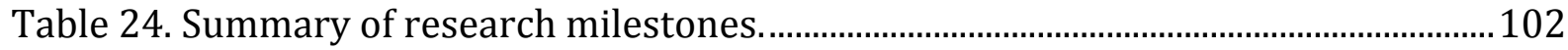




\section{Introduction}

\subsection{Chapter overview}

This chapter describes the motivation for the thesis, the need for addressing uncertainties of politics, economics, military conflict, technology, human behavior and others, when analyzing systems involving multiple stakeholders with possibly conflicting objectives and motives. It describes the purpose and scope of the thesis and introduces the general organization of chapters and material presented.

\subsection{Motivation}

System owners and operators are challenged by an uncertain and evolving future of technological, social, economic, security and environmental factors, all in the direction of 
resilient, sustainable, and robust systems. Multiple shared or conflicting aims of various stakeholders, whose individual "stakes" can range from large to small, which change over time must be taken into consideration in a negotiation of current and future priorities. The systems engineer has an important role in providing research, methods and tools to aid in the development of metrics, models, solutions, methods that prioritize among candidate solutions, and procedures for tracking/monitoring of progress. Furthermore, risk analysis has had a role identifying current and future stressors to which the system might be exposed, and understanding the impacts of these stressors. In volatile regions of the world "deep" uncertainties, without reliable knowledge of probability and severity, and changeable societal and governance conditions call for special consideration. Hamilton et al. (2015) address the above challenge with scenario-based preferences though with impractical requirements of stakeholder input and with strong assumptions about the underlying form of stakeholder preferences.

Investments in infrastructure are an important contribution to economic growth in developing countries (Kessides, 1993). In 2014, developed countries provided over US \$135 billion of official development assistance (Organisation for Economic Co-operation and Development, 2015) and a significant portion is allocated to infrastructure projects such as roads, port, waterways and electrical power grids. Despite these efforts, it is estimated that 1.5 billion people do not have access to electricity and thereof, $97 \%$ live in developing countries in sub-Saharan Africa and Asia (Doll \& Pachauri, 2010). Increasing availability and accessibility of electrical power enables both basic services such as 
lighting, communication and cooking as well as providing opportunities for economic growth in terms of manufacturing, agriculture and information technology and thereby investments in electric infrastructure contribute to social development and poverty reduction. However, funding mechanisms involving stakeholders in donor countries, developing countries and international agencies managing and promoting development initiatives are complex and vulnerable to fraud, waste and abuse. Corruption is prevalent in many countries and in some regions overseeing implementation and operation of funded projects is difficult due to unstable security conditions. The extent of corruption in the international development sector has been estimated to be between 600 billion USD and 1.5 trillion USD annually (Kaufmann, 2005). To minimize the potential of development aid being wasted or used to support terrorism and other illegal activities, associated risks must be identified and mitigation strategies developed to prevent further adversities.

Previous work on infrastructure systems for developing countries has demonstrated a framework to identify scenarios that are most influential to the priority setting of infrastructure initiatives (Lambert et al. 2012; Karvetski et al., 2009). The scenarios are uncertainties of military conflict, politics, economics, technology, environment, behaviors, institutions, and society. Some are directly advocated or brought about by particular stakeholder actions and policies, such as mismanagment of funds, while others such as natural disasters and industrial accidents may be less changeable by the stakeholders. When analyzing complex socio-economic systems involving multiple stakeholders 
stressed by various uncertain factors, traditional risk analysis, focusing on the probability and severity of adverse events, has a critical role. However, attempting to identify an exhaustive set of all future conditions and assessing corresponding probabilities presents a technical challenge and can fall short to address threats of macro-scale disruptions in economics, demographics, regulations, politics, etc. Integrating qualitative methods such as risk identification using hierarchical holographic modeling (Haimes, 2004; Lambert et al., 2001), and scenario planning with multi-criteria analysis promotes and supports robust strategic decision making (Montibeller \& Franco, 2010). 


\subsection{Purpose and scope}

This thesis adds a rule-based approach to scenario-based preferences for filtering of scenarios, and demonstrates the approach in a context of prioritizing initiatives that advance the electric power sector of Afghanistan. Relative to past effort, the approach reduces numerical elicitations and avoids strong assumptions of preference/value functions of stakeholders. In particular, it avoids a "weight and rate" technique. The sets of rules, based on counts from binary or similarly streamlined assessments, must comply with preferential properties of success criteria described by decision makers. The thesis thus demonstrates how various scenarios relatively influence the prioritization of capacity-building initiatives.

The demonstration alternates between two complementary formulations of strategic goals: First, the national government's official development strategy (Islamic Republic of Afghanistan, 2008), and, second, criteria derived from a framework for pursuing US national goals in Afghanistan (Embassy of the United States of America \& U.S. Forces, 2013), complemented by an independent US-based risk audit (Special Inspector General for Afghanistan Reconstruction, 2014). The method addresses "deep" uncertainty by assessing how disruptive are uncertainties of emergent and future conditions. Addressing several complementary sets of criteria acknowledges that multiple perspectives are necessary to model a complex system, which is especially relevant in the context of Afghanistan where the national government, the Western coalition, and insurgents might have competing objectives while generally being in favor of an electric grid capacity 
expansion. The perspective of Taliban insurgents is outside the scope of the demonstration. This approach loosens or eliminates a requirement for consensus among stakeholders even while advancing a capability for filtering sources of risk.

The method distinguishes itself from existing literature on risk filtering and ranking (Haimes et al., 2002) by filtering sources of risk by their potential to change priorities. It is not meant to replace the risk analysis triplet (Kaplan \& Garrick, 1981) but to complement it. Priorities in the context of this thesis can be interpreted as timelines of execution of different initiatives. Thus, the method asks the following questions:

- What can affect the timeline or prioritization of initiatives?

- How much is the timeline or prioritization disrupted?

Figure 1 illustrates the relationship between traditional risk analysis and the methods presented in this thesis. They recognize the need for asking what can go wrong, what are the likelihoods, consequences and time frames but focus specifically on the disruption of scenarios to priorities, rather than physical structures or binary decisions. 


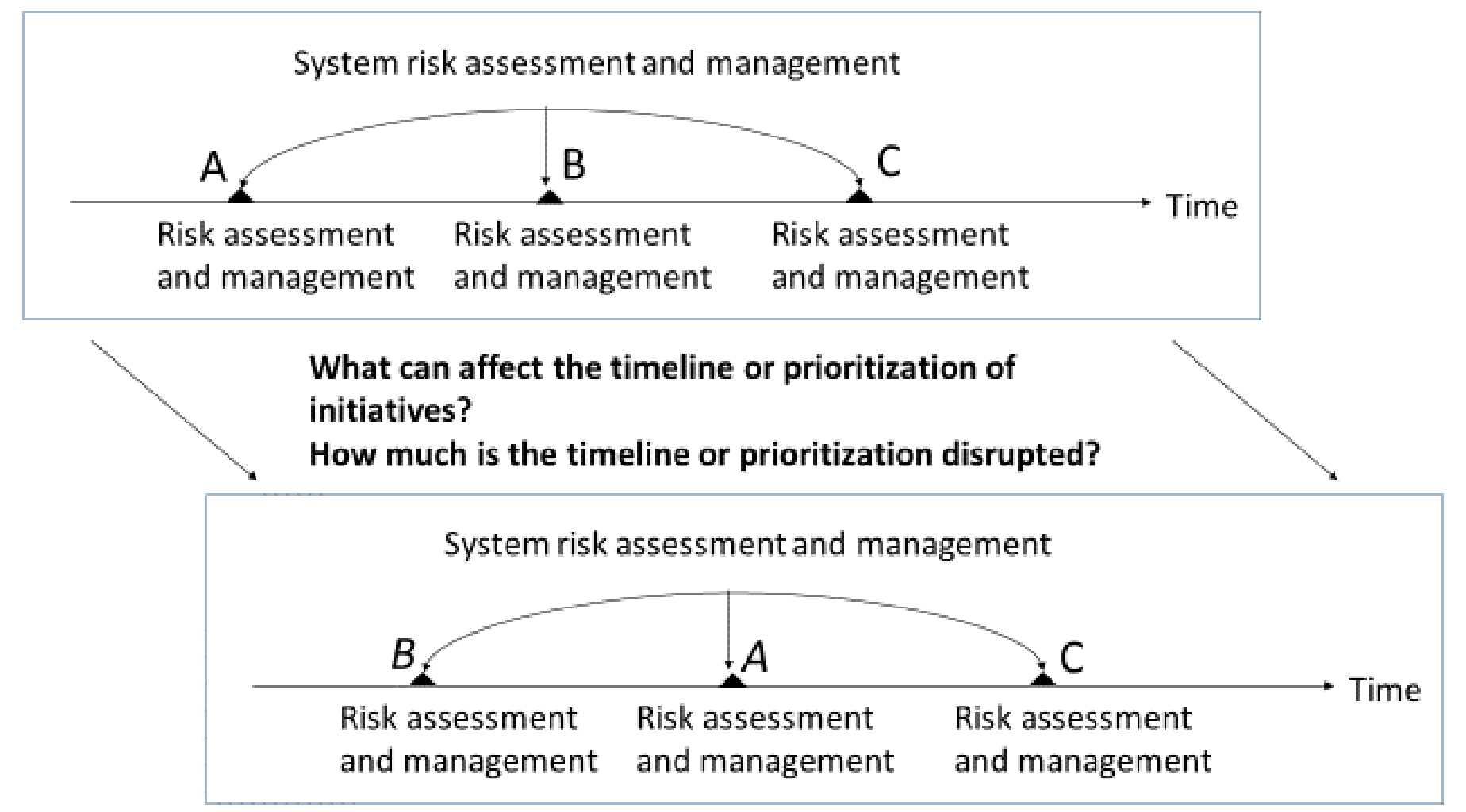

Figure 1. Key questions addressed by the thesis regarding the disruption of scenarios to a timeline or prioritization in relation to risk assessment and management. A, B and C in the figure are initiatives, which relative prioritization is subject to external or internal factors. 


\subsection{Organization of thesis}

The thesis is structured as follows: Chapter 2 reviews literature relevant to the scope of the thesis, including risk identification and filtering, scenario analysis, multicriteria analysis and rule-based assignment modeling. Chapter 3 describes the technical approach, explains necessary inputs and building blocks and methods used to create results. Chapter 4 applies the methods to an expansion planning effort of the Afghanistan power grid. Chapter 5 discusses implications of findings, the context in which results should be interpreted and limitations. Chapter 6 discusses review of accomplishments, intellectual contributions and topics for future work.

\subsection{Chapter summary}

This chapter provided an introduction to the later chapters of the thesis, stated the purpose of the research to identify scenarios that might disrupt the prioritization of initiatives that enhance the Afghanistan power sector and quantify their disruption. It presented the organization and structure of the thesis and asked questions that later chapters aim to answer. 


\section{Background}

\subsection{Chapter overview}

This chapter gives a review of the literature that provides the theoretical foundation of this thesis. It presents papers that describe methods that support the goals of the thesis, such as risk identification and filtering, multicriteria and scenario analysis, and rule-based assignment modeling. Figure 2 places the thesis in the context of key literature in terms of theory, methods and application. The chapter identifies challenges in current literature and concludes a rule-based approach to risk filtering by disruption of prioritization. 


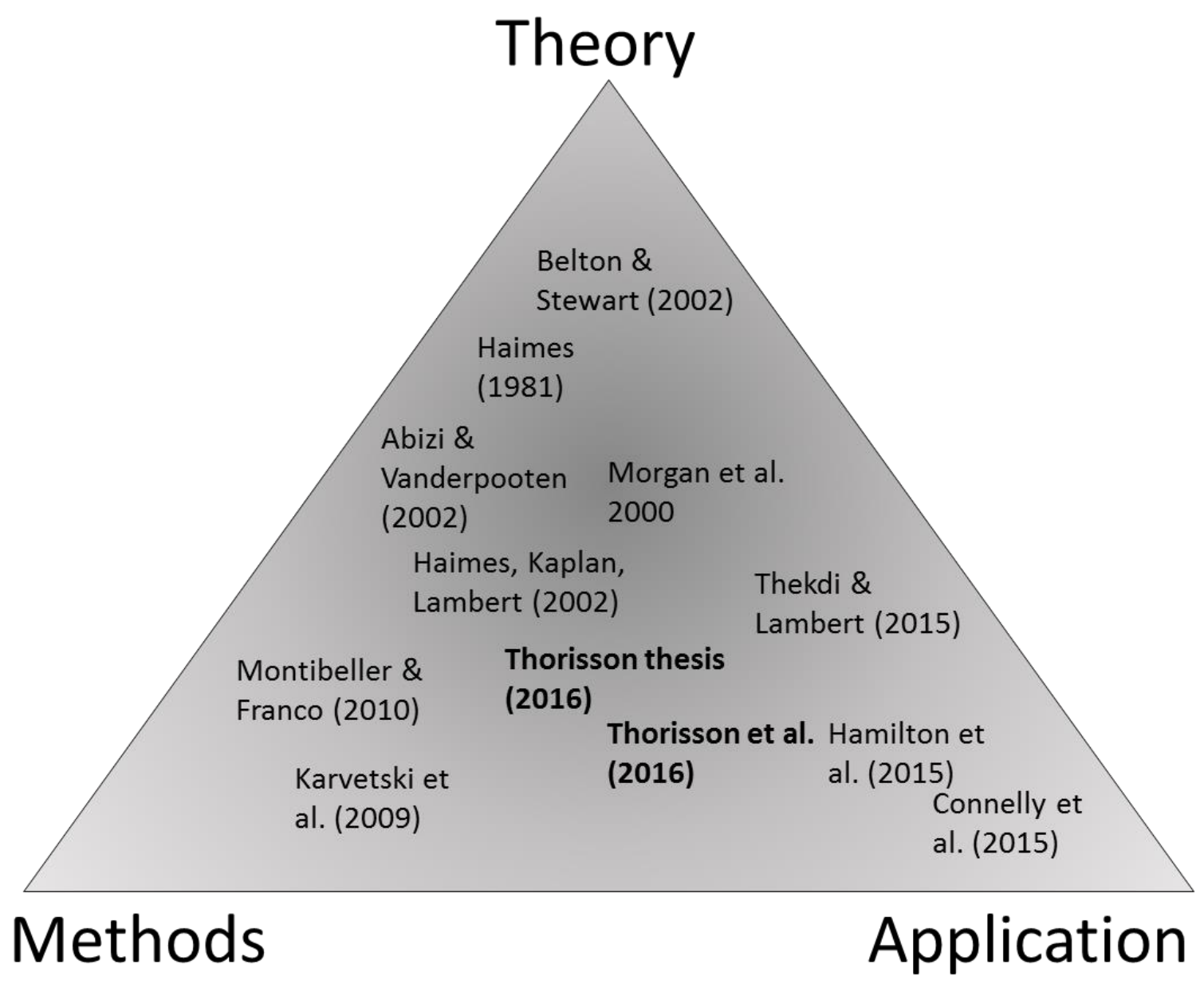

Figure 2. Sample literature reviewed during the preparation of the thesis. The proximity to the three corners indicates the relative emphasis of the publication on theory, methods and application. 


\subsection{Literature review}

In the domain of complex systems methodology, various formal methods have been developed to aid analysts in risk identification and filtering. Hierarchical holographic modeling (HHM) as described by Haimes $(2015,1981)$ describes that systems cannot be sufficiently modeled from a single perspective and offers a method to deconstruct systems into multiple, complementary hierarchical structures. Identifying potential threats to system success is an important step in risk analysis. Lambert et al. (2001) describe five mechanisms to identify sources of risk, or stressors:

- Interviews with stakeholders

- Review of requirements documents and other planning material

- $\quad$ Review of relevant third-party program analyses

- $\quad$ Review of lists of risk prepared by program managers

- $\quad$ Consult third-party consultants familiar with the program

Neiger et al. (2009) propose a method to identify risks in supply chains with the aim to add value to supply chain members in a holistic business framework. Qualitative or semiquantitative methods for risk filtering and ranking have been proposed by Morgan et al. (2000) and Baccarini \& Archer (2001). Morgan et al (2001) have studied the correlation between both individual and group and qualitative and quantitative risk ranking among risk analysts and conclude that the methods are fairly consistent. Haimes et al (2002) 
provide a methodological framework for risk filtering, ranking and management (RFRM), that constitutes eight phases, starting with scenario identification, followed by four phases and risk filtering and ranking, before continuing to risk management, safeguarding against missing critical items and iteration of the process.

Multicriteria analysis helps decision-makers to structure problems and make traceable, justifiable and explainable decisions (Belton \& Stewart, 2002; Chankong \& Haimes, 1983; Linkov et al., 2006) Integrating scenarios with multicriteria analysis has been used to support robust strategic decision making for systems (Montibeller \& Franco, 2010). In contrast to traditional risk analysis focusing on probabilities and consequences, multicriteria analysis with scenario-based preferences, has focused on risk as the influence of scenarios on priorities (Thekdi \& Lambert, 2014; Karvetski \& Lambert, 2012). Scenario planning has been useful in exploring uncertainties of complex systems where probabilities are derived from expert opinions and subject to cognitive bias (Goodwin \& Wright, 2001). This is particularly relevant to developing situations facing inherent deep uncertainties. Scenarios are developed from major risks identified, alone or in combination with each other, and the preference among criteria adjusted to account for the uncertainties introduced in each particular scenario, to create a new prioritization of initiatives for every scenario. The influence of each scenario on the prioritization has been quantified using rank correlation measures such as sum of squares ranking change (Hamilton et al., 2012), Spearman rank correlation coefficient (Thorisson et al., n.d.) and Kendall Tau-b distance (You et al., 2014). 
Measuring how the rank of initiatives deviates from the baseline under different scenarios provides a measure of their robustness. The quantification of disruptiveness is useful in filtering sources of risk. The method has been successfully applied to energy security (Hamilton et al., 2012; Karvetski et al., 2011), development of a biofuel industry (Connelly et al., 2015), disaster management (Lambert et al., 2013; Parlak et al., 2012), and impacts of climate change to infrastructure investment (Hamilton et al., 2015; You et al., 2014; Karvetski et al., 2011).

In previous literature on multicriteria analysis with scenario-based preferences, linear additive value functions have typically been used to aggregate across the multiple criteria, where each criterion has a numerical weight assigned to it. This approach can be criticized for a number of reasons. Weights imply a fixed trade-off between criteria and assumes independency among the criteria. The approach requires that the utility an alternative provides in terms of a certain criterion is quantified and these can be added to get a total utility which is used to compare alternatives. Expert assessments of alternative relations to criteria is on the other hand typically qualitative. Rule-based assignment or classification modeling is an alternative to the quantitative aggregation of multiple criteria. Azibi and Vanderpooten (2002) describe a general approach to construct a rulebased assignment model, requirements the rule base must comply with and how to check for inconsistencies. Olson et al. (1995) differentiate between different types of rules in a multicriteria classification problem and also consider consistency tests to ensure the integration of the different types. Bohanec and Rajkovic (1988) study rule-based 
multicriteria decision making, with the goal of improving decision knowledge acquisition and explanation, ultimately supporting better decisions.

\subsection{Chapter summary}

This chapter reviewed relevant literature on risk identification and filtering, multicriteria analysis and scenario analysis and rule-based assignment modeling. It identified a need for exploring a combination of scenario-based preferences with rule-based prioritization to evaluate the disruption potential of scenarios to the prioritization of initiatives. The methods used to achieve this evaluation are described in the upcoming Chapter 3. 


\section{Technical approach}

\subsection{Chapter overview}

This chapter describes a rule-based approach as a path to: Identify competing initiatives, assess the influence of a variety of scenarios to classification of the initiatives into priority classes, and evaluate the agreement and consistency of results across complementary sets of success criteria. Figure 3 summarizes the steps of the methodology. The chapter is organized as follows: goals of the methodology are stated, building blocks are defined, their relationships describes and finally commented on what types of output the methodology generates. 


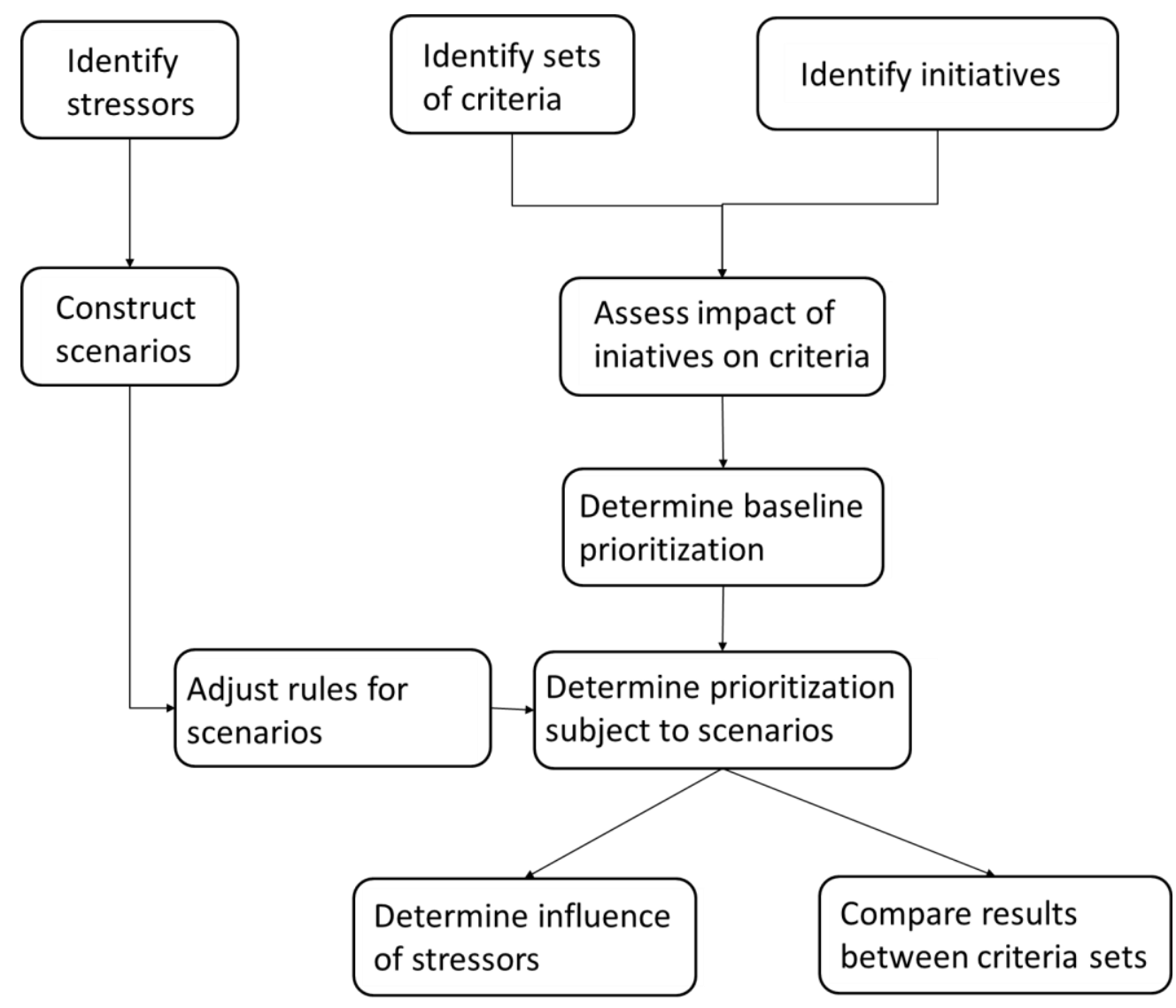

Figure 3. Methodology for rule-based prioritization of initiatives 


\subsection{Methodology}

An aim of the methodology is to measure the disruption of scenarios to the prioritization of initiatives. Intermediate outputs are a several prioritizations, different for each scenario.

Initiatives are projects and project elements, both planned and proposed, that compete for resources and funding. Due to limited resources the initiatives must be prioritized or classified such that comparison in terms of how well initiatives meet success criteria is possible. Success criteria are represent goals and objectives of different stakeholders of the system. Stressors are emergent and future conditions that may disrupt the prioritization of initiatives by posing danger to the system or exploiting vulnerabilities. Scenarios are stressors, alone and in combination, that represent a specific future or development of the system. Each of these building blocks and their properties are discussed in further detail in Chapter 4.3.

With expert elicitation, the impact initiatives have on the criteria are assessed. The assessments are given by linguistic terms, in the demonstration in Chapter 4 they are: significant impact, marginal impact or no/negligible impact. Using rule-based aggregation of the multiple criteria, no quantification of the impact levels is necessary.

The prioritization of initiatives is achieved by using rules that assign initiatives to priority classes or levels. The construction of rules can be achieved typically by two paths, expert elicitation and induction. Expert elicitation requires interviewing and interacting with 
stakeholders and decision makers and has been studied extensively, see for example Hickey \& Davis (2003), Ayyub (2001) and Kadane \& Wolfson (1998). Induction uses historical data or examples and follows certain algorithms to generate rules. In a system where the main goal is to provide stakeholders insight into decisions and risks, expert elicitation is more appropriate since induction requires a sufficiently large learning set to be consistent, which in the specific case of Afghanistan power sector investments is unavailable, as well as it can often result in a large number of rules, making it hard to trace back the logic of why an initiative is assigned to a certain priority class.

Rules take the form of IF-THEN statements where the IF conditions are based on the criteria assessments and the THEN outputs are different priority classes. Rules can be categorized by their characteristics and in the literature three types are prevalent (Azibi \& Vanderpooten, 2002; Olson et al., 1995). It should be noted that a rule-base can contain a combination of all categories.

- Cut-off, or absorption, rules: If an initiative has a certain performance on a specific initiative, that performance alone puts it into a priority class. Cut-off rules are often used to eliminate initiatives that do not meet a certain requirement.

- Example-based rules: An example-based rule describes a certain combination of criteria assessments and assigns the priority class based on this. If the number of criteria and levels of assessment is low, it is possible to enumerate all combinations, but in larger problems this is unrealistic and example rules should 
complement a more general approach. Example rules can be useful to evaluate specific or extreme cases.

- Compensation rules: These encompass rules that do not fall into either of the previous categories. They can be based on counts of different levels of assessments and describe certain trade-offs between different criteria and levels of assessment. The "weight-and-rate" method can be thought of as a special case of a compensation rule-base.

To ensure a logical completeness and consistency, the rule base must meet certain requirements, as described by Azibi \& Vanderpooten (2002).

- Completeness: Each initiative is assigned to at least one priority class.

- Exclusiveness: Each initiative is assigned to at most one priority class.

- Monotonicity requirement: An initiative that is dominated by another initiative in terms of criteria assessments cannot be assigned to a higher priority class than the initiative it is dominated by.

In the demonstration in Chapter 4, rules are driven by the high-level goals of the stakeholders, both Afghan and international. Based on the specific characteristics of the different scenarios, rules for classification vary by scenarios, and therefore a different prioritization arises from each scenario. The variability in the prioritizations is the main result of the analysis performed. 
The main results of the method is the disruption of different scenarios which can be measured in several ways. To generalize the idea, a disruption function for scenario $k$ is defined as a function of the prioritizations for the baseline scenario and scenario $k$ as displayed in equation (1)

$$
d\left(s_{k}\right) \equiv f\left(A_{b}, A_{k}\right), \quad s_{k} \in S
$$

The disruption function can take many forms. In a simple case, transition frequencies between priority classes can be used as a basis. A scenario is considered more disruptive if multiple initiatives transition between priority classes when subjected to that particular scenario. The disruption function is then the total number of transitions a scenario causes.

Extensions to using the simple transition frequency could include methods based on rank correlation techniques such as Spearman rank correlation coefficient and Kendall Tau-b distance. It is possible to view priority classes as ranks where all initiatives in one class are considered equally ranked. However, the rules used for classification do not imply a tie between initiatives within the priority classes, only preference of initiatives in higher classes to initiatives in lower classes. Furthermore, both Spearman rank correlation and Kendall Tau-b distance work best when there are few ties.

Having established an appropriate disruption function the most disruptive scenario, $s_{\max }$, and the least disruptive scenario, $s_{\text {min }}$, are defined as follows

$$
s_{\max } \equiv\left\{s \mid d(s)=\max _{t \in S} d\left(s_{k}\right)\right\}
$$




$$
s_{\min } \equiv\left\{s \mid d(s)=\operatorname{mind}_{t \in S}\left(s_{k}\right)\right\}
$$

That is, the most disruptive function is the one that has a disruption function value that is greater or equal to all other disruption function values of analyzed scenarios and the least disruptive function is the one that has a disruption function value that is less than or equal to all other disruption function values. The evaluation of disruption functions is central to risk filtering as it assesses the potential of scenarios to change the minds of decision makers. This is an essential property, since the performing of risk analysis does not benefit a decision making process if decision makers have no intention a changing their minds after new information is revealed.

To appreciate different lessons learned between the different sets of criteria, the disruptions of scenarios and prioritizations for the different sets of criteria are compared. The difference in the prioritization of each individual initiative between different sets of criteria is calculated, and the total difference is used as a measure of the separation of priorities between criteria sets under a particular scenario. This is illustrated in Chapter

\subsection{7.}

\subsection{Chapter summary}

This chapter described the methods for rule-based filtering of risk scenarios by the disruption of management priorities that in Chapter 4 are used to quantify the disruption of prioritizations of initiatives in the Afghanistan power sector when subjected to various scenarios. The chapter described necessary building blocks and their relationships, and 
how disruption is quantified with respect to prioritizations of initiatives under different scenarios, and how rules can be constructed to achieve the prioritizations. 


\section{Demonstration}

\subsection{Chapter overview}

Infrastructure development plays an important role in improving standards of living and reducing poverty in the developing regions of the world. In regions faced with uncertainties of military conflicts, politics, economics and others, resources have to be put not only into the technical aspects of strategic plans, but the social and organizational as well since shifts in stakeholder preferences or political or security landscapes might drastically affect the priority setting of initiatives. This chapter demonstrates the application of methods presented in Chapter 3 to a power grid capacity expansion plan in Afghanistan. It includes an historical background and discussion about the social context the methods are applied to, which is a major driver in the construction of scenarios and establishment of criteria. A motivational example for the need of risk analysis in the 
infrastructure sector is given. The scope of the demonstration is a power purchase and power delivery agreement involving local and international stakeholders, with multiple perspectives, goals and objectives.

The chapter goes through all necessary steps in the methodology, identifying stressors and scenarios, criteria, and initiatives, developing rules for prioritization, quantifying the disruption of the different scenarios and comparing results between different sets of criteria.

\subsection{Background}

\subsubsection{History of the region}

After the terrorist attacks on 9/11 and the subsequent invasion of the United States and its allies of Afghanistan, the country has been in the spotlight of the international community. Its history of conflict and social structure and political culture, however, traces longer back and cannot be explained sufficiently with any one theory. The state of Afghanistan emerged in 1879 as a "buffer" between India under the rule of the British Empire to the south and east and the Russian Empire to the north (Shahrani, 2002). The borders drawn at the time by Britain, Russia, China and Persia, still mostly intact, left a number of ethnic groups split on opposite sides of borders and resulted in Afghanistan being populated by many different groups with their own language and cultural identity, the Pashtun and Tajik being the two largest. Ever since, the central government has been under the influence and pressure of foreign powers, the Soviet Union, Pakistan and US 
having the strongest presence in the last 40 years, with periods of civil war between ethnic groups or anarchy in between.

Shahrani (2002) argues this continuous involvement of global superpowers in Afghan politics contributed to a traditionally weak central government, with much of the real power being held locally by tribal leaders. Furthermore, Giustozzi \& Ullah (2006) argue that the Pashtun communities in southern and eastern provinces, composing around $40 \%$ of the population, traditionally were less susceptible to warlordism than the predominantly Tajik population in the north and west and maintained a better relationship with whichever government was in control in Kabul at each time. However, this also lead to that the central government did not have sufficient military and political strength to withstand pressure from neighboring countries or have complete control of the country. In addition to traditional conflict centered explanations, Edwards (1996) argues that three contradictory and incompatible factors deeply rooted in Afghan society form the genesis of the weak state rather than ethnicity, religion or aspirations of individuals, namely: individualistic tribal codes of honor, universalist Islam ideas and the hierarchical structure and codes of monarchies.

This socio-political landscape made Afghanistan vulnerable to the rise of the Taliban in the 1990's and made it a safe haven for extreme Islamist groups, most notably al-Qaeda. Given the continuously turbulent history of the country, these same underlying factors are likely to contribute to the difficulties the Western coalition has had establishing 
stability in Afghanistan after the Taliban regime in Kabul was overthrown in the early 2000's.

\subsubsection{Kajaki Dam: Lessons learned}

The Kajaki hydro power plant in the southern province Helmand is the largest hydropower plant in Afghanistan, generating electricity for Helmand and Kandahar provinces, including and most importantly Kandahar City. The rehabilitation and expansion of the facility has been a main focus of the reconstruction efforts of the United States in recent years and considered a critical component of the counterinsurgency effort in the volatile southern part of Afghanistan (Brody, 2014; Ross, 2011). The power plant, originally built in 1975, has two generating units rehabilitated in the last decade. However, the major effort has been the construction and implementation of a new generating unit, known as Kajaki Unit 2, adding 18.5 MW generating potential to the existing 33 MW. This effort started in 2005 but was halted in 2008 when the contractor responsible for the design, manufacturing and installation withdrew from the project due to security concerns. A new contract was awarded in 2010, and in 2013 the management and implementation of the project was transferred to the Afghan government (United States Agency for International Development, 2015). The expected completion date as of June 2015 is March 2016, 11 years after the original contract was awarded. The experiences gained from the project can give valuable insight into future development of the electrical power system in Afghanistan. 
A review of the project in early 2015 identify "coordination of logistics and security with multiple agencies, maintaining the physical supply line, securing or training appropriately skilled labor, and minimizing plant outages during construction to minimize power disruption to the region" as major challenges to successful execution of the project (Boyce et al., 2015). Security of on-site staff, supplies and the facility itself is the most critical concern. The site is only accessible by road that is frequently blocked by insurgents, or by helicopter which is a costly alternative and has limited loading capacity. This has led to security being the single largest contributor to the overall cost of the project. When embarking on new investments, it is therefore important to plan for costs related to guaranteeing the security of contractors and later operations staff as well as developing and planning alternative routes to access the facility.

When the original contractor abandoned the project, a significant portion of the design already been done was not accessible when work was continued with the new contractor. Furthermore, instructions, operations and maintenance manuals and other documentation related to equipment previously bought were missing or damaged, making the utilization of these investments problematic. Therefore, documentation, reporting and oversight by stakeholders are critical in case there is a halt in construction due to change of contractors, security concerns, natural disasters or other reasons. This also calls for a need to build a local skilled workforce able to operate and maintain investments which may largely be designed and constructed by foreign contractors. This 
need includes the translation of all relevant documents to local languages as well as developing training programs for employees.

Kajaki Dam does not only provide water for electric power production but the water is also used for irrigation in the nearby agricultural provinces. This has caused some tension between the ministries responsible for energy production on one hand, which wants to preserve water in the reservoir over the summer to meet the increased electricity demand in the winter, and agriculture on the other, which wants to control the amount released for irrigation any given season. This illustrates the need for clear inter-agency agreements, especially when goals and objectives conflict.

The experience of the Kajaki hydro power plant project support the need for extensive security measures to protect investments while instability is prevalent in the region, according to officials the power lines from Kajaki Dam to consumers were cut over 2,000 times in 2015 (Jolly, 2016). Similarly important is documenting and maintaining updated versions of all technical information translated into relevant languages, and making clear agreements on the rights and responsibilities of different stakeholders. Furthermore, oversight and information sharing, both between interested parties and independent oversight agencies is necessary to ensure contracts are being carried out as agreed on and expenses stay within budgeted limits.

\subsubsection{Power Purchase and Power Delivery Agreement: An innovative approach} Decades of conflict have contributed to a drastically underdeveloped infrastructure system in Afghanistan. Only $28 \%$ of the population had access to reliable electricity in 
2014 (United States Agency for International Development, 2014) with the power grid divided into several unconnected islands and in some cases operating on different frequencies (Fichtner GmbH \& Co. KG, 2013). A major objective of agencies supporting infrastructure development in Afghanistan has been to connect the islands and ensure compatibility across the system as well as with the electric grids of the neighboring countries that supply the country with about 70\% of its electricity (Fichtner GmbH \& Co. KG, 2013). Establishing a national interconnected power grid would increase energy security by adding redundancy to the system. Moreover, resources such as the Sheberghan natural gas fields in the somewhat remote north-western part of the country could provide energy to the more heavily populated regions around the national capital, Kabul. However, volatility in the political, economic and security landscape is discouraging to potential donors, and planned projects are often delayed or abandoned altogether. With an uncertain security situation and underdeveloped public infrastructure, projects that couple military and civilian needs are particularly attractive to donors and investors.

Various government ministries as well as military and law enforcement facilities operated by the Afghan National Defense Security Forces (ANDSF) are currently powered by onsite diesel generators. Operating and maintaining the generator systems are expensive and concerns have been raised about corruption in the diesel fuel supply chain, and it has been estimated that $15-20 \%$ of fuel budget is lost due to poor quality, pilferage, waste, corruption and leakage during transportation" (Wilson, 2015a). Connecting 
aforementioned facilities to the power grid could create substantial savings, allowing surplus funding to be allocated to other infrastructure investments currently underfunded. However, with frequent load shedding and unplanned blackouts, the available capacity and reliability of the current system does not meet the minimum requirements of the government agencies. Western entities like NATO and the US Department of Defense that provide much of ANDSF funding have recognized the potential of supporting an integrated national power grid, that would service both defense facilities and civilian demand.

To meet these dual needs, a power delivery and power purchase agreement (PDPPA) was proposed to the ministries responsible for the Afghan security forces, the national utility company Da Afghanistan Breshna Sherkat (DABS), the Asian Development Bank (ADB), the US Agency for International Development (USAID), to be funded by NATO member states through the Combined Security Transition Command (CSTC-A). The objective of the agreement is to provide the ministries with reliable electric power while simultaneously benefiting the public by expanding the national power grid. Under the agreement the ministries pay the utility company an above-market rate for electricity, while still saving costs compared to powering facilities with diesel generators. The utility company agrees to use the surplus income to integrate ministry facilities into the grid with external funding from CSTC-A used to support higher level grid enhancement projects. In addition, a contribution of $\$ 200$ million from NATO member states is earmarked in the first three 
years of the total 10 year agreement, in order to accelerate the construction of infrastructure.

\subsection{Demonstration of methods}

This section will identify and quantify the disruption potential of several scenarios to the successful implementation of the components of the power purchase and delivery agreement.

\subsubsection{Identification of stressors}

The set $S=\left\{s_{1}, \ldots, s_{28}\right\}$ represents 28 uncertain stressors, listed in Table 1. Stressors are emergent and future conditions that might disrupt the prioritization of initiatives. Stressors can be internal, such as policies or assumptions about future conditions advocated by certain stakeholders, or external, such as military conflict or natural disasters. It is noted that the set is not a complete set of all possible future conditions. The stressors are drawn from stakeholder interviews, several reports (Embassy of the United States of America \& U.S. Forces, 2013; Independent Joint Anti-Corruption Monitoring and Evaluation Committee, 2014; Inspector General Department of Defense, 2015; Special Inspector General for Afghanistan Reconstruction, 2014; Wilson, 2015b) and previous case studies of prioritization of infrastructure in Afghanistan (Lambert et al., 2012) and revised and expanded after input from area experts at the US Army Corps of Engineers, USAID and CSTC-A. Attention is again drawn to the fact that the list is not an exhaustive and complete list of all possible factors possibly disrupting priorities but includes the main threats to the success of developing a sustainable power sector. 
Table 1. Stressors that, alone and in combination, might disrupt the prioritization of initiatives in the electric power sector of Afghanistan.

\begin{tabular}{|c|c|c|}
\hline & Stressor & Main source \\
\hline $\mathrm{s}_{1}$ & $\begin{array}{l}\text { Limited institutional and human-capital capacity in Afghan } \\
\text { institutions }\end{array}$ & SIGAR, 2014 \\
\hline s2 & $\begin{array}{l}\text { Operational demands and constraints imposed by an active } \\
\text { insurgency }\end{array}$ & SIGAR, 2014 \\
\hline S3 & $\begin{array}{l}\text { Widespread corruption in Afghan society and government } \\
\text { entities }\end{array}$ & SIGAR, 2014 \\
\hline $\mathrm{S}_{4}$ & $\begin{array}{l}\text { Afghan reluctance or inability to impose accountability, } \\
\text { especially on the wealthy or well-connected in government } \\
\text { and society }\end{array}$ & SIGAR, 2014 \\
\hline S5 & $\begin{array}{l}\text { Poor record keeping and data retention by U.S. agencies and } \\
\text { Afghan entities }\end{array}$ & SIGAR, 2014 \\
\hline s6 & $\begin{array}{l}\text { Frequent personnel turnover and loss of U.S. agencies' in } \\
\text { country institutional memory }\end{array}$ & SIGAR, 2014 \\
\hline S7 & $\begin{array}{l}\text { U.S. oversight personnel's noncompliance with existing } \\
\text { rules and regulations }\end{array}$ & SIGAR, 2014 \\
\hline s8 & $\begin{array}{l}\text { Lack of adequate, coordinated, context-sensitive planning to } \\
\text { guide program conduct }\end{array}$ & SIGAR, 2014 \\
\hline S9 & $\begin{array}{l}\text { Failure to give due weight to sustainability in considering } \\
\text { projects for Afghan control }\end{array}$ & SIGAR, 2014 \\
\hline s10 & Limited visibility into Afghan records & SIGAR, 2014 \\
\hline $\mathrm{s}_{11}$ & Mismanaged funds & Wilson, 2014 \\
\hline s12 & Power not provided by DABS & Wilson, 2014 \\
\hline $\mathrm{s}_{13}$ & ADB does not build necessary infrastructure & Wilson, 2014 \\
\hline $\mathrm{S}_{14}$ & ANDSF doesn't pay electric bill & Wilson, 2014 \\
\hline
\end{tabular}




\begin{tabular}{|c|c|c|}
\hline & Stressor & Main source \\
\hline S15 & $\begin{array}{l}\text { ANDSF Commanders resist to convert from generators to } \\
\text { grid }\end{array}$ & Wilson, 2014 \\
\hline S16 & $\begin{array}{l}\text { Public perceives ANDSF as consuming their electrical } \\
\text { capacity }\end{array}$ & Wilson, 2014 \\
\hline S17 & Disruption of electricity import & USACE, 2015 \\
\hline S18 & Meter tampering & USACE, 2015 \\
\hline S19 & Electricity subsidies terminated & USACE, 2015 \\
\hline S20 & Land tenure complications & USAID, 2015 \\
\hline S21 & Natural gas price volatility & USAID, 2015 \\
\hline S22 & National security upturn & $\begin{array}{l}\text { Lambert et al, } \\
2012\end{array}$ \\
\hline S23 & Lack of agency coordination & $\begin{array}{l}\text { Lambert et al, } \\
2012\end{array}$ \\
\hline$S_{24}$ & Raw materials decrease & $\begin{array}{l}\text { Lambert et al, } \\
2012\end{array}$ \\
\hline S25 & Contractor unavailability & $\begin{array}{l}\text { Lambert et al, } \\
2012\end{array}$ \\
\hline S26 & Trade problems & $\begin{array}{l}\text { Lambert et al, } \\
2012\end{array}$ \\
\hline S27 & Natural disaster & $\begin{array}{l}\text { Lambert et al, } \\
2012\end{array}$ \\
\hline S28 & Illicit economy growth & $\begin{array}{l}\text { Lambert et al, } \\
2012\end{array}$ \\
\hline
\end{tabular}




\subsubsection{Identification of scenarios}

The stressors, alone and in combination, are used as the basis for constructing scenarios. The quantification of the degree of disruption these scenarios impose on the prioritization of initiatives of the PDPPA is the main result of this thesis. The scenarios are constructed with the aim to address a wide range of possibilities. They are inspired by the multiple perspectives of stakeholders of the agreement, including agencies responsible for construction and operations, local and foreign governments, development agencies, the security forces and the civilian population. Tables 2-7 describe the scenarios. 
Table 2. Summary of definition and properties of scenario sc1: Insufficient power supply.

\section{Scenario}

sc1: Insufficient power supply

\section{Description}

ANDSF does not receive the agreed amount of electric power.

\section{Key stakeholders/perspective}

Construction and operations (DABS and ADB)

\section{Stressors}

s12: Power not provided by DABS

S13: ADB does not build necessary infrastructure

\section{Influences}

Calls for acceleration of large-scale infrastructure investments that either support electricity generation or import. Fines may be imposed on the utility company. 
Table 3. Summary of definition and properties of scenario sc2: Unsatisfactory local governance.

\section{Scenario}

sc2: Unsatisfactory local governance

\section{Description}

The implementation of the PDPPA meets significant obstacles in the Afghan administrative system.

\section{Key stakeholders/perspective}

Afghanistan national government

\section{Stressors}

s3: Widespread corruption in Afghan society and government entities

S4: Afghan reluctance or inability to impose accountability, especially on the wealthy or well-connected in government and society

S23: Lack of agency coordination

\section{Influences}

Initiatives are delayed, funds are wasted and trust of the international donor community decreases. 
Table 4. Summary of definition and properties of scenario sc3: Deteriorating security conditions.

\section{Scenario}

sc3: Deteriorating security conditions

\section{Description}

Insurgency hinders the construction, operation and maintenance of critical parts of the power grid.

\section{Key stakeholders/perspective}

Afghan National Defense Security Forces (ANDSF)

\section{Stressors}

S2: Operational demands and constraints imposed by an active insurgency

\section{Influences}

Army and police have to activate back-up diesel generators with associated costs and the public receives less power. 
Table 5. Summary of definition and properties of scenario sc4: Public perception problems.

\section{Scenario}

sc4: Public perception problems

\section{Description}

Significant public resistance to the connection of ANDSF facilities to the power grid.

\section{Key stakeholders/perspective}

The civilian population of Afghanistan

\section{Stressors}

S16: Public perceives ANDSF as consuming their electrical capacity

S19: Electricity subsidies terminated

\section{Influences}

The public gets subsidized electricity. If subsidies are terminated or decreased, or the availability is otherwise impacted, the general population may lose trust in the ANDSF. 
Table 6. Summary of definition and properties of scenario sc5: Electricity imports disrupted.

\section{Scenario}

sc5: Electricity imports disrupted

\section{Description}

Less availability of electricity increases competition about local energy.

\section{Key stakeholders/perspective}

Neighboring countries

\section{Stressors}

S17: Disruption of electricity import

\section{Influences}

Calls for strengthening regional ties, and integration of Afghanistan in the regional economy and politics in order to make reliable agreements with neighboring countries on electricity imports. 
Table 7. Summary of definition and properties of scenario sc6: International management and oversight lacking.

\section{Scenario}

sc6: International management and oversight lacking

\section{Description}

The US and other international agencies fail to efficiently manage and oversee development programs.

\section{Key stakeholders/perspective}

The international development community

\section{Stressors}

S5: Poor record keeping and data retention by U.S. agencies and Afghan entities

S6: Frequent personnel turnover and loss of U.S. agencies' in country institutional memory

S7: U.S. oversight personnel's noncompliance with existing rules and regulations

\section{Influences}

Funds are wasted and infrastructure construction may be delayed. Effort has to be put in strengthening the capacity of the agencies. 


\subsubsection{Identification of success criteria}

To measure the attractiveness of investment initiatives two sets of success criteria are established in this thesis. The sets represent strategic goals of two major stakeholders in the Afghan power infrastructure sector. The first set, $C^{1}=\left\{c_{1}^{1}, \ldots, c_{8}^{1}\right\}$ is derived from the goals of the Afghanistan National Development Strategy (ANDS) (Islamic Republic of Afghanistan, 2008). The ANDS describes the vision of the Government of the Islamic Republic of Afghanistan for the development of the country based on the pillars of security, governance, rule of law and human rights, and economic and social development. For each pillar, more detailed focus areas are identified and strategic goals developed. Investments in large-scale infrastructure, including the electric power sector, should support the realization of these goals. Appendix A illustrates the overall development goal structure of the ANDS. The number of goals listed in the strategy is relatively large, over 20, and since many of them have little relevance to power grid capacity planning, the structure has been reduced to eight criteria, which are used in further analysis. Table 8 describes the criteria. 
Table 8. National government criteria, success criteria derived from the Afghanistan National Development Strategy.

\begin{tabular}{ll}
\hline Index & Criteria \\
\hline $\mathrm{C}^{1}$ & Security and governance \\
$\mathrm{C}^{1}{ }^{1}$ & Infrastructure and transportation \\
$\mathrm{C}^{1}$ & Education, Culture, Health, Agriculture, Rural Development, Social Protection \\
$\mathrm{C}^{1}{ }^{1}$ & Economic governance \& Private Sector Development \\
$\mathrm{C}^{1}$ & Capacity building \\
$\mathrm{C}^{1}{ }^{1}$ & Regional cooperation \\
$\mathrm{C}^{1}$ & Environment \\
$\mathrm{C}^{1}{ }^{1}$ & Gender equality, counter-narcotics, anti-corruption \\
\hline
\end{tabular}


The ANDS provides success criteria as envisioned by one stakeholder, the government of Afghanistan, hereafter referred to as the national government criteria. However, various international agencies and foreign governments provide a critical part of the funding necessary to achieve the goals and they might have different ideas of how to measure the success of their efforts. The US Civil-Military Strategic Framework for Afghanistan (Embassy of the United States of America \& U.S. Forces, 2013) outlines the priorities of the US government in Afghanistan for 2015-2024. According to the framework, five areas of priority are identified to meet the overall national goals of disrupting, dismantling and defeat al-Qa'ida and its affiliates and strengthen Afghanistan so that it cannot become a safe haven for terrorists. The United States have spent over US $\$ 100$ billion on reconstruction and relief in Afghanistan since 2002 (Special Inspector General for Afghanistan Reconstruction, 2015). In order to guarantee the efficiency and effectiveness of reconstruction programs and detect and prevent fraud, waste and abuse, the Office of the Special Inspector General for Afghanistan Reconstruction (SIGAR) conducts audits and provides oversight over U.S. funded efforts. A recent report (Special Inspector General for Afghanistan Reconstruction, 2014) identifies seven areas that pose risk of failure to planned and progressing reconstruction programs.

The goals and objectives described in the two documents, the Civil-Military Framework and the SIGAR report, form the basis of the second set of criteria, the US government criteria. Similarly to the derivation of the national government criteria, the goals listed in these reports are clustered together to form a coherent, non-overlapping set of criteria. 
Table 9 lists the US government criteria, denoted with $C^{2}=\left\{c_{1}^{2}, \ldots, c_{7}^{2}\right\}$. Appendix B shows the overall structure of the objectives of the two reports.

\subsubsection{Identification of initiatives}

The set $X=\left\{x_{1}, \ldots, x_{37}\right\}$ represents 37 initiatives in the Afghanistan power sector which are listed in Table 10. The initiatives of the grid capacity plan are compiled from several sources, including both projects already planned and projects identified in a power sector master plan (Fichtner GmbH \& Co. KG, 2013) and its subsequent addendum (Neifer, 2014) as the most likely to be planned and completed in the coming decade. Being signatories of the PDPPA, the Asian Development Bank and USAID will manage the initiatives funded by the agreement, however, initiatives from other sources are included since under the influence of certain scenarios, new stakeholders should be brought to the table, widening the scope of the agreement. The initiatives include both physical structures such as transmission lines, substations and power generation units as well as project management, oversight and monitoring. Appendix C contains a map showing some of the physical initiatives as well as current electric power infrastructure. 
Table 9. US government criteria, derived from the US Civil-Military Strategic Framework for Afghanistan and the Office of the Special Inspector General for Afghanistan Reconstruction.

\begin{tabular}{cl}
\hline Index & \multicolumn{1}{c}{ Criteria } \\
\hline $\mathrm{c}^{2}$ & Development of key industries \\
$\mathrm{c}^{2}$ & Improve health and education \\
$\mathrm{C}_{3}{ }^{2}$ & Regional economic integration \\
$\mathrm{C}_{4}{ }^{2}$ & Development of key infrastructure \\
$\mathrm{C}_{5}{ }^{2}$ & Justice and legal improvements, anti-corruption \\
$\mathrm{C}^{2}$ & Strengthen governance \\
$\mathrm{C}^{2}$ & ANDSF capacity and capability \\
\hline
\end{tabular}


Table 10. Initiatives in the Afghan electric power sector (Type: $P G=$ Power Generation, $\mathrm{T}_{\text {Kabul }}=$ Transmission in Kabul, $\mathrm{T}_{\text {urban }}=$ Transmission in urban area outside Kabul, $\mathrm{T}_{\text {rural }}=$ Transmission in rural area, Tborder $_{\text { }}$ Transmission connecting to border, $\mathrm{SS}=$ Substation, $\mathrm{EQ}=$ Equipment, $\mathrm{PM}=$ Project management, oversight or monitoring. Program: USAID = US Agency for International Development; ADB = Asian Development Bank).

\begin{tabular}{|c|c|c|c|}
\hline & Initiative & Type & Program \\
\hline $\mathrm{x} 1$ & Sheberghan gas development & PG & \multirow{5}{*}{ USAID } \\
\hline $\mathrm{x} 2$ & $\begin{array}{l}\text { Arghundy to Kandahar } \\
\text { transmission line }\end{array}$ & Trural & \\
\hline хз & Salang Tunnel substation & SS & \\
\hline $\mathrm{x}_{4}$ & Kabul power system rehabilitation & TKabul & \\
\hline $\mathrm{x} 5$ & Kajaki Dam Unit 2 & PG & \\
\hline $\mathrm{X} 6$ & CASA-1000 & Tborder & World Bank \\
\hline $\mathrm{x} 7$ & $\begin{array}{l}\text { Kabul to Pakistan } \text { border } \\
\text { transmission line }\end{array}$ & Tborder & ADB TUTAP \\
\hline x8 & $\begin{array}{l}\text { Turkmenistan interconnection } \\
\text { phase } 1\end{array}$ & Tborder & $\begin{array}{l}\text { Power sector } \\
\text { masterplan }\end{array}$ \\
\hline X9 & Kunduz-Taloqan transmission line & Trural & \multirow{4}{*}{ ADB Tranche 1} \\
\hline $\mathrm{x} 10$ & $\begin{array}{l}\text { Baghlan and Kunduz distribution } \\
\text { networks }\end{array}$ & Turban & \\
\hline $\mathrm{x}_{11}$ & NEPS O\&M emergency equipment & EQ & \\
\hline $\mathrm{X} 12$ & $\begin{array}{l}\text { Rehabilitation of Sheberghan gas } \\
\text { wells }\end{array}$ & PG & \\
\hline
\end{tabular}




\begin{tabular}{|c|c|c|c|}
\hline & Initiative & Type & Program \\
\hline $\mathrm{x}_{13}$ & Tranche $1 \mathrm{PM}$ and implementation & PM & \\
\hline $\mathrm{x} 14$ & Tranche 4 preparation & PM & \\
\hline $\mathrm{x}_{15}$ & NEPS O\&M MTA contract & PM & \\
\hline $\mathrm{x}_{16}$ & $\begin{array}{l}\text { Chimtala S/S to South West S/S } \\
\text { transmission line }\end{array}$ & TKabul & \\
\hline $\mathrm{x}_{17}$ & Kabul South West S/S & SS & \\
\hline $\mathrm{x}_{18}$ & Kabul distribution network & TKabul & ADB Tranche 2 \\
\hline $\mathrm{x} 19$ & $\begin{array}{l}\text { Dual voltage transformers, oil } \\
\text { treatment plant and monitoring } \\
\text { devices }\end{array}$ & EQ & \\
\hline $\mathrm{x}_{20}$ & DABS management assistance & PM & \\
\hline $\mathrm{x}_{21}$ & $\begin{array}{lll}\text { Gereshk hydropower } & \text { plant } \\
\text { rehabilitation and upgrade } & \end{array}$ & PG & \\
\hline \multirow[t]{2}{*}{$\mathrm{x}_{22}$} & Gereshk distribution network & Turban & \\
\hline & upgrade & & ADB Tranche 3 \\
\hline $\mathrm{x} 23$ & Gereshk end-user metering system & EQ & \\
\hline $\mathrm{X}_{24}$ & $\begin{array}{l}\text { Tranche } 3 \text { project implementation } \\
\text { and supervision consultants }\end{array}$ & PM & \\
\hline $\mathrm{X} 25$ & $\begin{array}{l}\text { AFG/TKM border to Sheberghan } \\
\text { transmission line }\end{array}$ & Tborder & \\
\hline $\mathrm{X}_{26}$ & $\begin{array}{l}\text { Sheberghan to Mazar Sharif } \\
\text { transmission line }\end{array}$ & $\mathrm{T}_{\text {rural }}$ & ADB Tranche 4 \\
\hline $\mathrm{X}_{27}$ & $\begin{array}{l}\text { Andkhoy and Sheberghan } \\
\text { substations }\end{array}$ & SS & \\
\hline
\end{tabular}




\begin{tabular}{|c|c|c|c|}
\hline & Initiative & Type & Program \\
\hline $\mathrm{X} 28$ & Mazar Sharif substation expansion & SS & \\
\hline $\mathrm{X} 29$ & $\begin{array}{l}\text { Pul-e-Alam and Gardez } \\
\text { distribution networks }\end{array}$ & Turban & \\
\hline $\mathrm{X} 30$ & $\begin{array}{l}\text { Pul-e-Alam and Gardez substation } \\
\text { equipment }\end{array}$ & EQ & \\
\hline $\mathrm{X} 31$ & $\begin{array}{l}\text { Tranche } 4 \mathrm{PM} \text { and implementation } \\
\text { consultants }\end{array}$ & PM & \\
\hline $\mathrm{X} 32$ & Dashte Alwan substation & SS & \\
\hline $\mathrm{X} 33$ & $\begin{array}{l}\text { Tranche } 5 \text { project implementation } \\
\text { and supervision consultants }\end{array}$ & PM & ADB Tranche 5 \\
\hline $\mathrm{X} 34$ & $\begin{array}{l}\text { Dashte Alwan to Kabul Arghundy } \\
\text { transmission line }\end{array}$ & Trural & North-South nower \\
\hline X35 & Arghundy substation & SS & transmission \\
\hline $\mathrm{X} 36$ & $\begin{array}{l}\mathrm{N}-\mathrm{S} \text { power transmission project } \\
\text { implementation and supervision }\end{array}$ & PM & enhancement project \\
\hline
\end{tabular}




\subsubsection{Prioritization of initiatives to measure disruption of scenarios against}

The prioritization of initiatives is based on rules that are derived from assessments of impacts of initiatives on criteria. The assessments are based on interviews and teleconferences with stakeholders and review of planning documentation related to the initiatives. Table 11 shows the impact of initiatives on the national government criteria. Table 12 shows the impact of initiatives on the US government criteria. 
Table 11. Assessment of impacts of initiatives on national government criteria.

\begin{tabular}{|c|c|c|c|c|c|c|c|c|c|}
\hline & & 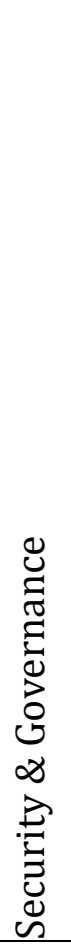 & 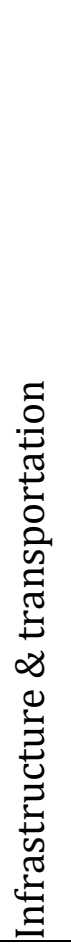 & 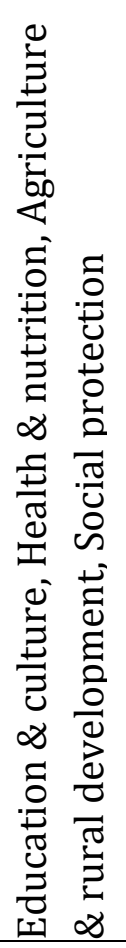 & 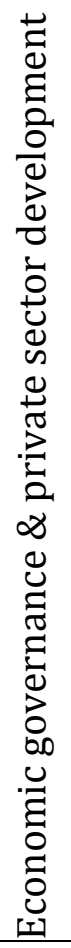 & 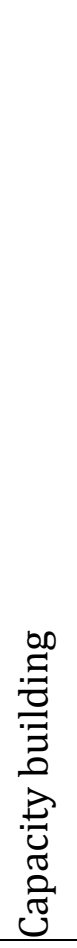 & 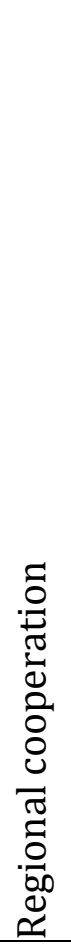 & 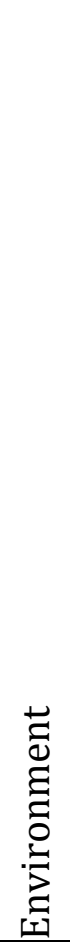 & 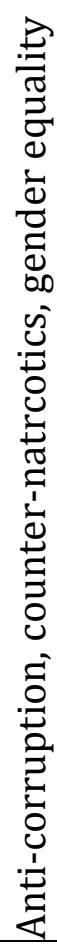 \\
\hline $\mathrm{X}_{1}$ & Sheberghan gas development & & $\bullet$ & & O & & & O & \\
\hline $\mathrm{X} 2$ & $\begin{array}{l}\text { Arghundy to Kandahar transmission } \\
\text { line }\end{array}$ & O & $\bullet$ & O & O & & & & \\
\hline $\mathrm{X} 3$ & Salang Tunnel substation & & O & & & & & & \\
\hline $\mathrm{X} 4$ & Kabul power system rehabilitation & O & $\bullet$ & & O & & & & \\
\hline $\mathrm{X} 5$ & Kajaki Dam Unit 2 & O & $\bullet$ & O & & & & O & \\
\hline $\mathrm{X} 6$ & CASA-1000 & & $\bullet$ & & & & $\bullet$ & & \\
\hline $\mathrm{X} 7$ & $\begin{array}{l}\text { TUTAP Kabul to PAK transmission } \\
\text { line }\end{array}$ & & • & & & & $\bullet$ & & \\
\hline $\mathrm{X} 8$ & TKM interconnection & O & $\bullet$ & & & & $\bullet$ & & \\
\hline $\mathrm{X} 9$ & Kunduz-Taloqan transmission line & $\bullet$ & O & & & & & & \\
\hline $\mathrm{X} 10$ & $\begin{array}{l}\text { Baghlan and Kunduz distribution } \\
\text { networks }\end{array}$ & $\bullet$ & O & & & & & & \\
\hline $\mathrm{X} 11$ & NEPS O\&M emergency equipment & O & O & & & O & & & \\
\hline $\mathrm{X} 12$ & $\begin{array}{l}\text { Rehabilitation of Sheberghan gas } \\
\text { wells }\end{array}$ & & O & & & & & O & \\
\hline
\end{tabular}




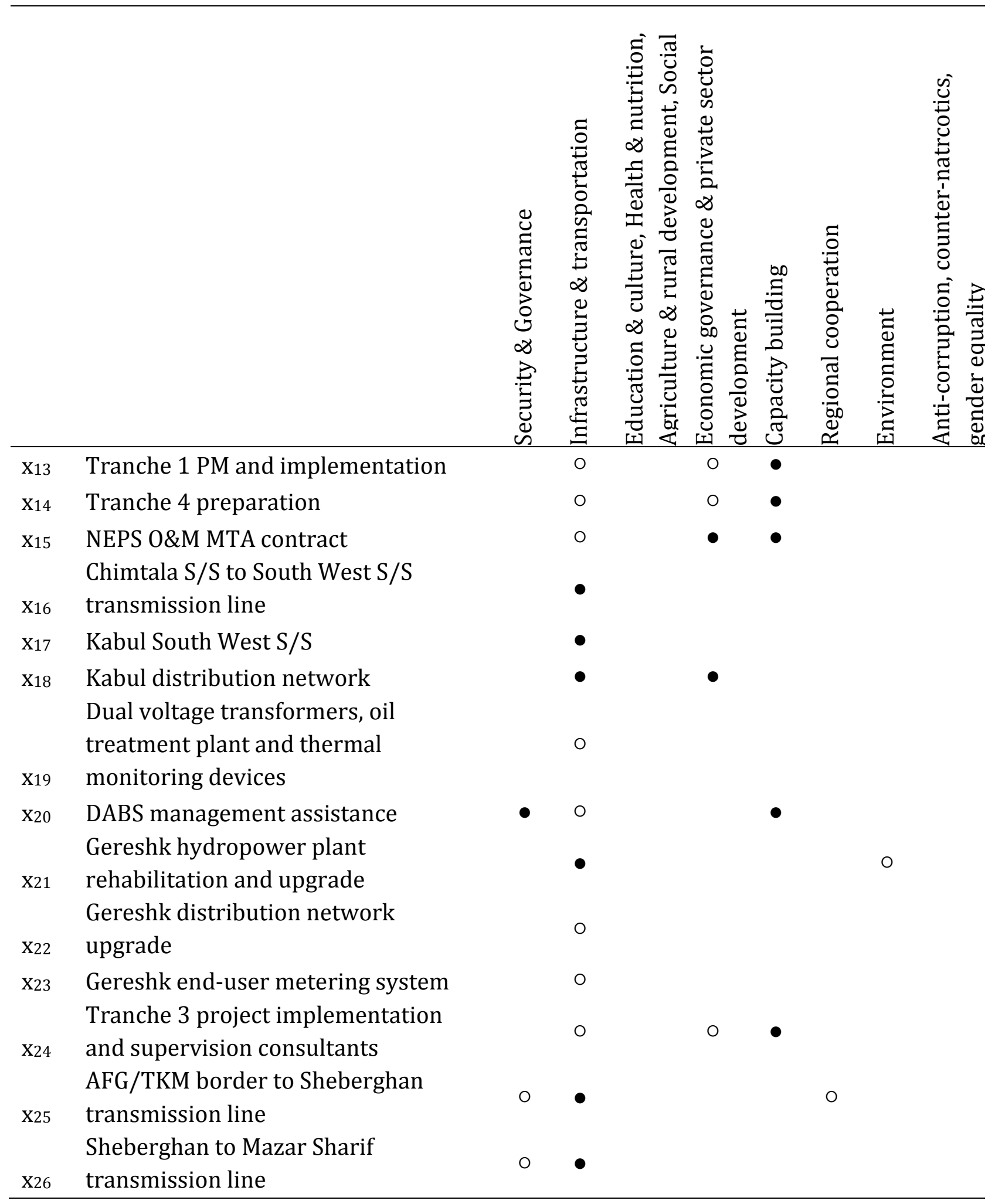




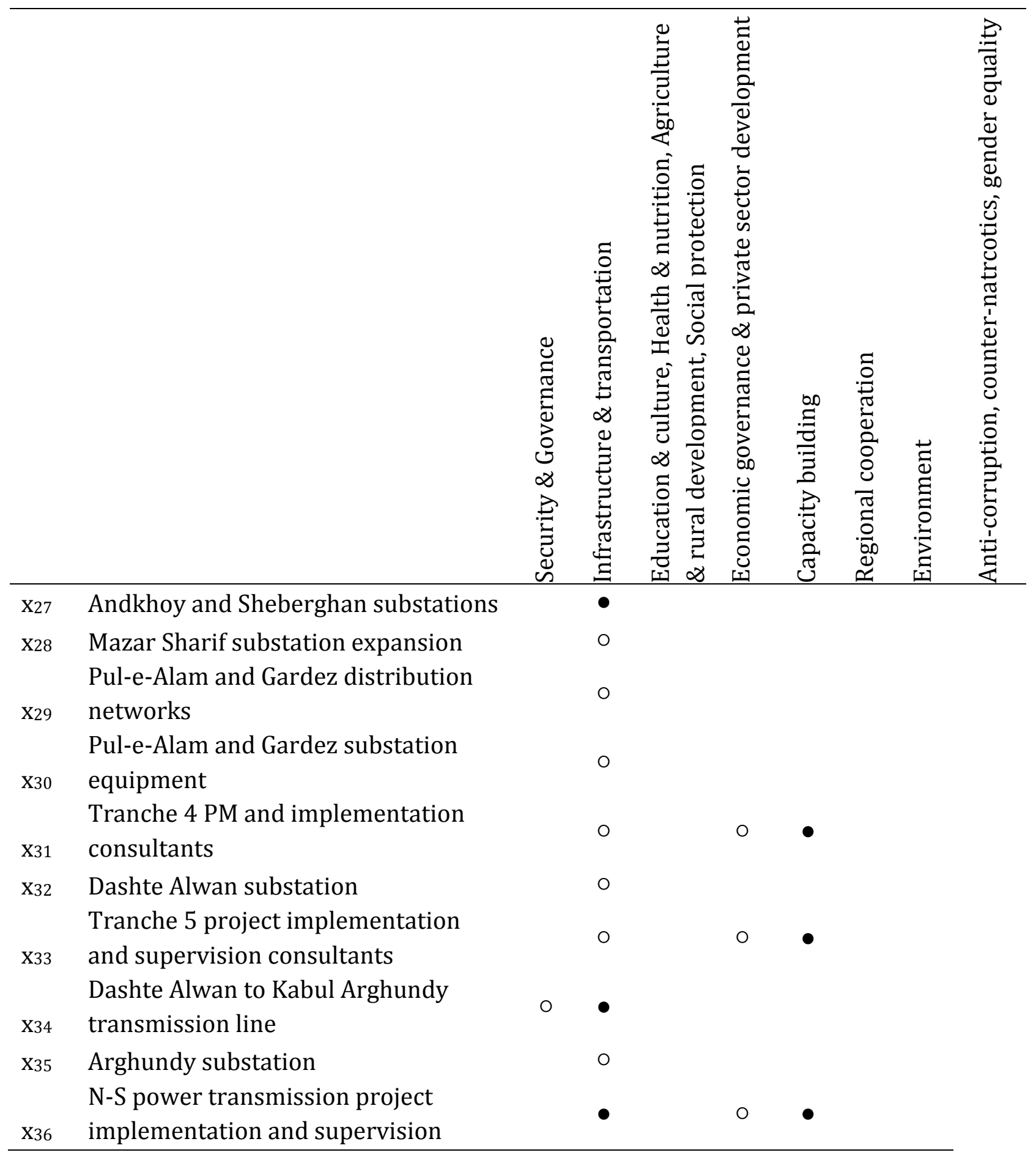


Table 12. Assessments of impacts of initiatives on US government criteria.

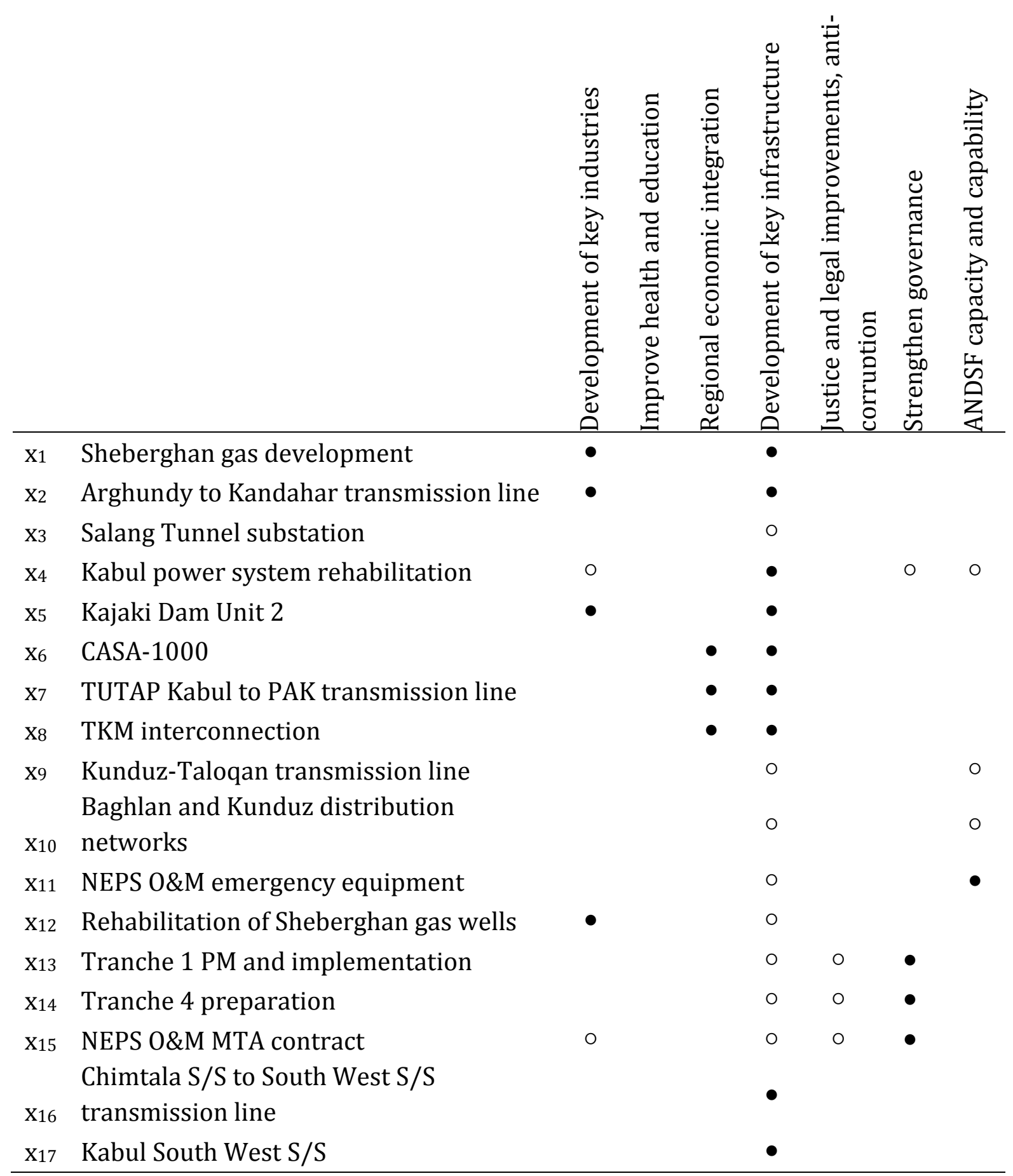




\begin{tabular}{|c|c|c|c|c|c|c|c|c|}
\hline & & 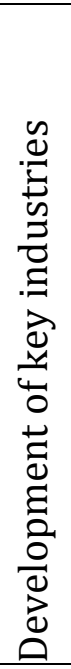 & 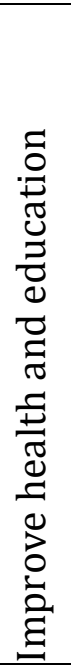 & 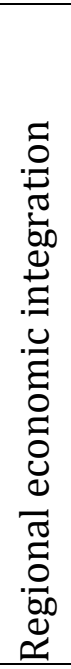 & 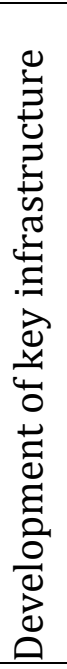 & 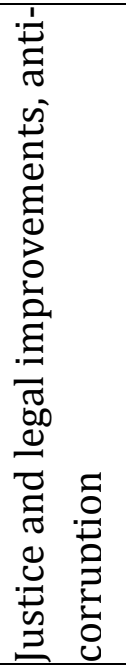 & 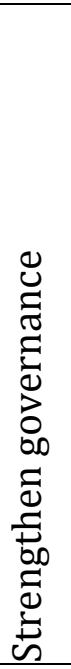 & 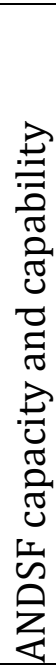 \\
\hline $\mathrm{X} 18$ & Kabul distribution network & $\bullet$ & & & $\bullet$ & & & \\
\hline $\mathrm{X} 19$ & $\begin{array}{l}\text { Dual voltage transformers, oil treatment } \\
\text { plant and thermal monitoring devices }\end{array}$ & & & & $\bullet$ & & & \\
\hline $\mathrm{X} 20$ & DABS management assistance & & & & ○ & o & $\bullet$ & \\
\hline $\mathrm{X} 21$ & $\begin{array}{l}\text { Gereshk hydropower plant rehabilitation } \\
\text { and upgrade }\end{array}$ & o & & & $\bullet$ & & & \\
\hline $\mathrm{X} 22$ & Gereshk distribution network upgrade & o & & & O & & & \\
\hline $\mathrm{X} 23$ & Gereshk end-user metering system & & & & 0 & & & \\
\hline $\mathrm{X} 24$ & $\begin{array}{l}\text { Tranche } 3 \text { project implementation and } \\
\text { supervision consultants }\end{array}$ & & & & 0 & 0 & o & \\
\hline $\mathrm{X} 25$ & $\begin{array}{l}\text { AFG/TKM border to Sheberghan } \\
\text { transmission line }\end{array}$ & & & & $\bullet$ & & & \\
\hline $\mathrm{X} 26$ & $\begin{array}{l}\text { Sheberghan to Mazar Sharif transmission } \\
\text { line }\end{array}$ & & & & • & & & \\
\hline $\mathrm{X} 27$ & Andkhoy and Sheberghan substations & & & & ○ & & & \\
\hline $\mathrm{X} 28$ & Mazar Sharif substation expansion & & & & O & & & \\
\hline $\mathrm{X} 29$ & $\begin{array}{l}\text { Pul-e-Alam and Gardez distribution } \\
\text { networks }\end{array}$ & & & & 0 & & & \\
\hline $\mathrm{X} 30$ & $\begin{array}{l}\text { Pul-e-Alam and Gardez substation } \\
\text { equipment }\end{array}$ & & & & 0 & & & \\
\hline $\mathrm{X} 31$ & $\begin{array}{l}\text { Tranche } 4 \text { PM and implementation } \\
\text { consultants }\end{array}$ & & & & O & o & • & \\
\hline X32 & Dashte Alwan substation & & & & ○ & & & \\
\hline
\end{tabular}




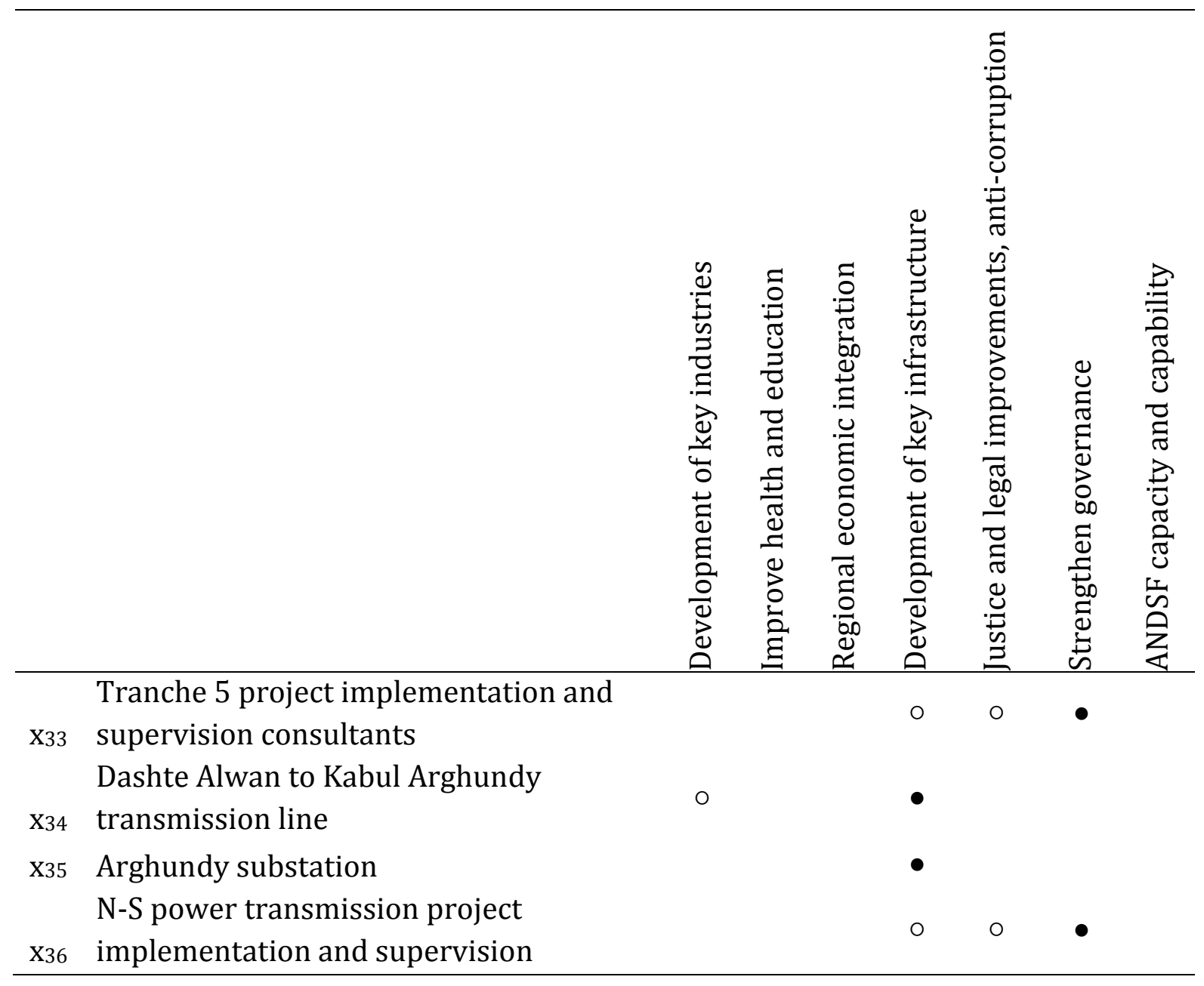


Table 13 describes the five priority classes used in this demonstration. The classification is time-based, meaning that a high priority initiative should be implemented before lower prioritized ones. This is reflected in the naming convention of the priority classes. The time boundaries of the classes are not fixed, since the significance of the prioritization is mostly the relative ordering of initiatives. However, approximately classes immediate to long term can be considered to be within the ten-year lifetime of the PDPPA, with the last class, distant future, outside that time frame. Noting that the maximum number of significant impact assessments and marginal impact assessments per initiative is three for each type, it is feasible to establish the baseline classification rules by using example-based rules, that is list out all possible combinations of assessments. If the assessments change, the rules would have to be updated to reflect the new situation. Table 14 describes the how different combinations of assessments assign initiatives into priority classes. The rules are descriptive of a negotiation rather than prescriptive and in the context of this thesis, the role of the prioritization is foremost to serve as a baseline prioritization to measure disruption of the scenarios to. 
Table 13. Definitions of priority classes that initiatives are assigned to.

\section{Priority class}

1 Immediate need

2 Near-term need

Within time frame of PDPPA

3 Mid-term need

4 Long-term need

5 Distant future need Outside timeframe of PDPPA 
Table 14. Rules for classifying initiatives into priority classes under the baseline scenario.

\begin{tabular}{|c|c|c|}
\hline $\begin{array}{l}\text { Number of significant } \\
\text { impact assessments }(\bullet)\end{array}$ & $\begin{array}{c}\text { Number of marginal } \\
\text { impact assessments }(\circ)\end{array}$ & Priority class \\
\hline 0 & 0 & Distant future \\
\hline 1 & 0 & Long-term \\
\hline 2 & 0 & Near-term \\
\hline 3 & 0 & Immediately \\
\hline 0 & 1 & Long-term \\
\hline 1 & 1 & Long-term \\
\hline 2 & 1 & Near-term \\
\hline 3 & 1 & Immediately \\
\hline 0 & 2 & Mid-term \\
\hline 1 & 2 & Near-term \\
\hline 2 & 2 & Immediately \\
\hline 3 & 2 & Immediately \\
\hline 0 & 3 & Near-term \\
\hline 1 & 3 & Immediately \\
\hline 2 & 3 & Immediately \\
\hline 3 & 3 & Immediately \\
\hline
\end{tabular}


The scenarios constructed in Chapter 4.3.2 and described in detail in Tables 2-8 may disrupt or upset the prioritization of the initiatives. The degree to which the scenarios affect the prioritization is modeled through the effect they have on criteria. Table 15 describes the primary criteria that each scenario affects, for both the national government criteria and US government criteria. The prioritization of initiatives under the influence of scenarios is based on the assessment of these primary criteria in addition to the overall counts of significant and marginal impact assessments. Scenario sc1: Insufficient power supply has the primary criteria $c_{2}^{1}$ : Infrastructure and transportation and $c_{4}^{2}$ : Development of key infrastructure, for the two criteria sets respectively, which are impacted by the vast majority of initiatives and therefore the rules used for prioritization under that scenario are significantly different than for the others. The rules for classifying initiatives into priority classes under scenario $\mathrm{sc}_{1}$ are described in Table 16. The rule Scenarios $\mathrm{sc}_{2}$-sc6 follow the same rule structure, which is described in Table 17. It should be noted that when a scenario has more than one primary criteria, it is sufficient that only one criteria meets the condition listed in Table 17, starting from the top. In other words, if the first condition is met, the latter two conditions need not be checked and so on. Using the categories of rules described in Chapter 3.2, this is a cut-off rule. 
Table 15. Primary criteria defined for the different scenarios for both criteria sets. Primary criteria are the basis on which initiatives are re-ordered for each scenario.

\begin{tabular}{|c|c|c|}
\hline Scenario & $\begin{array}{c}\text { Primary criteria for } \\
\text { national government } \\
\text { criteria }\end{array}$ & $\begin{array}{l}\text { Primary criteria for US } \\
\text { government criteria }\end{array}$ \\
\hline $\begin{array}{l}\text { sc }_{1} \text { : Insufficient power } \\
\text { supply }\end{array}$ & $\begin{array}{l}\mathrm{c}_{2}{ }^{1}: \text { Infrastructure and } \\
\text { transportation }\end{array}$ & $\begin{array}{l}\mathrm{C}_{4}^{2}: \text { Development of key } \\
\text { infrastructure }\end{array}$ \\
\hline $\begin{array}{l}\mathrm{sc}_{2} \text { : Unsatisfactory local } \\
\text { governance }\end{array}$ & $\begin{array}{l}\mathrm{C}_{5}{ }^{1} \text { : Capacity building } \\
\mathrm{C}^{1} \text { : Gender-equality, } \\
\text { counter-narcotics, anti- } \\
\text { corruption }\end{array}$ & $\begin{array}{l}\mathrm{C} 5^{2} \text { : Justice and legal } \\
\text { improvements, } \\
\text { anticorruption } \\
\mathrm{c}_{6}^{2} \text { : Strengthen } \\
\text { governance }\end{array}$ \\
\hline $\begin{array}{l}\text { sc3: Deteriorating security } \\
\text { conditions }\end{array}$ & $\mathrm{c}_{1}{ }^{1}$ : Security and governance & $\begin{array}{l}\mathrm{C}_{7}^{1}: \text { ANDSF capacity and } \\
\text { capability }\end{array}$ \\
\hline $\begin{array}{l}\mathrm{sc}_{4} \text { : Public perception } \\
\text { problems }\end{array}$ & $\begin{array}{l}\mathrm{c}_{4} 1: \text { Economic governance } \\
\text { and private sector } \\
\text { development }\end{array}$ & $\begin{array}{l}\mathrm{c}_{1}^{2}: \text { Development of key } \\
\text { industries } \\
\mathrm{C}^{2}: \text { Strengthen } \\
\text { governance }\end{array}$ \\
\hline $\begin{array}{l}\text { sc5: }_{5} \text { Electricity imports } \\
\text { disrupted }\end{array}$ & $\mathrm{C}_{6}{ }^{1}$ : Regional cooperation & $\begin{array}{l}\mathrm{c}_{3}^{2}: \text { Regional economic } \\
\text { integration }\end{array}$ \\
\hline $\begin{array}{l}\text { sc6: International } \\
\text { management and } \\
\text { oversight lacking }\end{array}$ & $\begin{array}{l}\mathrm{c}_{1}{ }^{1}: \text { Security and governance } \\
\mathrm{c}_{5}{ }^{1} \text { : Capacity building }\end{array}$ & $\begin{array}{l}\mathrm{c}_{6}{ }^{2}: \text { Strengthen } \\
\text { governance }\end{array}$ \\
\hline
\end{tabular}


Table 16. Rules for classification of initiatives into priority classes for sc1: Insufficient power supply.

\begin{tabular}{|c|c|c|}
\hline $\begin{array}{c}\text { Infrastructure assessment } \\
\text { condition }\left(\mathrm{c}_{2}{ }^{1} / \mathrm{c}_{4}{ }^{2}\right)\end{array}$ & $\begin{array}{c}\text { Conditions on non- } \\
\text { infrastructure criteria }\end{array}$ & $\begin{array}{l}\text { Priority } \\
\text { class }\end{array}$ \\
\hline Significant impact $(\bullet)$ & $>2$ other impact assessments & Immediately \\
\hline Significant impact $(\bullet)$ & 2 other impact assessments & Near-term \\
\hline Significant impact $(\bullet)$ & $\begin{array}{l}1 \text { other significant impact } \\
\text { assessment }(\bullet)\end{array}$ & Near-term \\
\hline Significant impact $(\bullet)$ & $\begin{array}{l}1 \text { other marginal impact } \\
\text { assessment }(0)\end{array}$ & Mid-term \\
\hline Significant impact $(\bullet)$ & 0 other impact assessment & Long-term \\
\hline Marginal impact $(\circ)$ & $>2$ other impact assessments & Near-term \\
\hline Marginal impact (O) & 2 other impact assessments & Mid-term \\
\hline Marginal impact ( $(0)$ & 1 other impact assessment & Mid-term \\
\hline Marginal impact $(\circ)$ & 0 other impact assessment & Long-term \\
\hline No impact & Any other impact assessment & $\begin{array}{l}\text { Distant } \\
\text { future }\end{array}$ \\
\hline
\end{tabular}


Table 17. Rules used to adjust priority classification of initiatives for scenarios $S C 2-S C 6$.

Priority criteria assessment (at least
one primary criteria meets condition) Priority class

Significant impact $(\bullet) \quad$ Up one class from baseline

Marginal impact (०) Same as baseline

No impact Down one class from baseline 
The results of the classification of initiatives for the national government criteria and US government criteria are shown in Table 18 and Table 19 as well as Figure 4 and Figure 5, respectively.

For the national government criteria, initiatives $x_{2}$ : Arghundy to Kandahar transmission line and x5: Kajaki Dam Unit 2 are prioritized for immediate need under the baseline scenario. Both drop down to near-term need under one or more scenario, $x_{2}$ under $s_{2}$ : Unsatisfactory local governance and $x_{5}$ under $s_{2}$ : Unsatisfactory local governance and $s c_{4}$ : Public perception problems. Other initiatives that are prioritized for immediate need under any scenario are all "soft" initiatives. Initiatives $x_{13}, x_{14}, x_{24}, x_{31}, x_{33}$ and $x_{36}$ which include preparation and project implementation assistance for the different tranches are prioritized for immediate need under sc2: Unsatisfactory local governance and $s_{6}$ : International management and oversight lacking. Furthermore x15: NEPS O\&M MTA contract is prioritized for immediate need under sc4: Public perception problems as well as $S C_{2}$ and $s C_{6}$, and $x_{20}$ : DABS management assistance is prioritized for immediate need under $s c_{3}$ : Deteriorating security conditions as well as $s c_{2}$ and $s c 6$. Initiatives $x_{6}$ : CASA-1000, $x 7$ : TUTAP Kabul to PAK transmission line and $x_{8}$ : TKM interconnection, are prioritized for immediate need under sc5: Electricity imports disrupted, which is not inconsistent with the influences of the scenario, since these initiatives enhance the integration of the Afghan power grid with the grid of neighboring countries. The prioritization of all initiatives is disrupted under at least one scenario, that is no initiative remains in its baseline priority class for all scenarios. 
For the US government criteria, $x_{4}$ : Kabul power system rehabilitation and $x_{15}$ : NEPS O\&M MTA contract are prioritized for immediate need under the baseline scenario. $x 4$ remains in the top class for all scenarios and is the only initiative which priority is not disrupted by any scenario. $x_{15}$ remains in the immediate need priority class for $s_{2}$ : Unsatisfactory local governance, sc4: Public perception problems and sc6: International management and oversight lacking, but is demoted to near-term need under sc1: Insufficient power supply, $s_{3}$ : Deteriorating security conditions and sc5: Electricity imports disrupted. Initiatives that are project implementation or management related, $x_{13}, x_{14}, x_{20}, x_{31}, x_{33}$ and $x_{36}$, achieve immediate need priority under sc2: Unsatisfactory local governance, sc4: Public perception problems and sc6: International management and oversight lacking. For the other scenarios however, these initiatives are assigned mid-term priority, one class down from the baseline scenario priority of near-term need. Similarly to the national government criteria, initiatives x6: CASA-1000, x7: TUTAP Kabul to PAK transmission line and x8: TKM interconnection, are prioritized for immediate need under sc5: Electricity imports disrupted. 
Table 18. Prioritization of initiatives for the national government criteria (Immediate $=$ I, Near-term = N, Mid-term = M, Long-term = L, Distant future = D) .

\begin{tabular}{|c|c|c|c|c|c|c|c|c|}
\hline & & 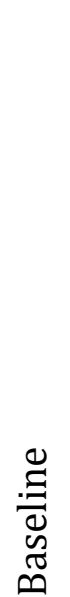 & 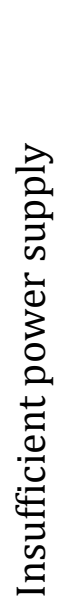 & 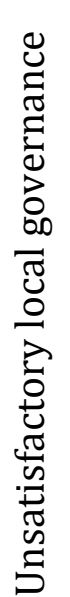 & 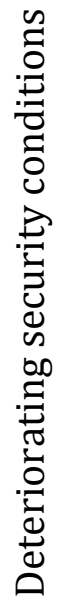 & 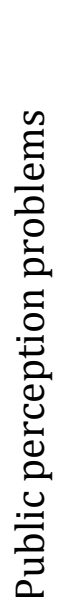 & 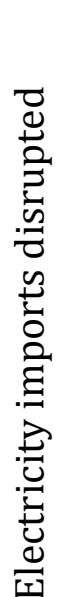 & 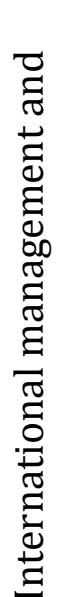 \\
\hline $\mathrm{x}_{1}$ & Sheberghan gas development & $\mathrm{N}$ & $\mathrm{N}$ & $\mathrm{M}$ & M & $\mathrm{N}$ & $\mathrm{M}$ & $\mathrm{M}$ \\
\hline $\mathrm{x}_{2}$ & $\begin{array}{l}\text { Arghundy to Kandahar } \\
\text { transmission line }\end{array}$ & I & I & $\mathrm{N}$ & I & I & I & I \\
\hline $\mathrm{x}_{3}$ & Salang Tunnel substation & $\mathrm{L}$ & $\mathrm{L}$ & $\mathrm{D}$ & $\mathrm{D}$ & $\mathrm{D}$ & $\mathrm{D}$ & $\mathrm{D}$ \\
\hline $\mathrm{X}_{4}$ & $\begin{array}{l}\text { Kabul power system } \\
\text { rehabilitation }\end{array}$ & $\mathrm{N}$ & $\mathrm{N}$ & M & $\mathrm{N}$ & $\mathrm{N}$ & $\mathrm{N}$ & $\mathrm{N}$ \\
\hline X5 & Kajaki Dam Unit 2 & $\mathrm{I}$ & I & $\mathrm{N}$ & I & $\mathrm{N}$ & I & I \\
\hline $\mathrm{x}_{6}$ & CASA-1000 & $\mathrm{N}$ & $\mathrm{N}$ & $\mathrm{M}$ & $\mathrm{M}$ & $\mathrm{M}$ & I & $\mathrm{M}$ \\
\hline$x_{7}$ & $\begin{array}{l}\text { TUTAP Kabul to PAK } \\
\text { transmission line }\end{array}$ & $\mathrm{N}$ & $\mathrm{N}$ & M & M & M & I & M \\
\hline х8 & TKM interconnection & $\mathrm{N}$ & $\mathrm{N}$ & $\mathrm{M}$ & $\mathrm{N}$ & M & I & $\mathrm{N}$ \\
\hline X9 & $\begin{array}{l}\text { Kunduz-Taloqan transmission } \\
\text { line }\end{array}$ & M & M & $\mathrm{L}$ & $\mathrm{N}$ & $\mathrm{L}$ & M & $\mathrm{N}$ \\
\hline $\mathrm{x}_{10}$ & $\begin{array}{l}\text { Baghlan and Kunduz } \\
\text { distribution networks }\end{array}$ & M & M & $\mathrm{L}$ & $\mathrm{N}$ & $\mathrm{L}$ & M & $\mathrm{N}$ \\
\hline
\end{tabular}




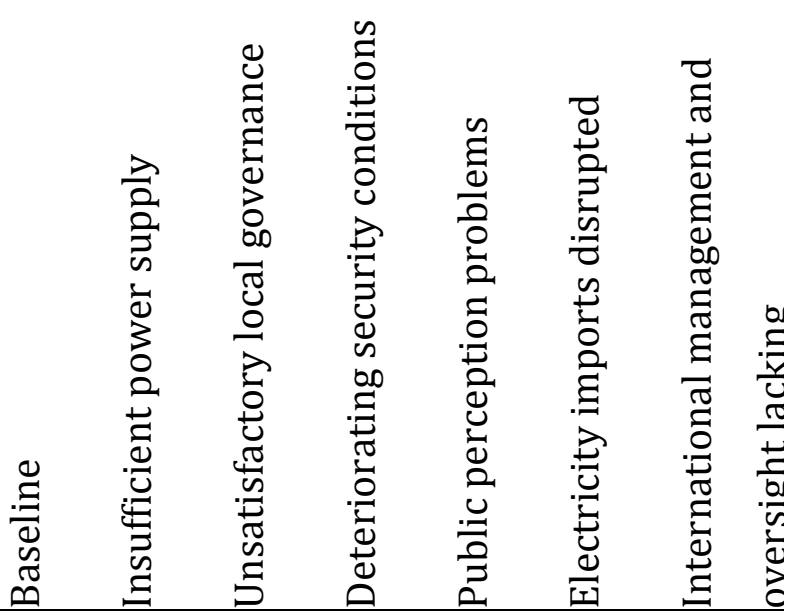

NEPS O\&M emergency

$\mathrm{X} 11$ equipment

$\begin{array}{lllllll}\mathrm{N} & \mathrm{M} & \mathrm{N} & \mathrm{N} & \mathrm{M} & \mathrm{N} & \mathrm{N}\end{array}$

Rehabilitation of Sheberghan gas

$\mathrm{X} 12$

wells

$\begin{array}{llllllll}\text { M } & \text { M } & \text { L } & \text { L } & \text { L } & \text { L } & \text { L }\end{array}$

Tranche $1 \mathrm{PM}$ and

$\mathrm{X} 13$

implementation

X14 Tranche 4 preparation

X15 NEPS O\&M MTA contract

Chimtala S/S to South West S/S

$\mathrm{X} 16$

transmission line

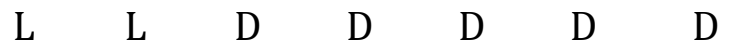

X17 Kabul South West S/S

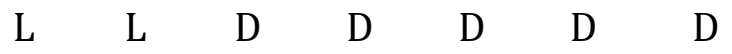

X18 Kabul distribution network

$\begin{array}{lllllll}\mathrm{N} & \mathrm{N} & \mathrm{M} & \mathrm{M} & \mathrm{I} & \mathrm{M} & \mathrm{M}\end{array}$

Dual voltage transformers, oil

X19 treatment plant and thermal

monitoring devices

$\begin{array}{lllllll}\text { L } & \text { L } & \text { D } & \text { D } & \text { D } & \text { D } & \text { D }\end{array}$

$\mathrm{X} 20$

DABS management assistance

$\begin{array}{lllllll}\mathrm{N} & \mathrm{M} & \mathrm{I} & \mathrm{I} & \mathrm{M} & \mathrm{N} & \mathrm{I}\end{array}$

Gereshk hydropower plant

$\mathrm{X} 21$

rehabilitation and upgrade

$\begin{array}{llllllll}\text { M } & \text { M } & \text { L } & \text { L } & \text { L } & \text { L } & \text { L }\end{array}$ 


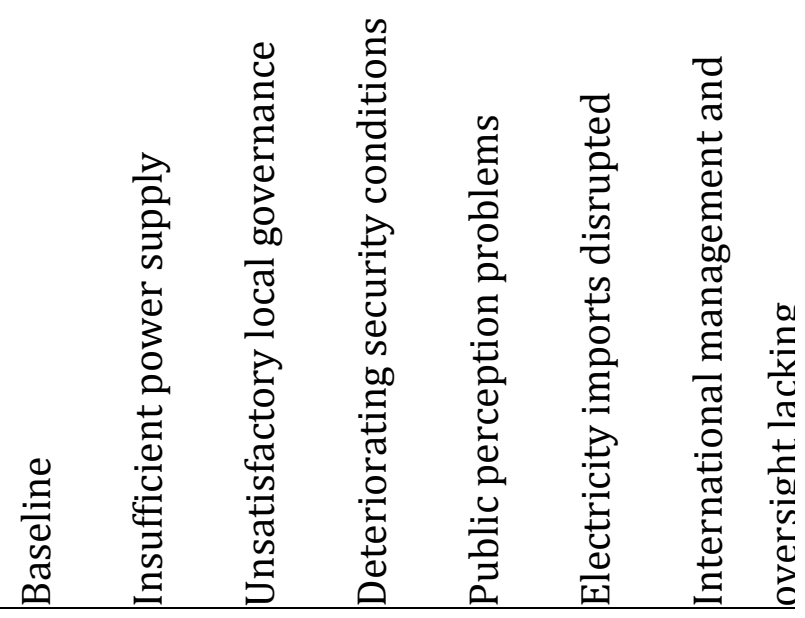

Gereshk distribution network

$\mathrm{X} 22$

upgrade

L L

D

D

D D

D

Gereshk end-user metering

$\mathrm{X} 23$

system

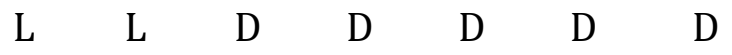

Tranche 3 project

X24 implementation and supervision

consultants

$\begin{array}{lllllll}\mathrm{N} & \mathrm{M} & \mathrm{I} & \mathrm{M} & \mathrm{N} & \mathrm{M} & \mathrm{I}\end{array}$

AFG/TKM border to Sheberghan

$\mathrm{X} 25$

transmission line

$\begin{array}{llllllll}\mathrm{N} & \mathrm{N} & \mathrm{M} & \mathrm{N} & \mathrm{M} & \mathrm{N} & \mathrm{N}\end{array}$

Sheberghan to Mazar Sharif

$\mathrm{X} 26$

transmission line

$\begin{array}{lllllll}\text { M } & \text { M } & \text { L } & \text { M } & \text { L } & \text { M } & \text { M }\end{array}$

Andkhoy and Sheberghan

$\mathrm{X} 27$

substations

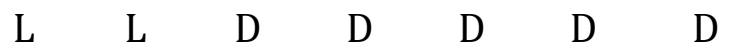

Mazar Sharif substation

$\mathrm{X} 28$

expansion

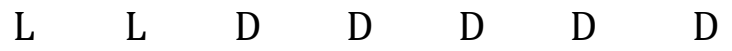

Pul-e-Alam and Gardez

$\mathrm{X} 29$

distribution networks

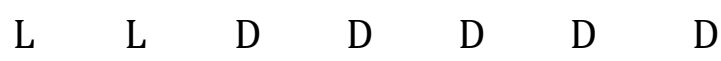




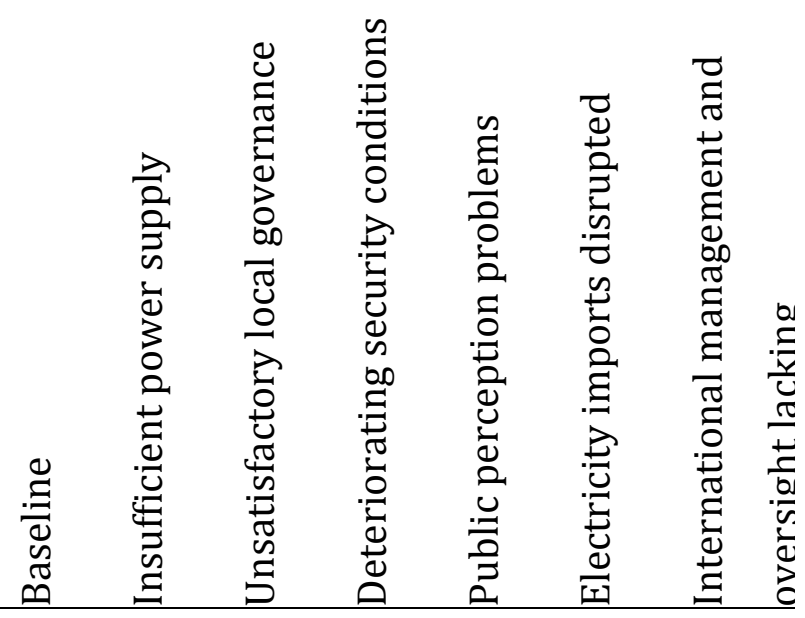

Pul-e-Alam and Gardez

X30 substation equipment

$\begin{array}{lllllll}\text { L } & \text { L } & \text { D } & \text { D } & \text { D } & \text { D } & \text { D }\end{array}$

Tranche $4 \mathrm{PM}$ and

X31

$\begin{array}{lllllllll}\text { implementation consultants } & \mathrm{N} & \mathrm{M} & \mathrm{I} & \mathrm{M} & \mathrm{N} & \mathrm{M} & \mathrm{I}\end{array}$

$\begin{array}{lllllllll}\text { X32 Dashte Alwan substation } & \text { L } & \text { L } & \text { D } & \text { D } & \text { D } & \text { D } & \text { D }\end{array}$

Tranche 5 project

X33 implementation and supervision

consultants

$\begin{array}{lllllll}\mathrm{N} & \mathrm{M} & \mathrm{I} & \mathrm{M} & \mathrm{N} & \mathrm{M} & \mathrm{I}\end{array}$

Dashte Alwan to Kabul

X34

Arghundy transmission line

$\begin{array}{lllllll}M & M & \text { L } & \text { M } & \text { L } & \text { M } & \text { M }\end{array}$

X35 Arghundy substation

L $\quad$ L $\quad$ D $\quad$ D $\quad$ D $\quad$ D $\quad$ D

$\mathrm{N}-\mathrm{S}$ power transmission project

X36

$\begin{array}{llllllllll}\text { implementation and supervision } & \mathrm{N} & \mathrm{N} & \mathrm{I} & \mathrm{M} & \mathrm{N} & \mathrm{M} & \mathrm{I}\end{array}$ 
Table 19. Prioritization of initiatives for the US government criteria (Immediate = I, Near-term $=2$, Mid-term $=3$, Long-term $=4$, Distant future $=5$ ) .

\begin{tabular}{|c|c|c|c|c|c|c|c|c|}
\hline & & 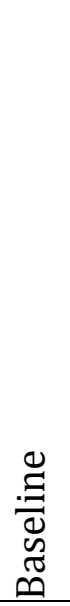 & 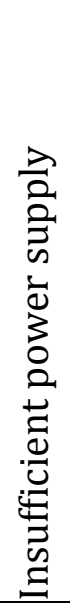 & 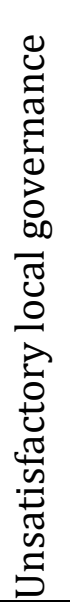 & 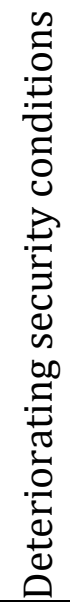 & 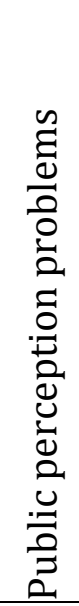 & 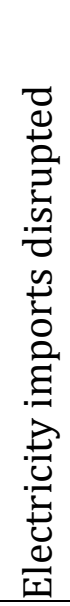 & 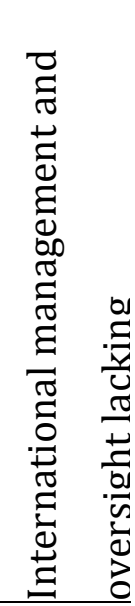 \\
\hline $\mathrm{x} 1$ & $\begin{array}{l}\text { Sheberghan gas } \\
\text { development }\end{array}$ & $\mathrm{N}$ & $\mathrm{N}$ & M & M & $\mathrm{I}$ & M & I \\
\hline $\mathrm{x}_{2}$ & $\begin{array}{l}\text { Arghundy to Kandahar } \\
\text { transmission line }\end{array}$ & $\mathrm{N}$ & $\mathrm{N}$ & $\mathrm{M}$ & $\mathrm{N}$ & I & I & I \\
\hline $\mathrm{x}_{3}$ & Salang Tunnel substation & $\mathrm{L}$ & $\mathrm{L}$ & $\mathrm{D}$ & $\mathrm{D}$ & $\mathrm{L}$ & $\mathrm{D}$ & $\mathrm{D}$ \\
\hline $\mathrm{X} 4$ & $\begin{array}{l}\text { Kabul power system } \\
\text { rehabilitation }\end{array}$ & I & $\mathrm{I}$ & I & $\mathrm{I}$ & $\mathrm{I}$ & $\mathrm{I}$ & I \\
\hline $\mathrm{x}_{5}$ & Kajaki Dam Unit 2 & $\mathrm{~N}$ & $\mathrm{~N}$ & M & $\mathrm{N}$ & I & I & I \\
\hline $\mathrm{X}_{6}$ & CASA-1000 & $\mathrm{N}$ & $\mathrm{N}$ & M & M & I & $\mathrm{N}$ & M \\
\hline $\mathrm{X}_{7}$ & $\begin{array}{l}\text { TUTAP Kabul to PAK } \\
\text { transmission line }\end{array}$ & $\mathrm{N}$ & $\mathrm{N}$ & M & M & I & $\mathrm{N}$ & M \\
\hline $\mathrm{X} 8$ & TKM interconnection & $\mathrm{N}$ & $\mathrm{N}$ & M & M & $\mathrm{I}$ & $\mathrm{N}$ & M \\
\hline X9 & $\begin{array}{l}\text { Kunduz-Taloqan } \\
\text { transmission line }\end{array}$ & M & M & $\mathrm{L}$ & M & M & $\mathrm{N}$ & $\mathrm{L}$ \\
\hline $\mathrm{X} 10$ & $\begin{array}{l}\text { Baghlan and Kunduz } \\
\text { distribution networks }\end{array}$ & M & $\mathrm{M}$ & L & $\mathrm{M}$ & M & $\mathrm{N}$ & $\mathrm{L}$ \\
\hline
\end{tabular}




\begin{tabular}{|c|c|c|c|c|c|c|c|c|c|}
\hline & & 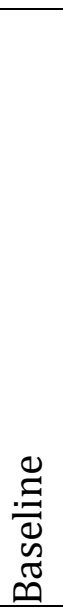 & 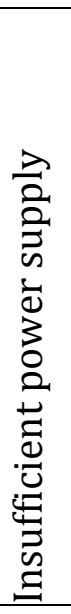 & 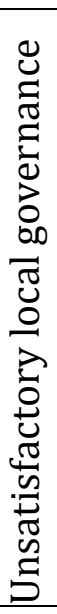 & 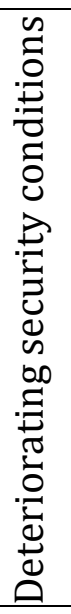 & 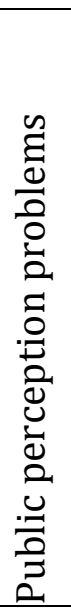 & 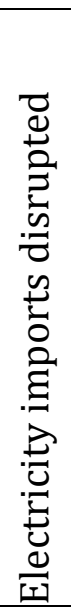 & 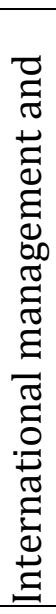 & 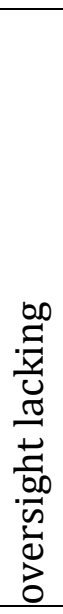 \\
\hline $\mathrm{X} 11$ & $\begin{array}{l}\text { NEPS O\&M emergency } \\
\text { equipment }\end{array}$ & $\mathrm{M}$ & M & $\mathrm{L}$ & $\mathrm{N}$ & M & $\mathrm{N}$ & $\mathrm{L}$ & \\
\hline $\mathrm{X} 12$ & $\begin{array}{l}\text { Rehabilitation of } \\
\text { Sheberghan gas wells }\end{array}$ & M & M & $\mathrm{L}$ & $\mathrm{L}$ & $\mathrm{M}$ & $\mathrm{L}$ & $\mathrm{N}$ & \\
\hline $\mathrm{X} 13$ & $\begin{array}{l}\text { Tranche } 1 \mathrm{PM} \text { and } \\
\text { implementation }\end{array}$ & $\mathrm{N}$ & M & I & M & $\mathrm{I}$ & M & $\mathrm{I}$ & \\
\hline $\mathrm{X} 14$ & Tranche 4 preparation & $\mathrm{N}$ & M & I & M & I & M & I & \\
\hline $\mathrm{X} 15$ & NEPS O\&M MTA contract & I & $\mathrm{N}$ & I & $\mathrm{N}$ & I & $\mathrm{N}$ & I & \\
\hline $\mathrm{X} 16$ & $\begin{array}{l}\text { Chimtala S/S to South West } \\
\text { S/S transmission line }\end{array}$ & $\mathrm{L}$ & $\mathrm{L}$ & $\mathrm{D}$ & $\mathrm{D}$ & M & $\mathrm{D}$ & $\mathrm{D}$ & \\
\hline $\mathrm{X} 17$ & Kabul South West S/S & $\mathrm{L}$ & $\mathrm{L}$ & $\mathrm{D}$ & $\mathrm{D}$ & M & $\mathrm{D}$ & $\mathrm{D}$ & \\
\hline $\mathrm{X} 18$ & Kabul distribution network & $\mathrm{N}$ & $\mathrm{N}$ & $\mathrm{M}$ & M & I & M & I & \\
\hline $\mathrm{X} 19$ & $\begin{array}{l}\text { Dual voltage transformers, } \\
\text { oil treatment plant and } \\
\text { thermal monitoring }\end{array}$ & & & & & & & & \\
\hline & devices & $\mathrm{L}$ & $\mathrm{L}$ & $\mathrm{D}$ & $\mathrm{D}$ & $\mathrm{M}$ & $\mathrm{D}$ & $\mathrm{D}$ & \\
\hline $\mathrm{X} 20$ & $\begin{array}{l}\text { DABS management } \\
\text { assistance }\end{array}$ & $\mathrm{N}$ & $\mathrm{M}$ & I & M & I & $\mathrm{M}$ & I & \\
\hline $\mathrm{X} 21$ & $\begin{array}{l}\text { Gereshk hydropower plant } \\
\text { rehabilitation and upgrade }\end{array}$ & $\mathrm{M}$ & M & $\mathrm{L}$ & $\mathrm{L}$ & $\mathrm{N}$ & $\mathrm{L}$ & M & \\
\hline
\end{tabular}




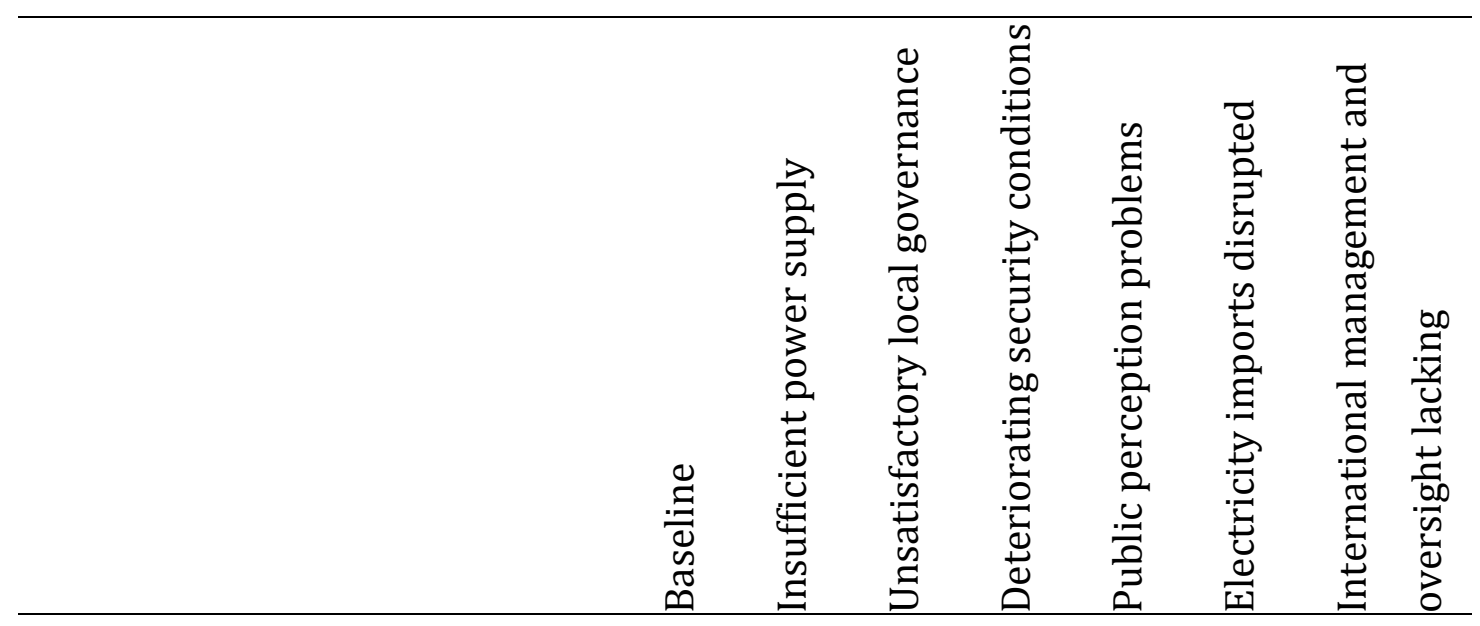

$\mathrm{X} 22$

Gereshk distribution

network upgrade

$\begin{array}{lllllll}\text { M } & \text { M } & \text { L } & \text { L } & \text { M } & \text { L } & \text { M }\end{array}$

Gereshk end-user metering

$\mathrm{X} 23$

system

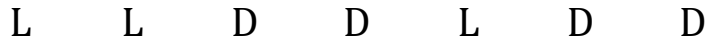

Tranche 3 project

X24 implementation and

$\begin{array}{llllllllll}\text { supervision consultants } & \mathrm{N} & \mathrm{M} & \mathrm{N} & \mathrm{M} & \mathrm{N} & \mathrm{M} & \mathrm{N}\end{array}$

AFG/TKM border to

X25 Sheberghan transmission

line

$\begin{array}{llllllll}\mathrm{N} & \mathrm{N} & \mathrm{M} & \mathrm{M} & \mathrm{I} & \mathrm{N} & \mathrm{M}\end{array}$

Sheberghan to Mazar

$\mathrm{X} 26$

Sharif transmission line

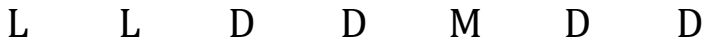

Andkhoy and Sheberghan

$\mathrm{X} 27$

substations

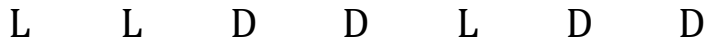

Mazar Sharif substation

$\mathrm{X} 28$

expansion

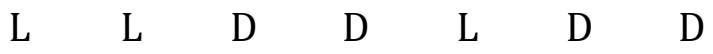

X29

Pul-e-Alam and Gardez

distribution networks

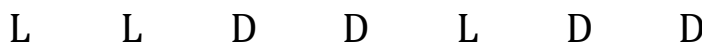




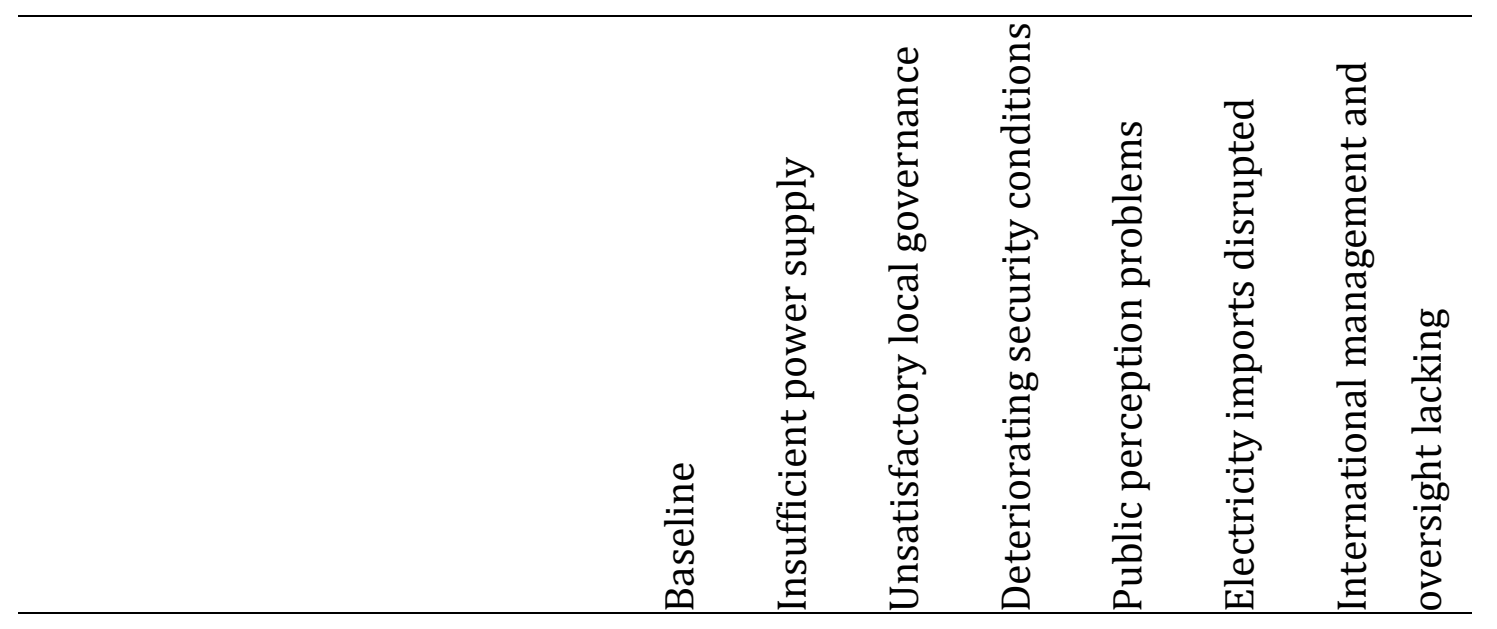

Pul-e-Alam and Gardez

$\mathrm{X} 30$

substation equipment

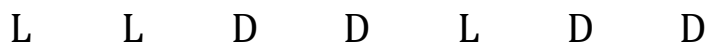

Tranche $4 \mathrm{PM}$ and

X31 implementation

consultants

$\begin{array}{lllllll}\mathrm{N} & \mathrm{M} & \mathrm{I} & \mathrm{M} & \mathrm{I} & \mathrm{M} & \mathrm{I}\end{array}$

X32 Dashte Alwan substation

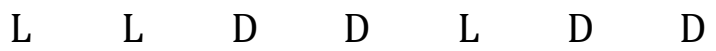

Tranche 5 project

X33 implementation and

supervision consultants

$\begin{array}{lllllll}\mathrm{N} & \mathrm{M} & \mathrm{I} & \mathrm{M} & \mathrm{I} & \mathrm{M} & \mathrm{I}\end{array}$

Dashte Alwan to Kabul

X34 Arghundy transmission

line

$\begin{array}{lllllll}\text { M } & \text { M } & \text { L } & \text { L } & \text { N } & \text { L } & \text { M }\end{array}$

X35 Arghundy substation

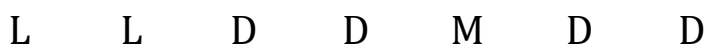

$\mathrm{N}-\mathrm{S}$ power transmission

X36 project implementation

and supervision

$\begin{array}{lllllll}\mathrm{N} & \mathrm{M} & \mathrm{I} & \mathrm{M} & \mathrm{I} & \mathrm{M} & \mathrm{I}\end{array}$ 


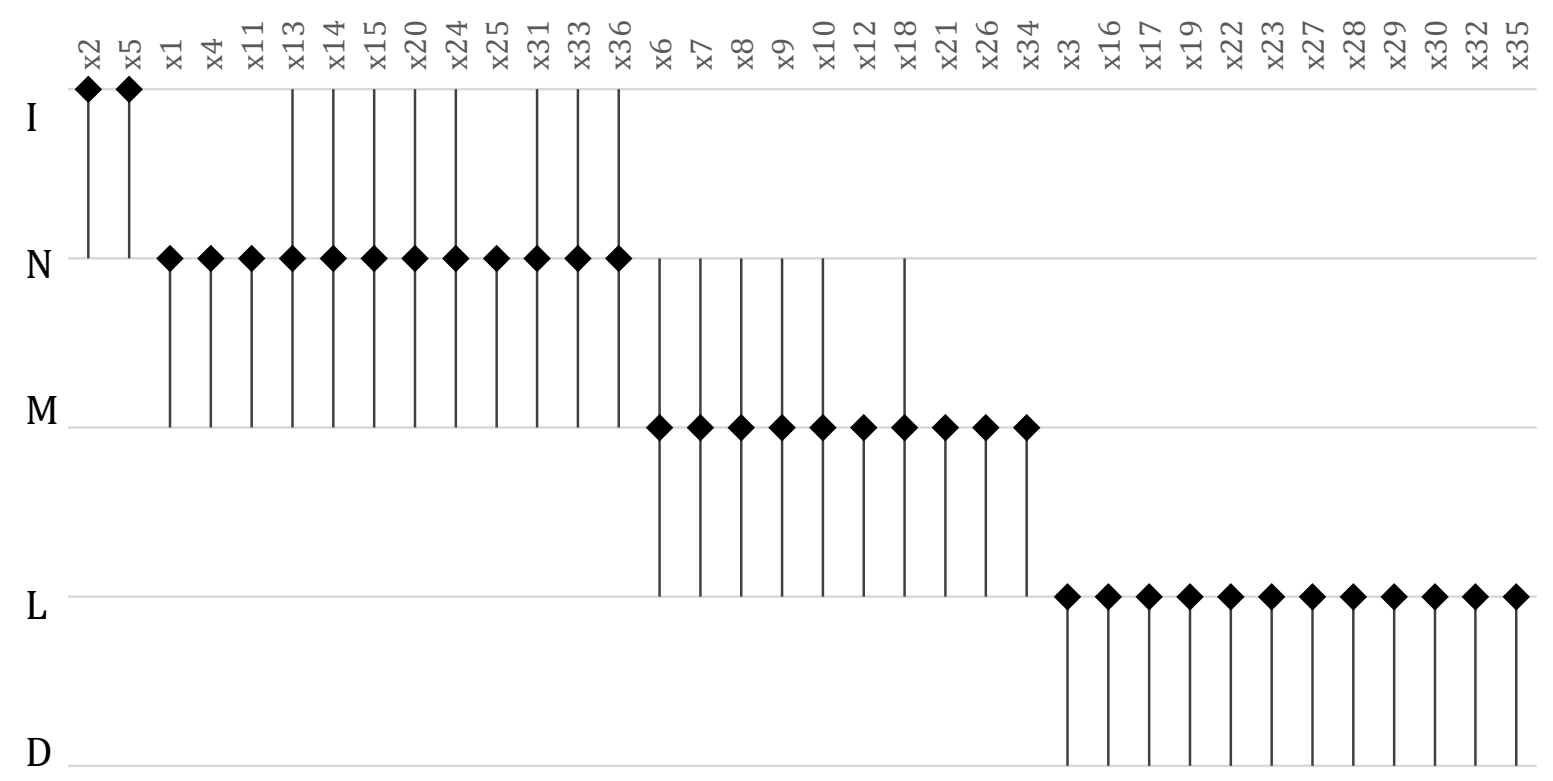

Figure 4. Range of priority classes of initiatives for the national government criteria. The diamond respresents the baseline prioritization of the whiskers extend to the highest and lowest class the initiative in classified to under any scenario. 


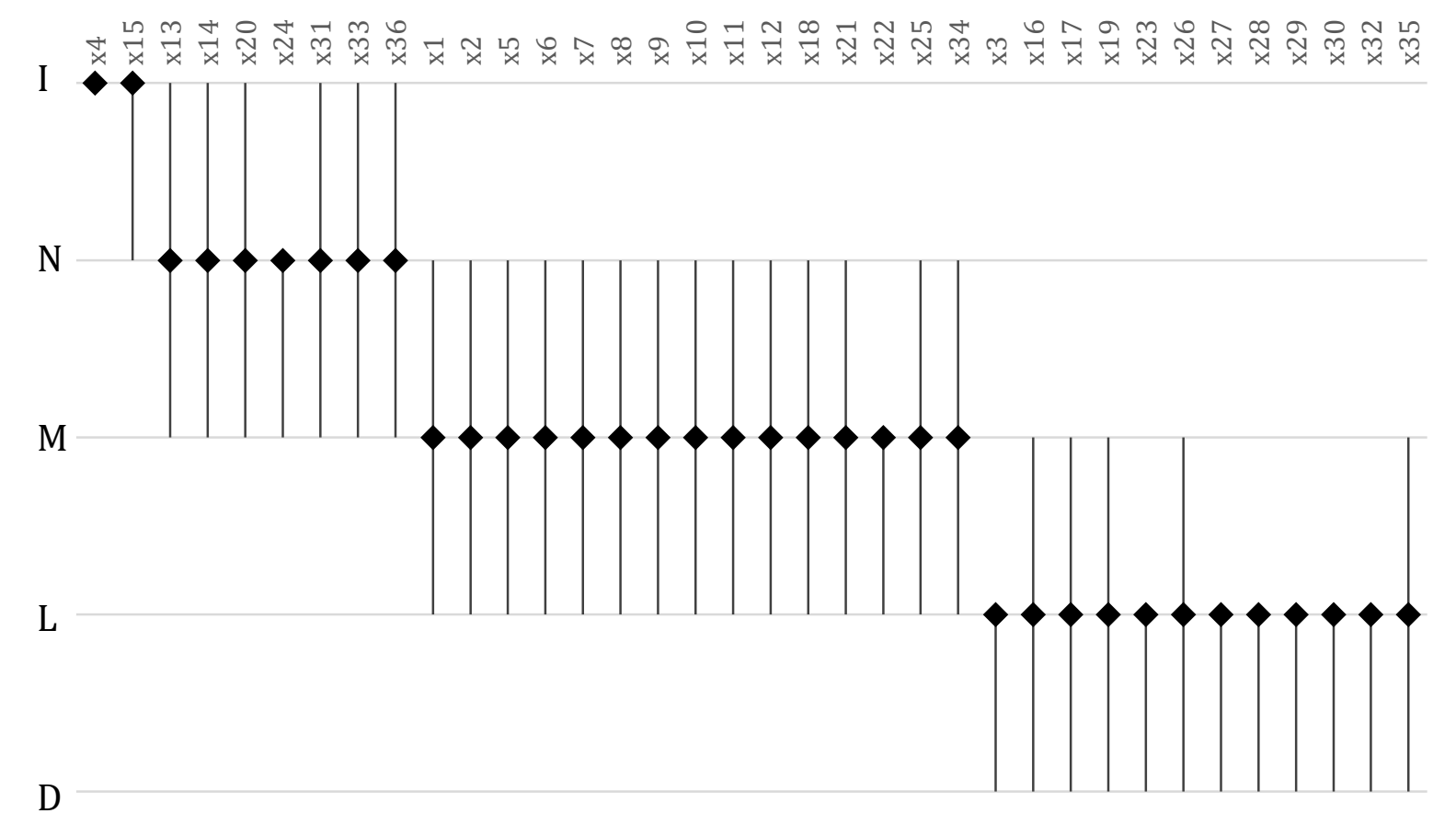

Figure 5. Range of priority classes of initiatives for the US government criteria. The diamond represents the baseline prioritization of the whiskers extend to the highest and lowest class the initiative in classified to under any scenario. 


\subsubsection{Disruptions of scenarios to prioritization of initiatives}

Table 20 and Table 21 summarize the disruptions of the scenarios to the prioritization of initiatives, for the national government criteria and US government criteria, respectively.

For the national government criteria, sc2: Unsatisfactory local governance disrupts the prioritization the most, with 35 out of the 36 initiatives being classified differently than in the baseline scenario. 8 initiatives rise in ranking, while 27 fall down a class. One initiative, $x_{11}$ : NEPS O\&M emergency equipment, remains in the same priority class. $s_{1}$ : Insufficient power generation disrupts the prioritization the least, with no initiative being promoted and 8 demoted.

For the US government criteria, sc2: Unsatisfactory governance disrupts the prioritization the most, 33 initiatives each. $s c_{2}$ promotes 6 initiatives and demotes 27 . Initiative, $x 4$ : Kabul power system rehabilitation, remains in the top priority class for all scenarios and is the only initiative whose prioritization is not disrupted be any scenario. The least disruptive scenario is sc1: Insufficient power supply, disrupting the prioritization of 8 initiatives, promoting none and demoting 8. 
Table 20. Disruption of scenarios to the prioritization of initiatives under the national government criteria.

\begin{tabular}{lccc}
\hline & Total & & \\
& disruption & Promotions & Demotions \\
& 8 & 0 & -8 \\
\hline sc1: Insufficient power supply & 35 & 8 & -27 \\
sc2: Unsatisfactory local governance & 28 & 3 & -25 \\
sc3: Deteriorating security conditions & 28 & 2 & -26 \\
sc4: Public perception problems & 26 & 3 & -23 \\
sc5: Electricity imports disrupted & & 10 & -18 \\
sc6: International management and & 28 & & \\
oversight lacking & & & \\
\hline
\end{tabular}


Table 21. Disruption of scenarios to the prioritization of initiatives under the $U S$ government criteria.

\begin{tabular}{lccc}
\hline & Total & & \\
& disruption & Promotions & Demotions \\
& 8 & 0 & -8 \\
\hline sc1: Insufficient power supply & 33 & 6 & -27 \\
sc2: Unsatisfactory local governance & 31 & 1 & -30 \\
sc3: Deteriorating security conditions & 21 & 21 & 0 \\
sc4: Public perception problems & 31 & 5 & -26 \\
sc5: Electricity imports disrupted & 30 & 11 & -19 \\
sc6: International management and & & & \\
oversight lacking & & & \\
\hline
\end{tabular}




\subsubsection{Comparison between two sets of success criteria}

Comparing results between the national government criteria and the US government criteria is an important results of the analysis. Table 22 shows the absolute difference between the prioritization of initiatives between the two criteria sets, for all scenarios. The total difference between the two criteria sets can be used as a measure of the agreement between the results for the two sets. The baseline scenario and $s c_{1}$ : Insufficient power supply have the most agreement, with 7 initiatives being prioritized differently. Scenario sc4: Public perception problems has the greatest difference in prioritization. 31 initiatives are assigned to different priority classes and 12 of them are two priority classes apart. Scenario Sc6: International management and oversight lacking comes second in terms of difference between criteria sets, with a total absolute difference of 21 priority classes. Three initiatives, x4: Kabul power distribution network, x22: Gereshk distribution network upgrade and $x_{26}$ : Sheberghan to Mazar-e-Shariftransmission line, receive different priorities with the two criteria sets under all scenarios. 
Table 22. Absolute difference in prioritization of initiatives for the national government criteria and the US government criteria, by scenario.

\begin{tabular}{|c|c|c|c|c|c|c|c|c|}
\hline & & 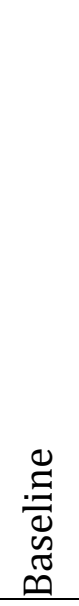 & 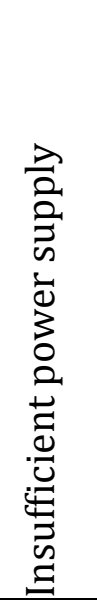 & 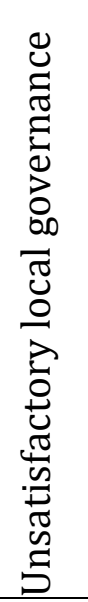 & 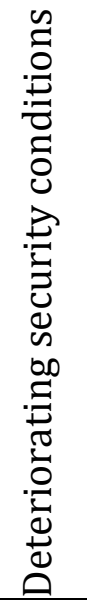 & 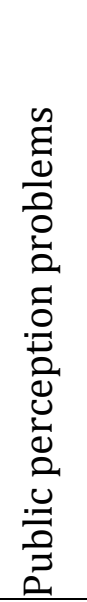 & 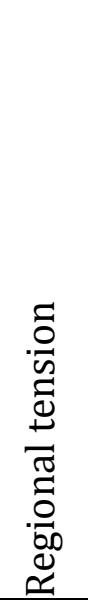 & 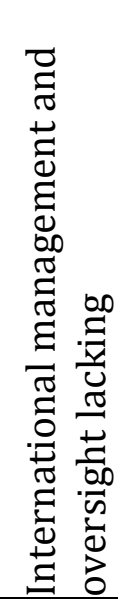 \\
\hline $\mathrm{x} 1$ & $\begin{array}{l}\text { Sheberghan gas } \\
\text { development }\end{array}$ & 0 & 0 & 0 & 0 & 1 & 0 & 2 \\
\hline $\mathrm{x} 2$ & $\begin{array}{l}\text { Arghundy to Kandahar } \\
\text { transmission line }\end{array}$ & 1 & 1 & 1 & 1 & 0 & 0 & 0 \\
\hline x3 & Salang Tunnel substation & 0 & 0 & 0 & 0 & 1 & 0 & 0 \\
\hline $\mathrm{x} 4$ & $\begin{array}{l}\text { Kabul power system } \\
\text { rehabilitation }\end{array}$ & 1 & 1 & 2 & 1 & 1 & 1 & 1 \\
\hline x5 & Kajaki Dam Unit 2 & 1 & 1 & 1 & 1 & 1 & 0 & 0 \\
\hline x6 & CASA-1000 & 0 & 0 & 0 & 0 & 2 & 1 & 0 \\
\hline $\mathrm{x} 7$ & $\begin{array}{l}\text { TUTAP Kabul to PAK } \\
\text { transmission line }\end{array}$ & 0 & 0 & 0 & 0 & 2 & 1 & 0 \\
\hline x8 & TKM interconnection & 0 & 0 & 0 & 1 & 2 & 1 & 1 \\
\hline x9 & $\begin{array}{l}\text { Kunduz-Taloqan } \\
\text { transmission line }\end{array}$ & 0 & 0 & 0 & 1 & 1 & 1 & 2 \\
\hline $\mathrm{x} 10$ & $\begin{array}{l}\text { Baghlan and Kunduz } \\
\text { distribution networks }\end{array}$ & 0 & 0 & 0 & 1 & 1 & 1 & 2 \\
\hline x11 & $\begin{array}{l}\text { NEPS 0\&M emergency } \\
\text { equipment }\end{array}$ & 1 & 0 & 2 & 0 & 0 & 0 & 2 \\
\hline $\mathrm{x} 12$ & $\begin{array}{l}\text { Rehabilitation of } \\
\text { Sheberghan gas wells }\end{array}$ & 0 & 0 & 0 & 0 & 1 & 0 & 2 \\
\hline x13 & $\begin{array}{l}\text { Tranche } 1 \mathrm{PM} \text { and } \\
\text { implementation }\end{array}$ & 0 & 0 & 0 & 0 & 1 & 0 & 0 \\
\hline x14 & Tranche 4 preparation & 0 & 0 & 0 & 0 & 1 & 0 & 0 \\
\hline
\end{tabular}




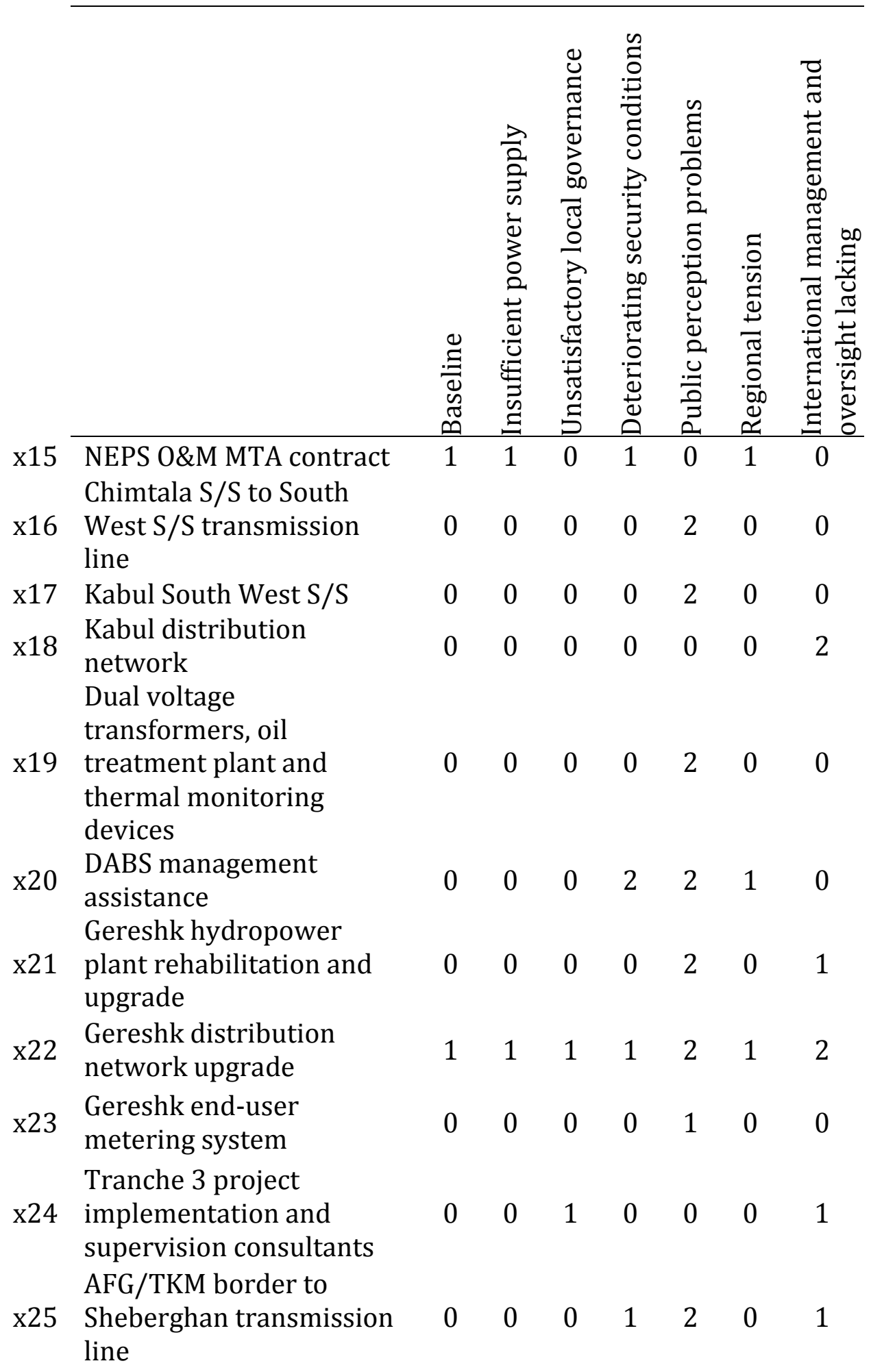




\begin{tabular}{|c|c|c|c|c|c|c|c|c|}
\hline & & 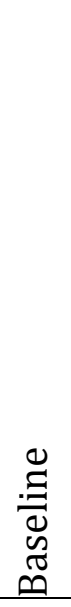 & 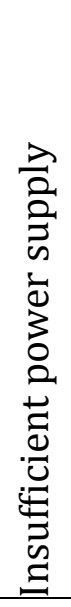 & 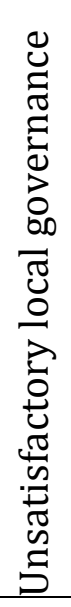 & 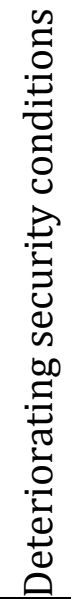 & 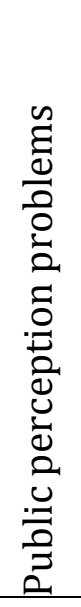 & 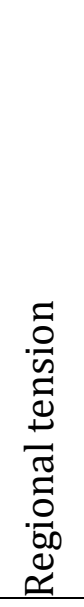 & 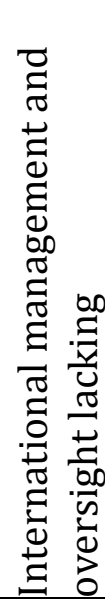 \\
\hline x26 & $\begin{array}{l}\text { Sheberghan to Mazar } \\
\text { Sharif transmission line }\end{array}$ & 1 & 1 & 1 & 2 & 1 & 2 & 2 \\
\hline x27 & $\begin{array}{l}\text { Andkhoy and Sheberghan } \\
\text { substations }\end{array}$ & 0 & 0 & 0 & 0 & 1 & 0 & 0 \\
\hline x28 & $\begin{array}{l}\text { Mazar Sharif substation } \\
\text { expansion }\end{array}$ & 0 & 0 & 0 & 0 & 1 & 0 & 0 \\
\hline$x 29$ & $\begin{array}{l}\text { Pul-e-Alam and Gardez } \\
\text { distribution networks }\end{array}$ & 0 & 0 & 0 & 0 & 1 & 0 & 0 \\
\hline x30 & $\begin{array}{l}\text { Pul-e-Alam and Gardez } \\
\text { substation equipment }\end{array}$ & 0 & 0 & 0 & 0 & 1 & 0 & 0 \\
\hline x31 & $\begin{array}{l}\text { Tranche } 4 \mathrm{PM} \text { and } \\
\text { implementation } \\
\text { consultants }\end{array}$ & 0 & 0 & 0 & 0 & 1 & 0 & 0 \\
\hline x32 & Dashte Alwan substation & 0 & 0 & 0 & 0 & 1 & 0 & 0 \\
\hline x33 & $\begin{array}{l}\text { Tranche } 5 \text { project } \\
\text { implementation and } \\
\text { supervision consultants } \\
\text { Dashte Alwan to Kabul }\end{array}$ & 0 & 0 & 0 & 0 & 1 & 0 & 0 \\
\hline x34 & $\begin{array}{l}\text { Arghundy transmission } \\
\text { line }\end{array}$ & 0 & 0 & 0 & 1 & 2 & 1 & 0 \\
\hline x35 & Arghundy substation & 0 & 0 & 0 & 0 & 2 & 0 & 0 \\
\hline \multirow[t]{2}{*}{ x36 } & $\begin{array}{l}\mathrm{N}-\mathrm{S} \text { power transmission } \\
\text { project implementation } \\
\text { and supervision }\end{array}$ & 0 & 1 & 0 & 0 & 1 & 0 & 0 \\
\hline & Total & 7 & 7 & 9 & 14 & 43 & 12 & 21 \\
\hline
\end{tabular}




\subsection{Software interface}

This chapter shows samples of the software interface, implemented in MS Excel, that was designed for the demonstration. Inputs to the interface are lists of initiatives, criteria and scenarios. Figures 6 and 7 show samples of worksheets. Figure 6 illustrates how impact assessments can be input directly into the interface, which will instantly change the output. Figure 7 shows a sample results worksheet where the number of significant and marginal impact assessments are shown, priority classification and the disruption of each initiative by scenario. The prioritization using rules is implemented using nested IF functions. 


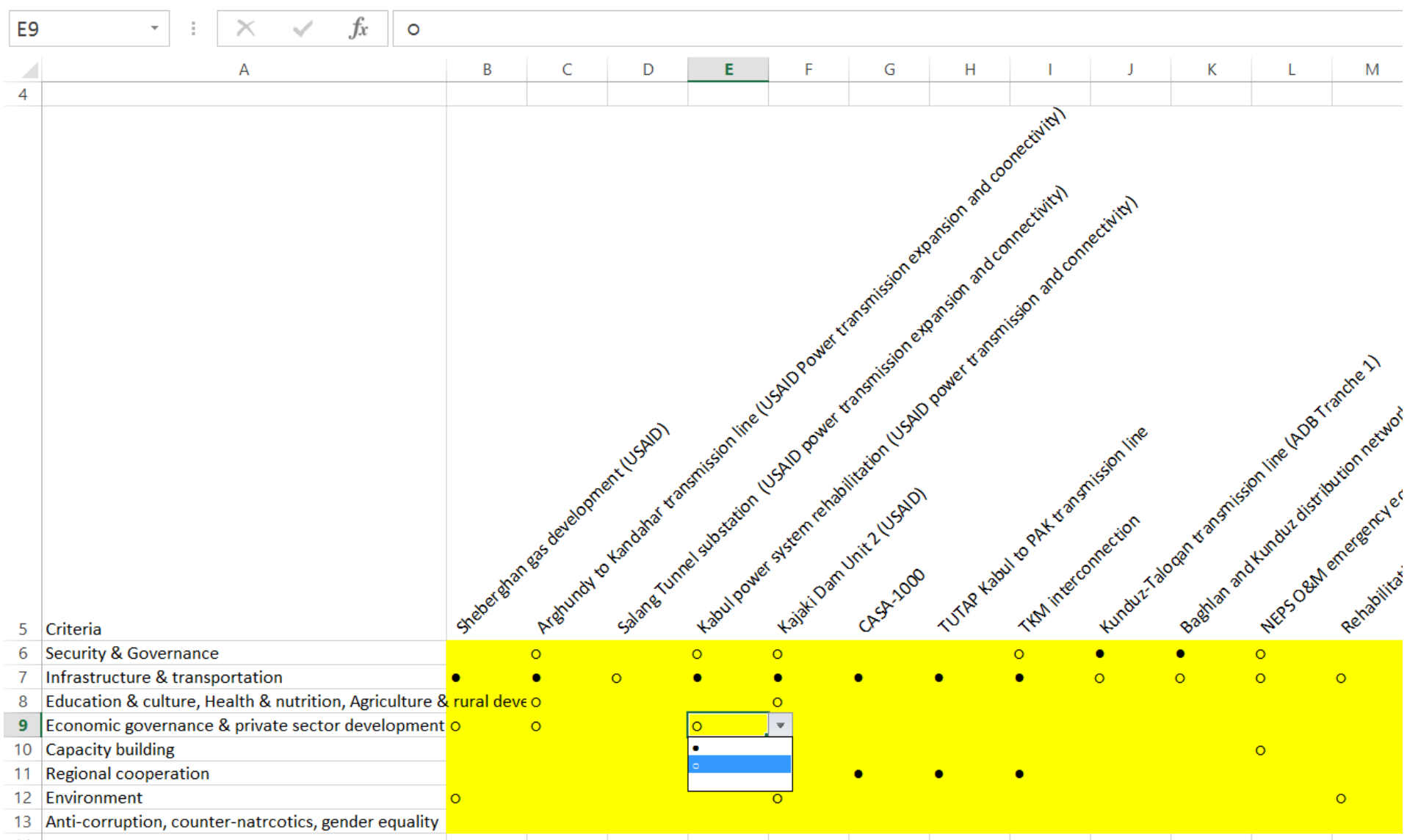

Figure 6. Sample of worksheet where impact assessment is performed. 


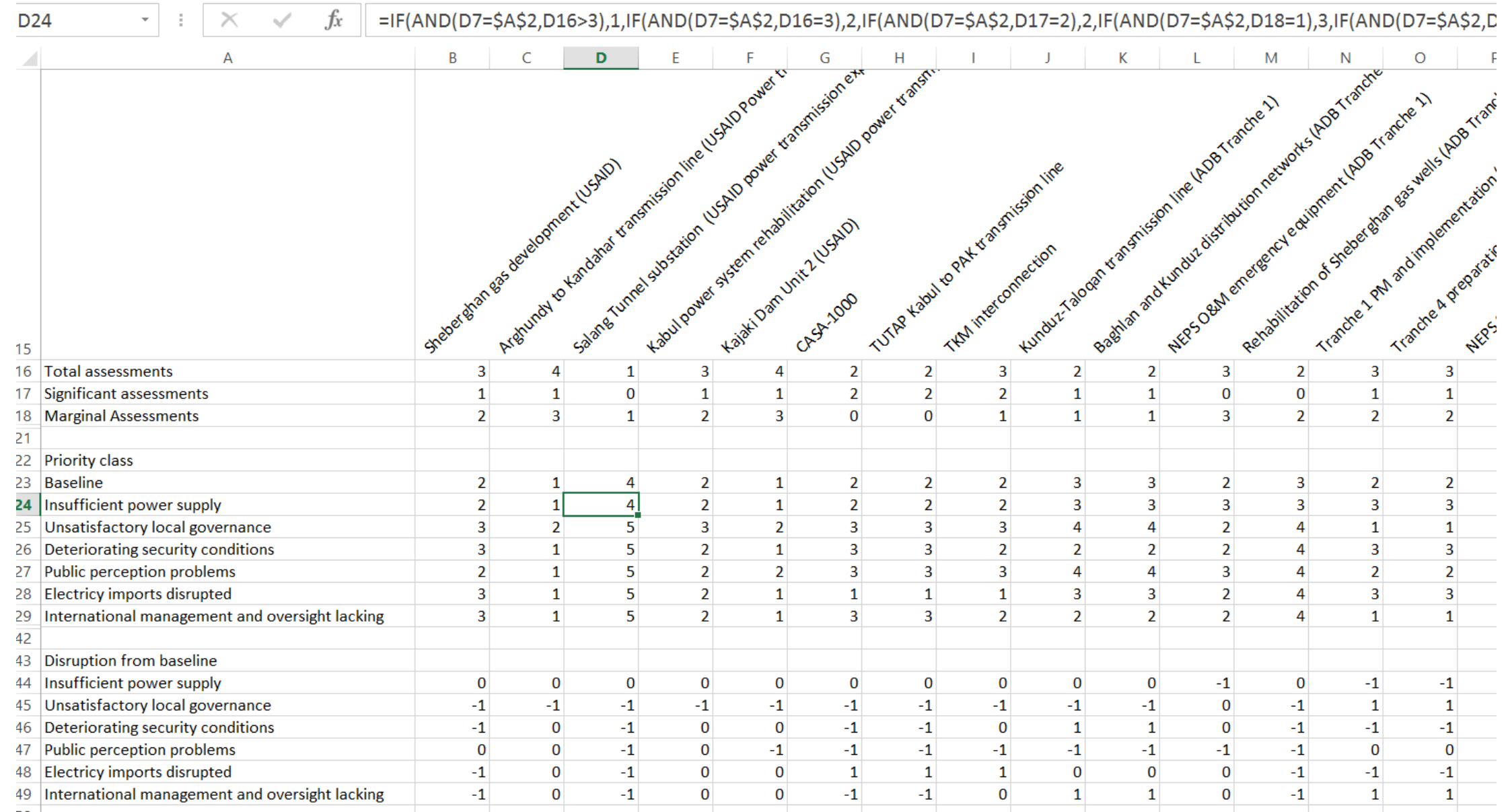

Figure 7. Sample of results worksheet. Assignment into priority classes is achieved using IF statements. 


\subsection{Chapter summary}

The section demonstrated the application of the methods presented in Chapter 3 to quantify the disruption of scenarios to the priorities of a power purchase and power delivery plan in Afghanistan. The scenarios cover a range of different possible trajectories, and each scenario is driven by particular stakeholder perspectives. Table 23 summarizes the main results from Chapter 4.3. For both sets of criteria, sc2: Unsatisfactory local governance is most disruptive to the prioritization of initiatives and $s_{1}$ : Insufficient power supply is the least disruptive. For the national government criteria, initiatives $x_{2}$ : Arghundy to Kandahar transmission line and $x_{5}$ : Kajaki Dam Unit 2 are prioritized in the two highest classes, immediate need and near-term need, under all scenarios. For the US government criteria, $x_{4}$ : Kabul power system rehabilitation and $x_{15}$ : NEPS O\&M MTA contract are prioritized for immediate or near-term need under all scenarios. Scenarios that had the largest difference in their prioritization of initiatives between scenarios are sc4: Public perception problems and sc6: International management and oversight lacking. Scenarios with the smallest difference are sc1: Insufficient power supply and sc2: Unsatisfactory local governance, which are respectively the least and most disruptive scenarios within both criteria sets. 
Table 23. Summary of key results.

\begin{tabular}{|c|c|c|}
\hline & $\begin{array}{c}\text { National government } \\
\text { criteria }\end{array}$ & US government criteria \\
\hline Most disruptive & $\mathrm{sc}_{2}$ : Unsatisfactory local & $\mathrm{sc}_{2}$ : Unsatisfactory local \\
\hline scenario & governance & governance \\
\hline Least disruptive & sc1: Insufficient power & \\
\hline scenario & supply & $\mathrm{sc}_{1}$ : Insufficient power supply \\
\hline High priority & x2: Arghundy to Kandahar & X4: Kabul power system \\
\hline initiatives stable & transmission line & rehabilitation \\
\hline across scenarios & x5: Kajaki Dam Unit 2 & X15: NEPS O\&M MTA contract \\
\hline & \multicolumn{2}{|c|}{ sc4: Public perception problems } \\
\hline criteria sets & \multicolumn{2}{|c|}{ sc6: International management and oversight lacking } \\
\hline Scenario with least & \multicolumn{2}{|c|}{$\mathrm{sc}_{1}$ : Insufficient power supply } \\
\hline separation between & & \\
\hline criteria sets & \multicolumn{2}{|c|}{ sc2: Unsatisfactory local governance } \\
\hline
\end{tabular}




\section{Discussion}

\subsection{Chapter overview}

This chapter discusses some key findings and considerations regarding the methodology and the demonstration. The methods used in the thesis are compared to previous research on risk filtering and scenario-based preferences. Key challenges and limitations are discussed, as well as the usefulness and appropriate interpretation of results. Finally, a brief overview of the relevant state of the power purchase and power delivery agreement and power sector in Afghanistan as of late March 2016 is given.

\subsection{Findings and considerations}

The methods presented in this thesis can be viewed as a complement to traditional risk analysis by identifying the scenarios that are most in need of further investigation, 
including risk analysis, simulation, experimentation, data collection and analysis, etc. The aim is not decision making, but rather a triage of what issues are potentially important, via construction of a prototype of a decision making process. The scenarios are then introduced to quantify the separation between the timeline of priorities in the baseline scenario and the adjusted timeline when the system is subject to particular stressors. In this sense, the thesis is not inconsistent with traditional definitions risk analysis, as the methods can provide a step in risk filtering. In the context of the RFRM framework of Haimes et al (2002), risk scenarios are filtered by likelihood and consequences, as well as their ability to defeat three defensive properties of the system: robustness, resilience and redundancy. The methods used in this thesis complement these steps by filtering scenarios by their potential to disrupt the priority ordering of initiatives, thus addressing how scenarios affect the time horizon of initiatives.

The thesis addresses the degree of disruption of a timeline of priorities, relative to an asplanned timeline. Figures 8a-c illustrates this view, this visualization is inspired by, though not a direct extension of the work of Kaplan (1997). Figure 8a shows the baseline scenario, so, in the space of milestones or implementation timeline of the initiatives. Figure $8 \mathrm{~b}$ and Figure $6 \mathrm{c}$ illustrate how the timeline is disrupted by scenarios and recovers and achieves the planned end state (Fig. 8b) or adjusts to a new end state (Fig 8c). The closeness of the disrupted timelines to the as-planned timeline is an illustration of the disruptive potential of the respective scenario. 

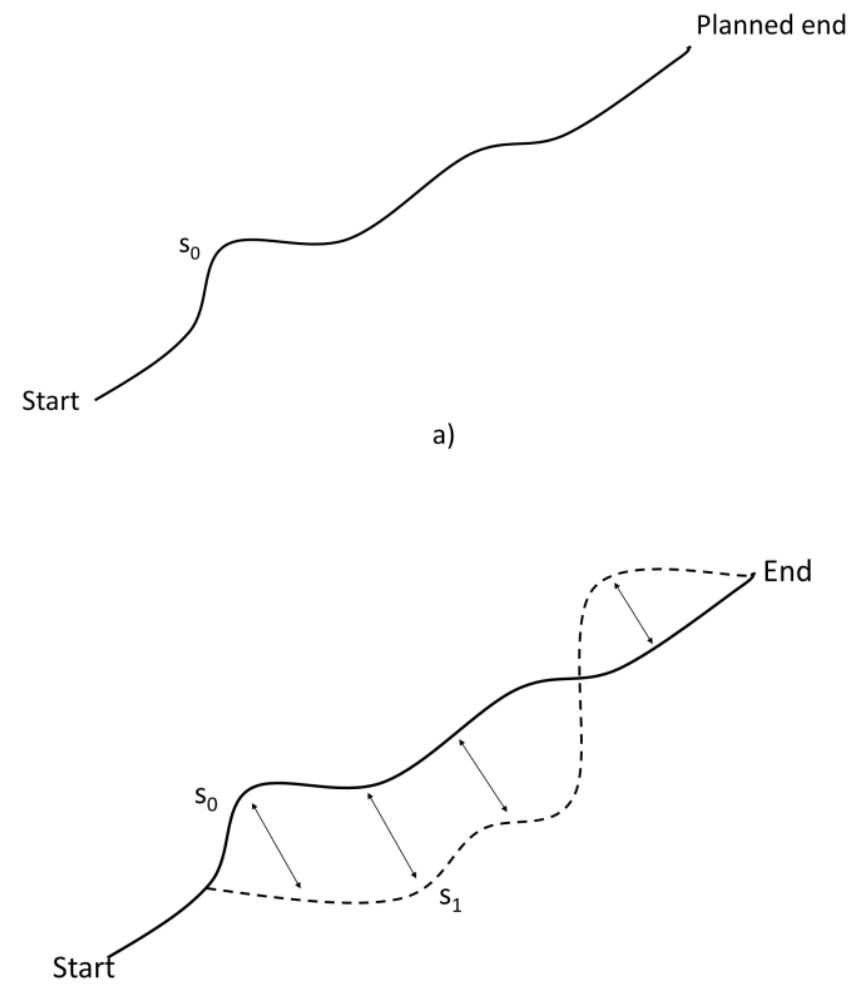

b)

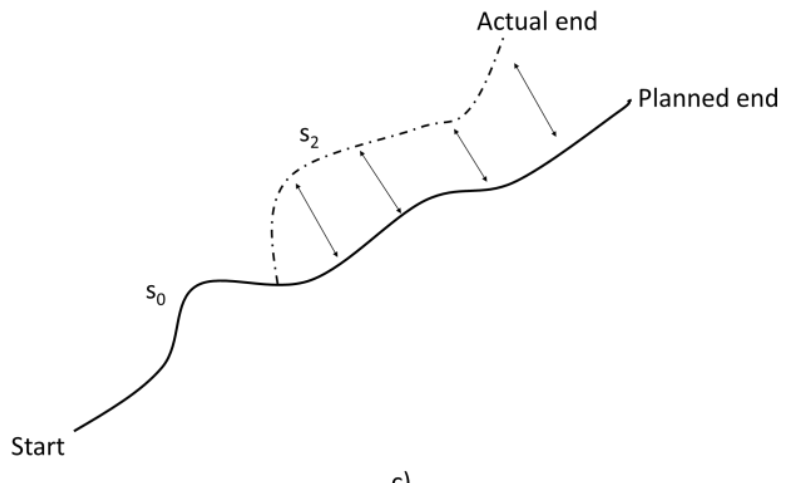

c)

Figure 8. Illustration of the disruption of a timeline of priorities. The methods developed in this thesis characterize the separation of the timeline from an as-planned timeline when subjected to scenarios. 
When interpreting the results, the prioritization of initiatives should not be considered the main results, although it is a necessary step in the process of quantifying the disruptions of scenarios. In order to develop a full ranking of initiatives that can be interpreted as a timeline of priorities, information would be needed that is not available to the author. Most importantly, interdependencies and interconnections between initiatives would need much more consideration that they have been given in this thesis. However, detailed information is not available about many of the initiatives, and in addition initiatives are derived from multiple sources so sufficiently establishing the necessary interdependencies would require data collection and technical insight that is well beyond the scope of this thesis.

Data availability and reliability is one of the main limitations of the demonstration of methods. When compiling information, many initiatives had outdated information. As an example, all initiatives in the program "ADB Tranche 1" were scheduled to be finished in 2012, but when interviewing employees in the development sector in Afghanistan in early 2015, it became clear that these projects were not yet finished.

The establishment of criteria sets, construction of scenarios, assessments of impact of initiatives on criteria and development of rules is an important part in the execution of the methodology presented in this thesis. These are subjective in nature, and should include extensive expert and stakeholder engagement. In the earlier stages of this research, from January to June 2015, weekly discussions were held with representatives of the United States Agency for International Development (USAID), the Combined 
Security Transition Command - Afghanistan (CSTC-A) and the US Army Corps of Engineers (USACE). Furthermore, during the period experts from the Asian Development Bank, the Afghan national utility company, Da Afghanistan Breshna Sherkat (DABS), and the Afghan ministries of interior and defense provided feedback and revisions. Despite this extensive engagement, the assessments remain subjective to the opinions of the experts and stakeholders that contributed. This subjectivity can be seen as a limitation of the methodology but can in fact also be seen to be in line with the philosophy of different criteria sets representing different stakeholders, and scenarios potentially being advocated by particular groups.

Due to the limitations discussed in previous paragraphs, the methods developed to quantify disruptions, rules for classification and comparison between criteria sets are kept as simple as possible. This supports ease of interpretation, and increases transparency of relationships between building blocks. The disruption of initiatives has in the literature been quantified using rank correlation measures such as Kendall tau-b and Spearman rank correlation coefficient (Connelly, 2015; You et al., 2014). For situations where ties in rank are very common, such as is the case for prioritization of 36 initiatives into five priority classes, looking at transitions between classes is at least as appropriate and captures better the aim of finding the disruption since prioritizations could be strongly correlated despite all initiatives being promoted or demoted by one priority class. This is especially true in the case in this thesis, since for scenarios $S C_{2}-S C_{6}$, the rules used for the prioritization correlate the scenario priorities to baseline priorities. 
Thus counts of transitions, although not as statistically sophisticated provide a more consistent and transparent quantification of disruption of scenarios.

The involvement of stakeholders supports and motivates the emphasis on quantifying disruptions of strategic plans in the regime of priorities and mindsets, rather than just in physical structures. Some of the events that most drastically affected the world so far in the $21^{\text {st }}$ century share this characteristic. The $9 / 11$ attacks on New York and Washington in 2001, raised the importance of security for many offices and agencies and sparked the establishment of a new US federal agency, the Department of Homeland Security. Similarly, the economic recession in 2008-2009 raised the importance of fiscal responsibility and Hurricane Katrina in 2005 raised the importance of serving underrepresented social groups in disasters. This can help justifying the selected regime of this thesis: Why scenarios influence a change in the relative priority ordering of initiatives, rather than how the scenarios might directly impact the execution of the individual initiatives.

In previous research addressing the disruption of scenarios to priorities (Connelly et al., 2015; Hamilton et al., 2015; Thekdi \& Lambert, 2014) the prioritization of initiatives is developed by the usage of a linear additive value function (Keeney \& Von Winterfeldt, 2011; Keeney, 2007). Weights are assigned to the criteria, and the impact assessments, significant and marginal (or similar), are quantified. The weighted scores of the initiatives are then used to establish a rank ordering. The influence of scenarios is then modeled by adjusting the weights of criteria and a new rank ordering is calculated for each scenario. 
The rule-based approached developed in this thesis improves the previously described "weight-and-rate" method in several ways. It adds transparency by explicitly assigning initiatives into priority classes without the additional step of calculating a value score and there is a clearly defined relationship between impact assessments, priority classification and adjustments due to scenarios. In the "weight-and-rate" method, weight adjustments are achieved by introducing "worth multipliers". Experience has taught that these are hard to elicit and stakeholders have difficulties interpreting them. Furthermore, rules provide more flexibility in terms of having the flexibility of mixing cut-off rules, example rules and compensation rules. "Weight-and-rate" can be considered a special case of compensation rules, and cut-off rules and example rules are hard to model using a simple linear additive model. However, the construction of rules can be more complicated than eliciting weights and mathematically minded individuals might prefer a simple mathematical model rather than a set of rules, which can potentially be include dozens of rules. Therefore, depending on whether stakeholders are more qualitatively and quantitatively minded, both methods can be justified.

The usefulness of the methods and results presented in this thesis should be considered in the context of negotiations or development of terms for strategic plans. By considering multiple perspectives and quantifying how different scenarios might affect a timeline of priorities the analysis quantifies which scenarios have the most potential to cause a change of mind among stakeholders, which can also be interpreted as which scenarios might prompt renegotiations. Thus, a possible interpretation of sc2: Unsatisfactory local 
governance being more disruptive to the prioritization than sc1: Insufficient power supply, is that even though insufficient power supply might be a threat to the realization of the plan, it does not prompt much replanning of the timeline, initiatives that were important under the baseline remain important. However, if local governance proves unsatisfactory compared to what was envisioned when the plan was agree upon, some stakeholders might deem it best to reprioritize the initiatives to mitigate the effects of the scenario.

As this is written the power purchase and power delivery agreement has been signed by all parties, including USAID, Combined Security Transition Command - Afghanistan, Asian Development Bank, DABS (Afghanistan national utility company), and the Afghan ministries of interior and defense (Harrington, 2015; Resolute Support Mission, 2015; US Army, 2015). The necessary $\$ 200$ million contribution came from NATO member states Australia, Belgium, Canada, Germany and the Netherlands and is managed by the Asian Development Bank. Of the total contribution, $\$ 55$ million are requested in the fiscal year 2017 budget of the Afghanistan Security Forces Fund (Office of the Secretary of Defense, 2016). Appendix D contains sample news coverage on the agreement.

However, the security situation, economy and politics in Afghanistan continue to be fragile. Many of the initiatives used for this demonstration were already years behind schedule, funding had run out, or information about the status was inaccessible. Business practices are lacking, and the withdrawal of Western forces from the country will put increased pressure on Afghan national defense organizations. In late January 2016, transmission lines connecting Kabul to Uzbekistan power supply were cut by Taliban 94 
insurgents in the northern Baghlan province, causing further rationing and blackouts in Kabul last for several weeks (Jolly, 2016; Radio Free Europe/Radio Liberty, 2016). Increasing the resilience of planning, funding and implementing mechanisms should be a major aim of decision makers as a more resilient system will be better capable of withstanding disruptions caused by the scenarios discussed in this thesis and other uncertain future conditions. Tracking and monitoring current projects and performing periodic risk management activities are essential to the successful construction, operation and maintenance of a national electric grid.

\subsection{Chapter summary}

This chapter expands on the philosophy the thesis is founded on, and place the methods in a theoretical context. It discusses limitations in the work, with an emphasis on the subjective nature of the methods to stakeholder or expert preferences and the limited data availability related to the Afghanistan power sector. Finally, it concludes that even though funds have been committed to the implementation of an extensive power purchase and power delivery agreement, enhancing both civil and military access to electricity, the security, economic and political situation in Afghanistan continues to be volatile, and there is still a need for regular updates to risk assessment and management strategies. 


\section{Conclusions}

\subsection{Chapter overview}

This chapter summarizes the contributions and accomplishments leading to this thesis and discusses future research directions.

\subsection{Contributions}

The main contributions of this thesis to the literature of risk analysis and systems engineering are discussed below and Figure 9 describes the contributions in the context of current literature.

Contribution 1: Rule-based extension. The thesis demonstrates how current research on disruption of priorities with scenario-based preferences can be extended to rule-based 
preference relationships. This includes adding to traditional risk analysis by prioritizing risks that disrupt current priorities as well as risks with the highest likelihood and consequences. Rules can add flexibility in assigning priorities to additive value functions used in previous research, and provide a clearer relationship between the input and output.

Contribution 2: Complementary criteria. $A$ new dimension is added to the methodology by analyzing two complementary sets of criteria and comparing the results between the different criteria sets. This can be useful in negotiations between stakeholders that have different values and objectives, as controversial issues can be traced to the fundamental values that inspire the conflict. Assembling this with contributions 1 loosens the requirement for consensus among stakeholders when performing risk filtering, by recognizing that no one perspective is sufficient to characterize the scenarios that most influence a negotiation or decision making process.

Contribution 3: Demonstration to power grid. The methods are demonstrated on a grid capacity planning effort in Afghanistan, working with USAID, Asian Development Bank, CSTC-A, and US Army Corps of Engineers. This included weekly teleconferences with representatives of the aforementioned agencies for several months, identification of stressors and construction of scenarios, development of success criteria, identification of capacity building initiatives, and impact assessments leading to a quantification of the disruption of the scenarios to the prioritization or timeline of initiatives. The analysis found that unsatisfactory local governance in Afghanistan is the most disruptive of the 
examined scenarios to the prioritization of initiatives that enhance the national grid, for both the national government criteria and the US government criteria. 


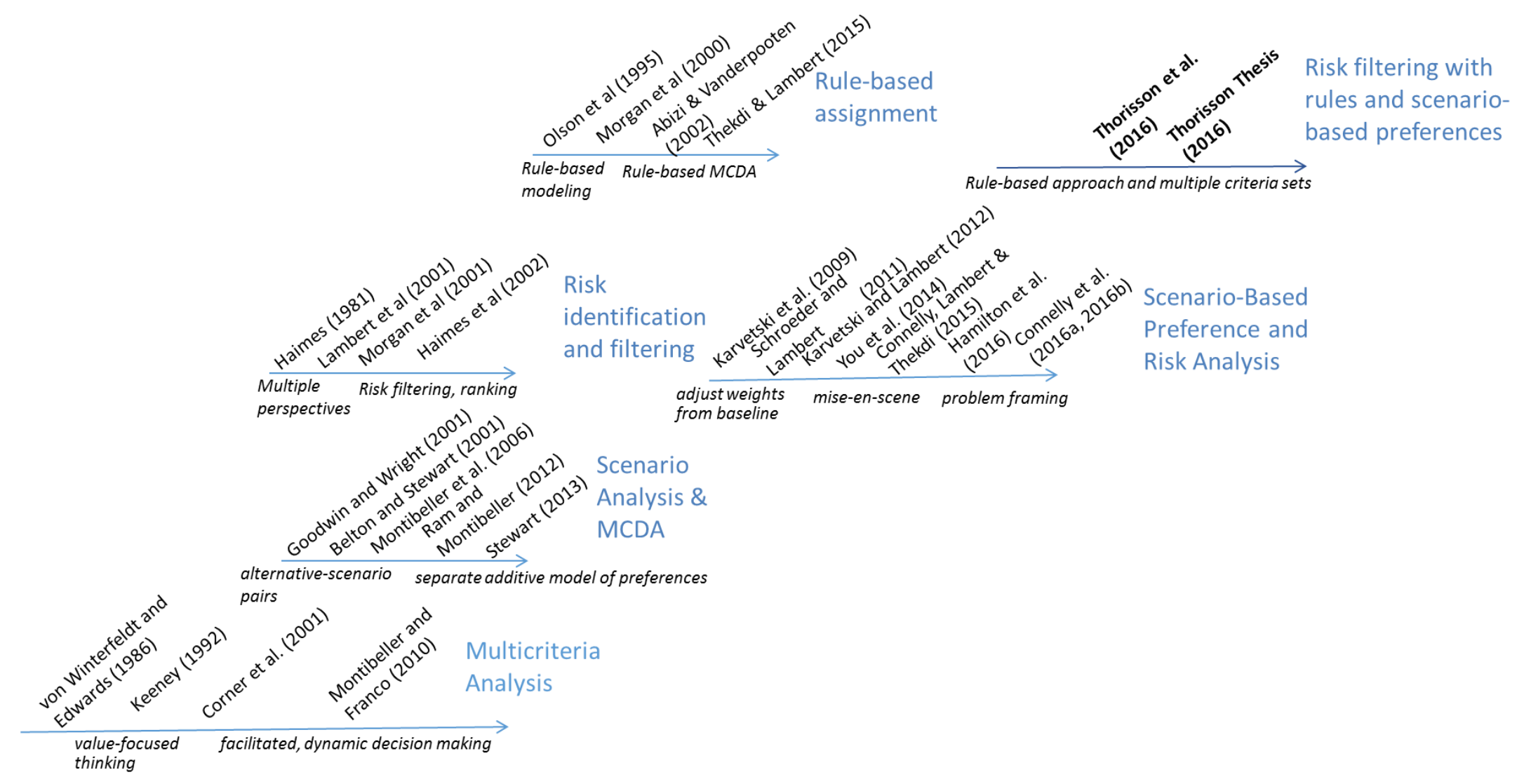

Figure 9. Innovations of this thesis to theory and methodology of systems engineering and risk analysis. 
In addition to the thesis, the following academic activities are a directly relevant to this research:

- Co-author of a paper is being prepared for the journal Risk Analysis, with revisions submitted in February 2016. Among co-authors of the paper is the Deputy Mission Director at USAID in Afghanistan, John Cardenas.

Thorisson, H., Lambert, J.H., Cardenas, J., Linkov, I. “Resilience Analytics for Grid Capacity Planning in a Volatile Region". Submitted to Risk Analysis.

- Presenter of the work at the Annual Meeting of the Society for Risk Analysis (SRA) in December 2015.

Thorisson, H., Lambert, J.H. “Prioritizing investment risks and opportunities for the power grid in a volatile post-conflict region". Presented at the Society for Risk Analysis Annual Meeting in Arlington, VA. December 2015.

- Accepted presenter at the SRA-Europe conference in England in June. Thorisson, H., Lambert, J.H., Ditmer, R.D. “Interactions of risk analysis and policy making in infrastructure planning in developing countries". Scheduled for Society for Risk Analysis Europe Conference in Bath, England. June 2016.

- Co-author of a conference paper for the IEEE Systems Conference 2016. Collier, Z.A., Connelly, E.B., Thorisson, H., Lambert, J.H. (2016). “Resilience of Initiatives for Shifting Management Priorities Under Emergent and Future Conditions". Presented at IEEE Systems Conference in Orlando, FL. IEEE. 
- Participant at the 2015 USAID Infrastructure Workshop: Strengthening the Sustainability and Resilience of USAID Infrastructure Projects, in Washington DC, December 14-18, 2015.

- Member of the Community of Practice for Development Risk Practitioners, an initiative led by the World Bank Group, and participant at its launch event in Washington DC, February 16, 2016.

- Technical assistance to translators of the PDPPA framework from English into Dari, June-July 2015.

Table 24 summarizes activities undertaken in the progress towards thesis defense. 
Table 24. Summary of research milestones.

\section{Literature review}

2 Weekly teleconferences/briefings with stakeholders 3 Identify success criteria, initiatives and stressors

4 Establish relationships between model building blocks

5 Interpret results of refine analysis

6 Deliver a report to stakeholders

7 Submit paper to Risk Analysis

8 Develop logical rules for classification of priorities

9 Thesis proposal

10 Present research at SRA Annual Meeting

11 Participate in 2015 USAID Infrastructure Workshop

12 Refine methods and iterate

13 Submit revised paper to Risk Analysis

Participate in the launch of the Community of Practice

14 for Development Risk Practioners

15 Thesis defense

16 Present research at SRA-Europe Conference

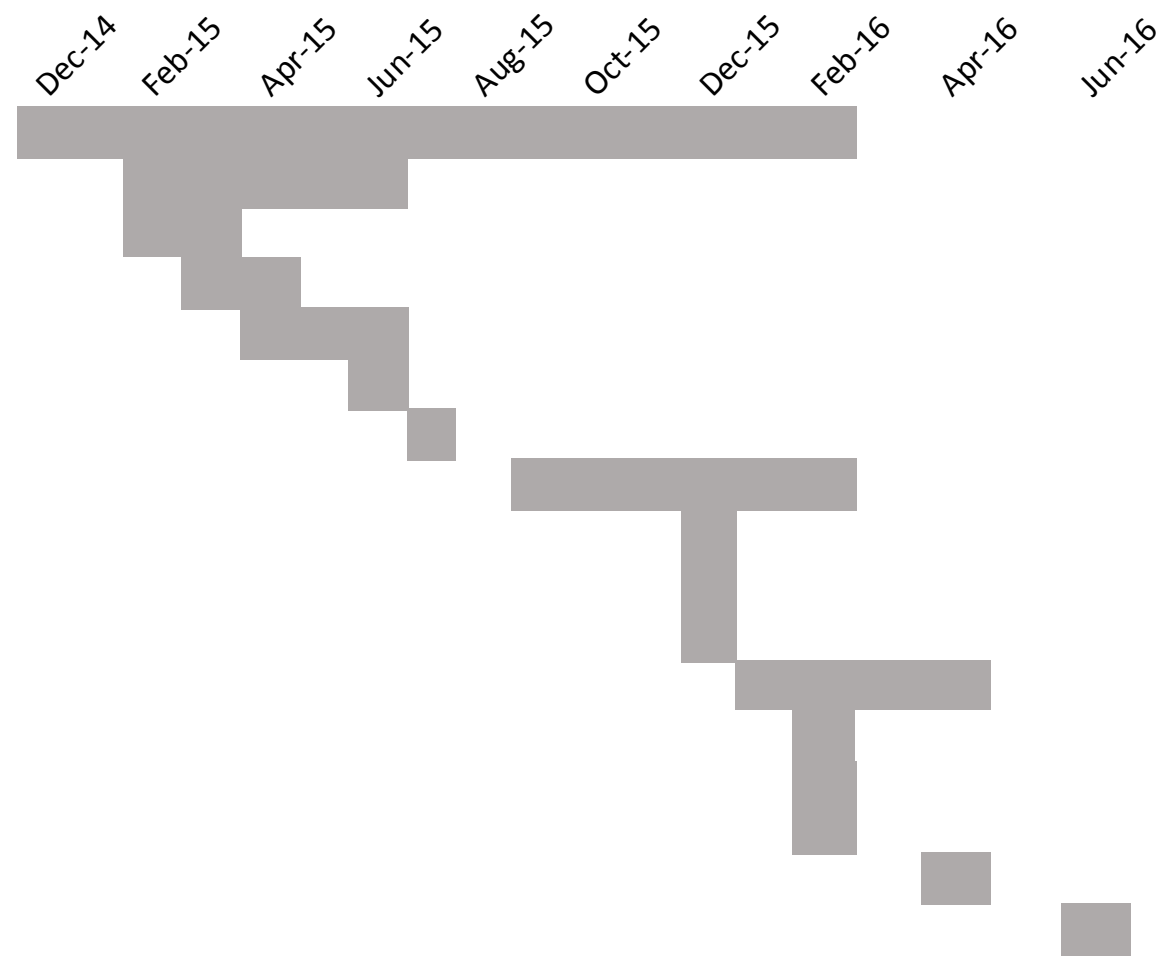




\subsection{Future work}

Opportunities to extend this research are plentiful. The use of rules to prioritize in an innovation in the context of scenario-based preferences and should be explored further, applied to more cases and the possibility for a formal process to develop the rules should be studied. This all would contribute to the validation of the technique, which is currently somewhat lacking. A particularly relevant progress would be to explore the possibility to achieve a more granular prioritization, more priority classes or a full ranking, without increasing the complexity of the rule development.

The methods of this thesis can provide a step in risk filtering. A further integration into frameworks of risk identification, filtering and ranking might be considered. Currently the methods are proposed as a step in the RFRM framework of Haimes et al (2002), however further research might include a case study formally performing all the steps and evaluating how these methods fit in the framework.

The continuity and iteration of risk assessment and management is critical to ensure practical validity and reflect the current state of the world. Communicating the need to regularly revise values, relevant stressors and scenarios and others, to stakeholders is a critical component and future research might include addressing how to best train or prepare agencies, and streamline elicitations and other risk assessment processes such that analysis of the sort that is presented in this thesis is easily replicable within organizations. 


\subsection{Chapter summary}

This chapter summarized the contributions of the thesis to the systems engineering and risk analysis literature, claiming three main contributions: rule-based extension to scenario-based preferences, analyzing complementary sets of criteria, and the application to the Afghanistan power sector. Furthermore, future areas of research are identified. 


\section{References}

Ayyub, B. M. (2001). Elicitation of Expert Opinions for Uncertainty and Risks. CRC Press.

Azibi, R., \& Vanderpooten, D. (2002). Construction of rule-based assignment models. European Journal of Operational Research, 138(2), 274-293. http://doi.org/10.1016/S03772217(01)00246-6

Baccarini, D., \& Archer, R. (2001). The risk ranking of project a methodology. International Journal of Project Management, 19, 139-145. http://doi.org/10.1016/S02637863(99)00074-5

Belton, V., \& Stewart, T. (2002). Multiple Criteria Decision Analysis: An Integrated Approach. Springer Science and Business Media.

Bohanec, M., \& Rajkovic, V. (1988). Knowledge Acquisition and Explanation for Multi-Attribute 105 
Decision Making. Proceedings of the 8th International Workshop: Expert Systems and Their Applications, 1(1), 59-78.

Boyce, R. D., Duncan, B. L., \& Orya, M. (2015). Kajaki hydro power plant: Project development at a remote and difficult site. United States Agency for International Development.

Brody, B. (2014, August 8). USAID’s $\$ 500$ million dam project circling the drain in Afghanistan. Global Post. Retrieved from http://www.globalpost.com/dispatches/globalpostblogs/groundtruth/usaid-kajaki-dam-afghanistan-failure

Chankong, V., \& Haimes, Y. Y. (1983). Multiobjective Decision Making: Theory and Methodology. Dover.

Connelly, E. B. (2015). Resilience Analysis and Value of Information with Application to Aviation Biofuels. University of Virginia.

Connelly, E. B., Colosi, L. M., Clarens, A. F., \& Lambert, J. H. (2015). Risk Analysis of Biofuels Industry for Aviation with Scenario-Based Expert Elicitation. Systems Engineering, 18(2), 178-191.

Doll, C. N. H., \& Pachauri, S. (2010). Estimating rural populations without access to electricity in developing countries through night-time light satellite imagery. Energy Policy, 38(10), 5661-5670. http://doi.org/10.1016/j.enpol.2010.05.014

Edwards, D. (1996). Heroes of the Age: Moral Fault Lines on the Afghan Frontier. University of California Press.

Embassy of the United States of America, K., \& U.S. Forces, A. (2013). U.S. Civil-Military Strategic Framework for Afghanistan. 
Fichtner GmbH \& Co. KG. (2013). Islamic Republic of Afghanistan : Power Sector Master Plan.

Giustozzi, A., \& Ullah, N. (2006). Tribes and warlords in southern Afghanistan, 1980-2005 (No. 2). Retrieved from http://eprints.lse.ac.uk/41562/

Goodwin, P., \& Wright, G. (2001). Enhancing strategy evaluation in scenario planning : a role for decision analysis. Journal of Management Studies, (January). http://doi.org/10.1111/14676486.00225

Haimes, Y. Y. (1981). Hierarchical Holographic Modeling. IEEE Transactions on Systems, Man, and Cybernetics, 11(9), 606-617. http://doi.org/10.1109/TSMC.1981.4308759

Haimes, Y. Y. (2015). Risk Modeling, Assessment, and Management. Wiley.

Haimes, Y. Y., Kaplan, S., \& Lambert, J. H. (2002). Risk Filtering , Ranking , and Management Framewerk Using Hierarchical Holographie Modeling. Risk Analysis, 22(2).

Hamilton, M. C., Lambert, J. H., Keisler, J. M., Holcomb, F. H., \& Linkov, I. (2012). Research and Development Priorities for Energy Islanding of Military and Industrial Installations. Journal of Infrastructure Systems, 19(3), 121011224809006.

http://doi.org/10.1061/(ASCE)IS.1943-555X.0000133

Hamilton, M. C., Lambert, J. H., \& Valverde, L. J. (2015). Climate and Related Uncertainties Influencing Research and Development Priorities. Journal of Risk Uncertainty in Engineering Systems, 1(2). http://doi.org/10.1061/AJRUA6.0000814.

Harrington, S. (2015). NATO allies and partners commit \$200M to power ANDSF. Retrieved March 21, 2016, from https://www.youtube.com/watch?v=dgs14pWn7VA\&feature=youtu.be 
Hickey, A. M., \& Davis, A. M. (2003). Elicitation technique selection: how do experts do it? Proceedings. 11th IEEE International Requirements Engineering Conference, 2003., 11, 10. http://doi.org/10.1109/ICRE.2003.1232748

Independent Joint Anti-Corruption Monitoring and Evaluation Committee. (2014). Writing Off the Unpaid Electricity Bills of Government Entities and Influential Individuals Contributes to Corruption in the Electricity Sector. Retrieved from http://www.mec.af/files/2014_09_16_DABS_Press_Release_English.pdf

Inspector General Department of Defense. (2015). The Government of Islamic Republic of Afghanistan's Controls Over the Contract Management Process for U.S. Direct Assistance Need Improvement.

Islamic Republic of Afghanistan. (2008). Afghan National Development Strategy.

Jolly, D. (2016, January 27). Taliban Sabotage Cuts Major Power Source for Afghanistan Capital. New York Times. New York. Retrieved from http://www.nytimes.com/2016/01/28/world/asia/taliban-electricity-afghanistanuzbekistan-kabul.html?_r=0

Kadane, J. B., \& Wolfson, L. J. (1998). Experiences in elicitation. Journal of the Royal Statistical Society: ..., 47(1), 3-19. http://doi.org/10.1111/1467-9884.00113

Kaplan, S. (1997). The words of risk analysis. Risk Analysis, 17(4), 407-417. http://doi.org/10.1111/j.1539-6924.1997.tb00881.x

Kaplan, S., \& Garrick, B. J. (1981). On The Quantitative Definition of Risk. Risk Analysis, 1(1), 1127. 
Karvetski, C. W., \& Lambert, J. H. (2012). Evaluating Deep Uncertainties in Strategic PrioritySetting with an Application to Facility Energy Investments. Systems Engineering, 15, 483493. http://doi.org/10.1002/sys

Karvetski, C. W., Lambert, J. H., Keisler, J. M., \& Linkov, I. (2011). Integration of decision analysis and scenario planning for coastal engineering and climate change. Systems, Man and Cybernetics, Part A: Systems and Humans, IEEE Transactions on, 41(1), 63-73.

Karvetski, C. W., Lambert, J. H., \& Linkov, I. (2009). Emergent conditions and multiple criteria analysis in infrastructure prioritization for developing countries. Journal of Multi-Criteria Decision Analysis, 16, 125-137. http://doi.org/10.1002/mcda

Karvetski, C. W., Lambert, J. H., \& Linkov, I. (2011). Scenario and multiple criteria decision analysis for energy and environmental security of military and industrial installations. Integrated Environmental Assessment and Management.

Kaufmann, D. (2005). Myths and Realities of Governance and Corruption. Governance: An International Journal of Policy And Administration, (September), 81-98. Retrieved from http://papers.ssrn.com/sol3/papers.cfm?abstract_id=829244

Keeney, R. L. (2007). Modeling values for anti-terrorism analysis. Risk Analysis, 27(3), 585-596. http://doi.org/10.1111/j.1539-6924.2007.00910.x

Keeney, R. L., \& Von Winterfeldt, D. (2011). A Value Model for Evaluating Homeland Security Decisions. Risk Analysis, 31(9), 1470-1487. http://doi.org/10.1111/j.15396924.2011.01597.x

Kessides, C. (1993). The Contributions of Infrastructure to Economic Development. Washington, 


\section{D.C.: The World Bank.}

Lambert, J. H., Haimes, Y. Y., Li, D., Schooff, R. M., \& Tulsiani, V. (2001). Identification, ranking, and management of risks in a major system acquisition. Reliability Engineering and System Safety, 72(3), 315-325. http://doi.org/10.1016/S0951-8320(01)00009-6

Lambert, J. H., Karvetski, C. W., Spencer, D. K., Sotirin, B. J., Liberi, D. M., Zaghloul, H. H., ... Linkov, I. (2012). Prioritizing infrastructure investments in Afghanistan with multiagency stakeholders and deep uncertainty of emergent conditions. ASCE Journal of Infrastructure Systems, 18(2), 155-166. http://doi.org/10.1061/(ASCE)IS.1943-555X.0000078

Lambert, J. H., Parlak, A. I., Zhou, Q., Miller, J. S., Fontaine, M. D., Guterbock, T. M., ... Thekdi, S. A. (2013). Understanding and managing disaster evacuation on a transportation network. Accident Analysis and Prevention, 50, 645-658. http://doi.org/10.1016/j.aap.2012.06.015

Linkov, I., Satterstrom, F. K., Kiker, G., Batchelor, C., Bridges, T., \& Ferguson, E. (2006). From comparative risk assessment to multi-criteria decision analysis and adaptive management: Recent developments and applications. Environment International, 32(8), 1072-1093. http://doi.org/10.1016/j.envint.2006.06.013

Montibeller, G., \& Franco, A. (2010). Handbook of Multicriteria Analysis. In C. Zopounidis \& P. M. Pardalos (Eds.), Handbook of Multicriteria Analysis (1st ed., Vol. 103, pp. 25-44). SpringerVerlag Berlin Heidelberg. http://doi.org/10.1007/978-3-540-92828-7

Morgan, K. M., DeKay, M. L., Fischbeck, P. S., Morgan, M. G., Fischhoff, B., \& Florig, H. K. (2001). A deliberative method for ranking risks (II): Evaluation of validity and agreement among risk managers. Risk Analysis : An Official Publication of the Society for Risk Analysis, 21(5), 92337. http://doi.org/10.1111/0272-4332.215162 
Morgan, M. G., Florig, H. K., DeKay, M. L., \& Fischbeck, P. (2000). Categorizing risks for risk ranking. Risk Analysis : An Official Publication of the Society for Risk Analysis, 20(1), 49-58. http://doi.org/10.1111/0272-4332.00005

Neifer, R. (2014). Afghanistan : Addendum to the Afghanistan Power Sector Master Plan.

Neiger, D., Rotaru, K., \& Churilov, L. (2009). Supply chain risk identification with value-focused process engineering. Journal of Operations Management, 27(2), 154-168. http://doi.org/10.1016/j.jom.2007.11.003

Office of the Secretary of Defense. (2016). Justification for FY 2017 Overseas Contingency Operations (OCO) Afghanistan Security Forces Fund (ASFF). Washington, D.C. Retrieved from http://comptroller.defense.gov/Portals/45/Documents/defbudget/fy2017/FY17_J-BookASFF.pdf

Olson, D. L., Methitov, A. I., \& Moshkovich, H. M. (1995). The Role of Rules and Examples in the Process of Knowledge Acquisition in Direct Classification Tasks. Expert Systems with Applications, 8(1), 203-212.

Organisation for Economic Co-operation and Development. (2015). Development aid stable in 2014 but flows to poorest countries still falling. Retrieved June 11, 2015, from http://www.oecd.org/dac/stats/development-aid-stable-in-2014-but-flows-to-poorestcountries-still-falling.htm

Parlak, A. I., Lambert, J. H., Guterbock, T. M., \& Clements, J. L. (2012). Population behavioral scenarios influencing radiological disaster preparedness and planning. Accident Analysis and Prevention, 48, 353-362. http://doi.org/10.1016/j.aap.2012.02.007 
Radio Free Europe/Radio Liberty. (2016). Afghan Official: Power To Be Restored Soon In Kabul. Retrieved from http://gandhara.rferl.org/a/afghan-official-says-power-restored-soonkabul/27565027.html

Resolute Support Mission. (2015). No Title. Retrieved March 21, 2016, from https://www.facebook.com/ISAF/posts/10153712900583454

Ross, J. (2011, April 22). Artillery Marines hold back insurgents in key Afghan district. Unites States Central Command. Retrieved from http://www.centcom.mil/en/news/articles/artillery-marines-hold-back-insurgents-inkey-afghan-district

Shahrani, N. M. (2002). War, Factorialism, and the State in Afghanistan. American Anthropologist, 104(3), 715-722.

Special Inspector General for Afghanistan Reconstruction. (2014). High-Risk List.

Special Inspector General for Afghanistan Reconstruction. (2015). About SIGAR. Retrieved June 24, 2015, from https://www.sigar.mil/about/

Thekdi, S. A., \& Lambert, J. H. (2014). Quantification of Scenarios and Stakeholders Influencing Priorities for Risk Mitigation in Infrastructure Systems. Journal of Management in Engineering, 30(1), 32-40. http://doi.org/10.1061/(ASCE)ME.1943-5479.0000170

Thorisson, H., Lambert, J. H., Cardenas, J. J., \& Linkov, I. (n.d.). Resilience Analytics for Grid Capacity Planning in a Volatile Region. Submitted for Publication.

United States Agency for International Development. (2014). Infrastructure Fact Sheet. Retrieved from https://www.usaid.gov/afghanistan/infrastructure 
United States Agency for International Development. (2015). Installation of Turbine Generator Unit 2 at Kajaki Dam Hydropower Plant (Kajaki Unit 2). Retrieved June 22, 2015, from http://www.usaid.gov/news-information/fact-sheets/installation-turbine-generator-unit2-kajaki-dam-hydropower-plant

US Army. (2015). Huntsville Center utility program instrumental in developing reliable energy for Afghan security. Retrieved March 21, 2016, from Huntsville Center utility program instrumental in developing reliable energy for Afghan security

Wilson, D. R. (2015a). Guide to the Financial Model of the Power Delivery Power Purchase Agreement Project. Kabul.

Wilson, D. R. (2015b). PPA General Officer Steering Committee. Kabul.

You, H., Connelly, E. B., Lambert, J. H., \& Clarens, A. F. (2014). Climate and other scenarios disrupt priorities in several management perspectives. Environment Systems and Decisions, 34(4), 540-554. http://doi.org/10.1007/s10669-014-9525-2 


\section{Appendix A: Goal structure of the Afghanistan National Development Strategy}

Afghanistan National Development Strategy (ANDS) Structure

\begin{tabular}{|c|c|c|c|c|c|c|c|}
\hline SECURITY & GOVERNANCE & \multicolumn{6}{|c|}{ SOCIAL AND ECONOMIC DEVELOPMENT } \\
\hline Pillar 1 & Pillar 2 & Pillar 3 & Pillar 4 & Pillar 5 & Pillar 6 & Pillar 7 & Pillar 8 \\
\hline 1-Security & 2 - Good Governance & $\begin{array}{l}3 \text { - Infrastructure \& } \\
\text { Natural Resources }\end{array}$ & 4 - Education \& Culture & 5 - Health \& Nutrition & $\begin{array}{c}6 \text { - Agriculture \& Rural } \\
\text { Development }\end{array}$ & 7 - Social Protection & $\begin{array}{c}8 \text { - Economic } \\
\text { Governance \& Private } \\
\text { Sector Development }\end{array}$ \\
\hline \multicolumn{8}{|c|}{ Sectors } \\
\hline \multirow[t]{6}{*}{ Security } & Justice & Energy & Education & Health and Nutrition & $\begin{array}{l}\text { Agriculture and Rural } \\
\text { Development }\end{array}$ & Social Protection & $\begin{array}{c}\text { Private Sector } \\
\text { Development and Trade }\end{array}$ \\
\hline & $\begin{array}{l}\text { Governance, Public } \\
\text { Administrative Reform \& } \\
\text { Human Rights }\end{array}$ & Transportation & $\begin{array}{l}\text { Culture, Media and } \\
\text { Youth }\end{array}$ & & & $\begin{array}{c}\text { Refugees, Returnees } \\
\text { and Internal Displaced } \\
\text { Persons }\end{array}$ & \\
\hline & Religeous Affairs & $\begin{array}{c}\text { Water Resource } \\
\text { Management }\end{array}$ & & & & & \\
\hline & & $\begin{array}{l}\text { Information and } \\
\text { Communications } \\
\text { Technology }\end{array}$ & & & & & \\
\hline & & Urban Development & & & & & \\
\hline & & Mining & & & & & \\
\hline \multicolumn{8}{|c|}{ Cross-Cutting Issues } \\
\hline \multicolumn{8}{|c|}{ Capacity Building } \\
\hline \multicolumn{8}{|c|}{ Gender Equity } \\
\hline \multicolumn{8}{|c|}{ Counter Narcotics } \\
\hline \multirow{2}{*}{\multicolumn{8}{|c|}{$\begin{array}{l}\text { Regional Cooperation } \\
\text { Anti-Comuption }\end{array}$}} \\
\hline & & & & & & & \\
\hline \multicolumn{8}{|c|}{ Environment } \\
\hline
\end{tabular}

Exhibit 1. The overall structure of the Afghanistan National Development Strategy Structure. 


\title{
Appendix B: Goal structure of US strategic documents
}

\author{
This appendix showcases the overall structure of the goals that form the US government
} criteria.

Special Inspector General for Afghanistan Reconstruction

High-Risk Areas

Special Inspector General for Afghanistan Reconstruction (SIGAR) has created the High-Risk List to call attention to program areas and elements of the U.S.-funded reconstruction effort in Afghanistan that are especially vulnerable to significant waste, fraud, and abuse. With the list, SIGAR seeks to identify and address systemic problems facing U.S.-funded reconstruction efforts. The list will highlight program areas on which SIGAR believes the implementing agencies need to focus. It will also discuss how specific agencies are failing to mitigate risks in areas that involve their operations.

Congress created SIGAR in 2008 via Public Law 110-181 as an independent inspector-general body tasked with oversight of all aspects of the U.S. reconstruction effort in Afghanistan. The High-Risk List also will serve as an internal planning tool for SIGAR to guide its oversight work and build a body of knowledge necessary to develop macro-level recommendations to help Congress and the agencies correct major problems. It proposes key questions to help Congress, U.S. agencies, and the public improve reconstruction programs. It should also assist the new Afghan national unity government in implementing its reform agenda.

There are numerous reconstruction challenges in Afghanistan. The High-Risk List focuses on program areas and elements that are:

- essential to the success of the reconstruction effort;

- at risk of significant and large-scale failure due to waste, fraud, or abuse;

- part of ongoing or planned reconstruction efforts; and

- subject to the control or influence of the U.S. government.

Using these criteria, SIGAR has identified seven issues for this initial SIGAR High-Risk List:

- Corruption/Rule of Law

- Sustainability

- Afghan National Security Forces (ANSF) Capacity and Capabilities

- On-Budget Support

- Counternarcotics

- Contract Management and Oversight Access

- Strategy and Planning

Exhibit 2. Excerpt from SIGAR High Risk List 


\section{US Civil-Military Strategic Framework Goal Structure}

\section{Security}

\section{Governance}

Support constitutional succession through a credible, inclusive and transparent Afghan presidential election in 2014

Strengthen checks and balances within GIRoA and independent institutions external to GIRoA

Strengthen governance architecture and functionality, revenue collection and budget prioritization, execution, and accountability at both national and sub-national levels

Stem corruption through support for more open and accountable government

\section{Rule of law}

Build capacity of the GIRoA justice and legal systems

Combat corruption within Afghan government agencies and institutions

Increase access and understanding of the formal justice and legal systems, in order to empower civil society and protect women's rights in accordance with Afghan law and international obligations.

Strengthen linkages between the formal and customary justice sectors

\section{Political reconciliation and reintegration}

Role of women in society

$$
\text { Borders }
$$

Information initiatives

Regional cooperation

Exhibit 3. Overall goal structure of the US Civil-Military Strategic Framework

\section{Socio-economic development}

Support economic growth through development of key industries, including agriculture, extractives, telecommunications, light manufacturing, and services

Improve the health and education of Afghans through advice and assistance to GIRoA, as well as related investments in health and education

Promote Afghanistan's regional economic integration through support and assistance to relevant GIRoA ministries

Support economic growth through development of key economic infrastructure and strengthen GIRoA capacity to manage that infrastructure 


\section{Appendix C: Electric power infrastructure map}

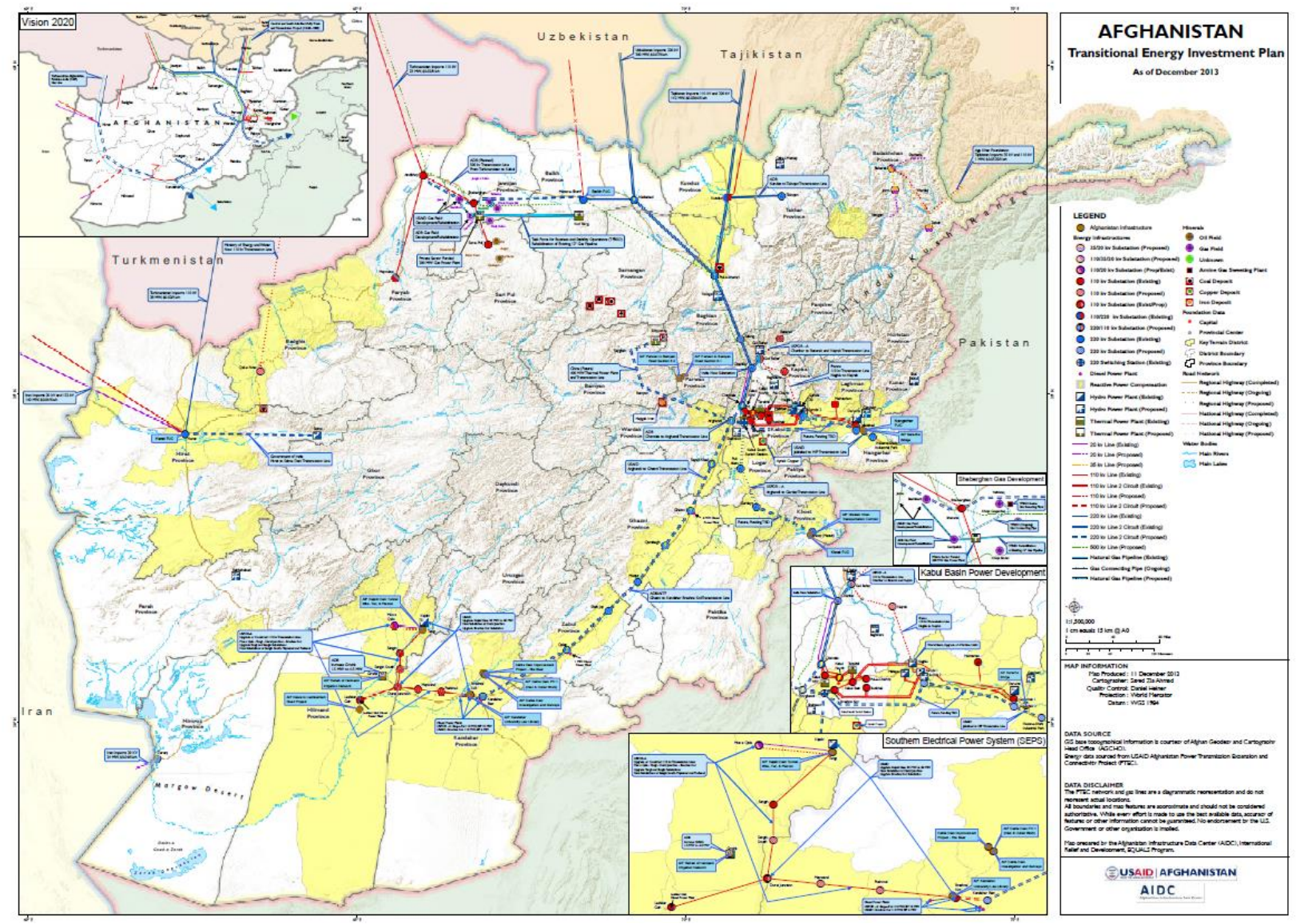

Exhibit 4. Transitional Energy Invest Plan, showing current and planned electric power infrastructure in Afghanistan. 


\section{Appendix D: Sample of news coverage of PDPPA}

This appendix contains a sample of news coverage the power purchase and power delivery agreement received.

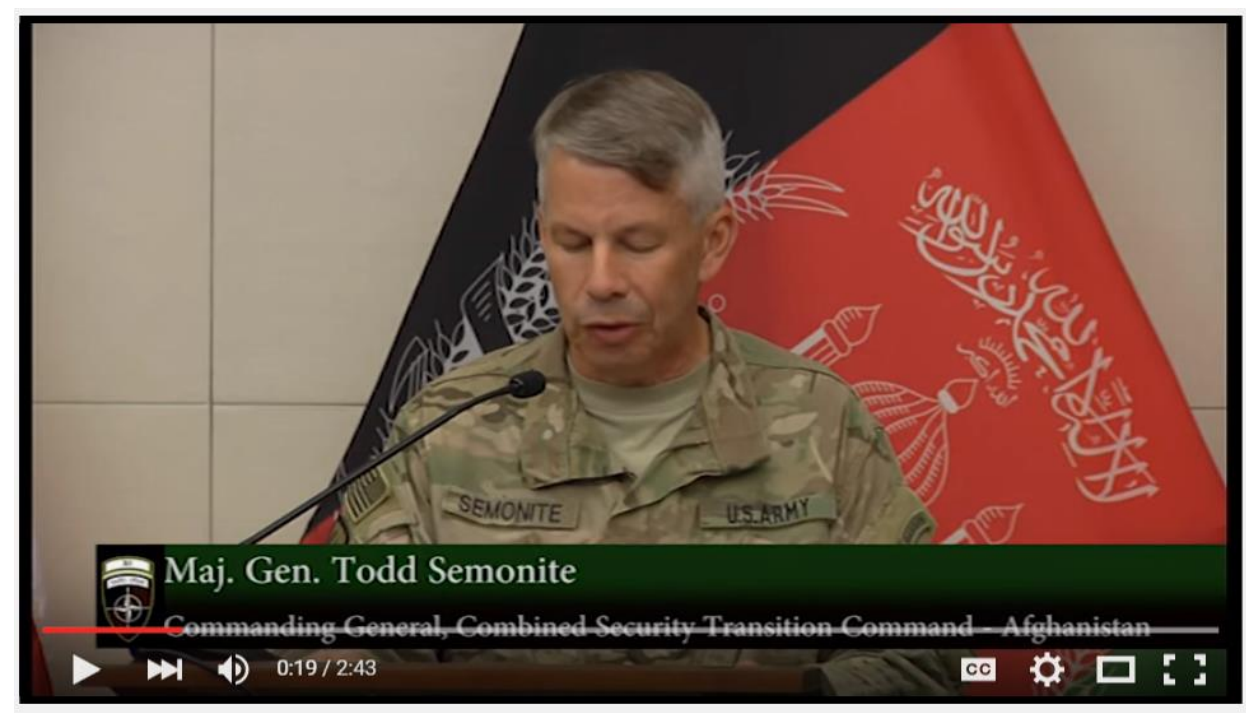

NATO allies and partners commit $\$ 200 \mathrm{M}$ to power ANDSF

Exhibit 5. Screenshot from a press conference on the announcement of the PDPPA. The video can be found at https://www.youtube.com/watch?v=dgs14pWn7VA\&feature=youtu.be 


\section{Huntsville Center utility program instrumental in developing reliable energy for Afghan security}

December 2, 2015

G.1 (0) Lise Be the frot of your tiends os like this

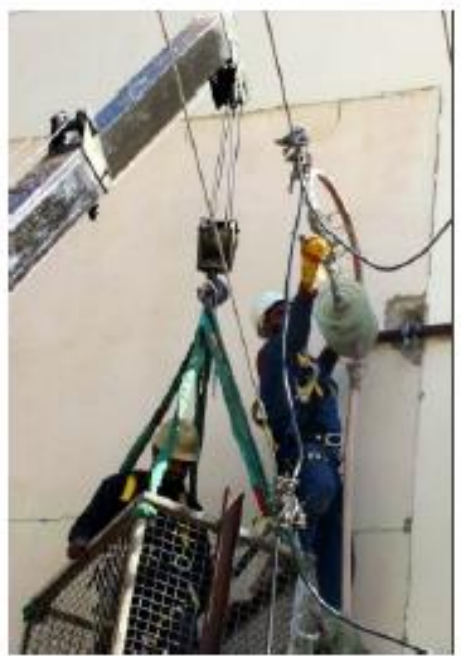

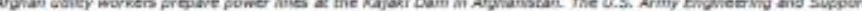

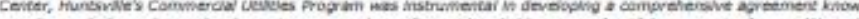

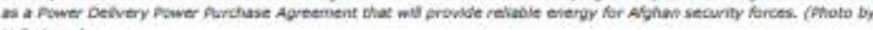
U.S. Avmy)

$$
\begin{aligned}
& \begin{array}{l|l}
\text { The U.S. Army Engineering and Support Center, } & \text { Related Liniks }
\end{array} \\
& \text { Huntsville's Commercial Utlities Program (CUP) used a } \\
& \text { Multeple Award Task Order Contract to select an American } \\
& \text { company as the Power Punchase Agreement consultant to } \\
& \text { veltes progra: }
\end{aligned}
$$

Enabling Afghan Notional Defense and Security Forces (ANDSF) to transition from expensive, unreliable diesel-generated electricky to a more cost-effective power grid was a concept developed by the Combined Securtty Transition Command - Afphanistan (CSTC-A), which tasked the U.S. Arrmy Engineer Aerearch and Development Center (ERDC) for support.

The five-person team of engineers and scientists ERDC put together induded Bernard Givan, Huntsvilie Center's CUP program manager. Givan, a public utilities specialist, said he was asked to join the team because of his expertise in utility projects.

"They (ERDC) asked me to provide contract and technical support in the development of a framework," Givan said. "However, the requirements for this project are different from Huntsvilie Center's Power Purchase Agreement program, which is based on third-party financing of renewable energy."

The framework actually imvolved more than the typical PPA because a substantial amount of power delwery intrastructure is necessary to interconnect the new generation assets to improve and stabilize electrical power supply for ANDSF. That's why using the consultant under the CUP MATOC was instrumental to determine how the framework would shape up."

Givan said the framework covered terms and conditions, contingencies for various scenarios, legal protections for the parties involved and methods for resolving disputes or modifying the agreement. CSTC-A then used the framework to insert specific agreement terms that were decided by the pertinent parties in theater

As the utility consultant provided the research for the framework, other ERDC tesm members detaled the potential risks caused by political, economic, natural and potential 


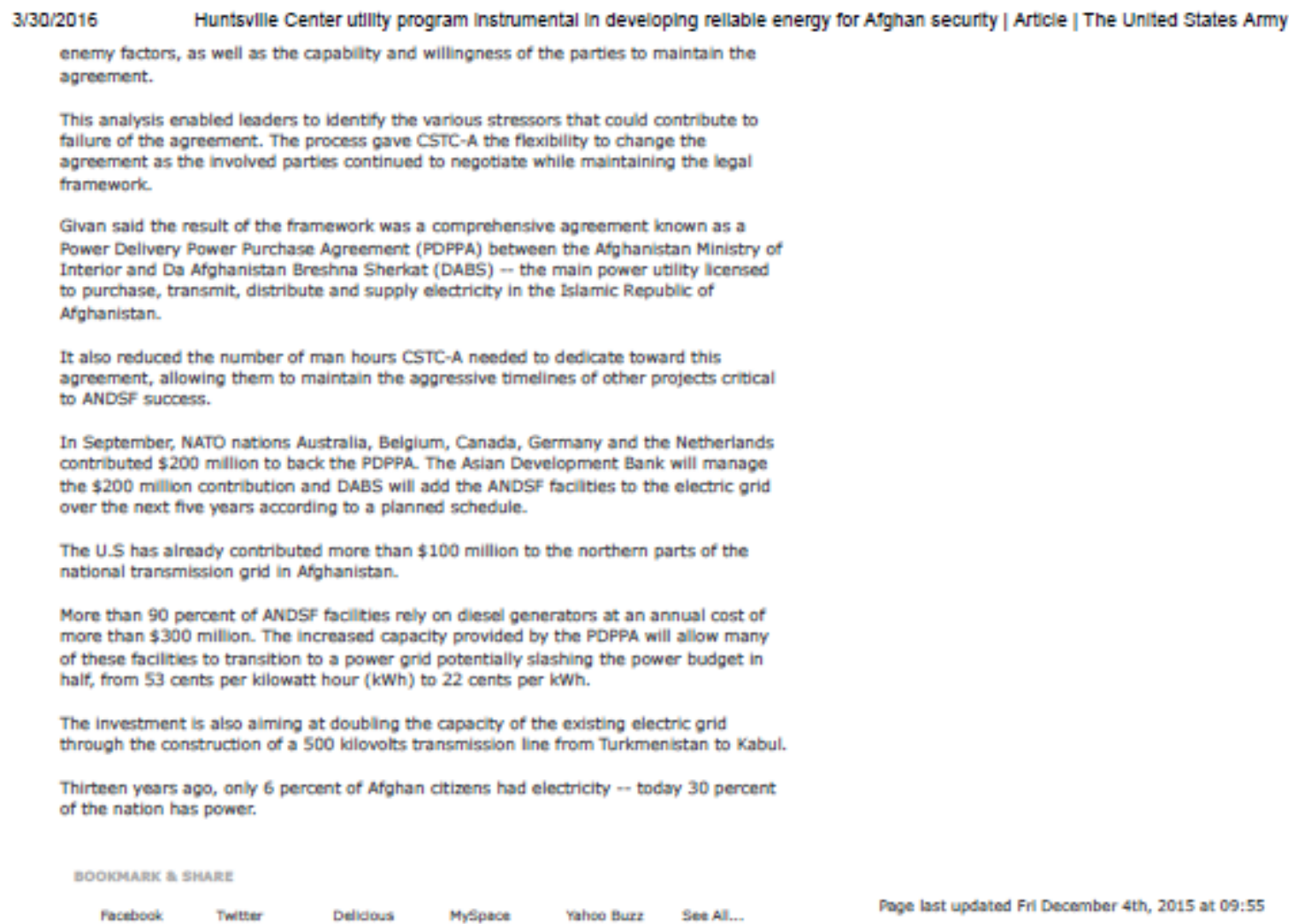

Exhibit 6. Article from the US Army news archive from the perspective of the Huntsville Center Utility Program. Article can be retrieved at http://www.army.mil/article/159381/Huntsville_Center_utility_program_instrumental _in_developing_reliable_energy_for_Afghan_security_/ 